\title{
A CASE STUDY OF SCHOOL TECHNOLOGY SUPPORT NETWORKS
}

\author{
A Dissertation \\ Presented to \\ The Faculty of the Curry School of Education \\ University of Virginia \\ In Partial Fulfillment \\ Of the Requirements for the Degree \\ Doctor of Education \\ By \\ John R. Hiltz \\ B.A. University of Virginia \\ M.Ed. University of Virginia
}

May, 2011 
CCopyright by John R. Hiltz

All Rights Reserved May 2011 
A Case Study of School Technology Support Networks

\author{
Abstract \\ John R. Hiltz \\ University of Virginia 2011 \\ Advisor: Sara Dexter
}

Since the last decade of the $20^{\text {th }}$ Century, there has been an effort to integrate technology into classroom instruction. The success of this effort has been uneven, as teachers have resisted this change. There has been a great deal of recent research on the importance of teacher-to-teacher interactions and successful organizational change. This descriptive and exploratory case study was conducted to: (1) learn about the social networks teachers form in order to support technology integration in the classroom, (2) learn about how the instructional technology resource teacher (ITRT) is positioned in these social networks and to see if the instructional background of the ITRT affects that position, and (3) learn how technology leadership on the part of the school principal and the ITRT affects the structure of these networks.

The study was conducted at two middle schools located near a large city along the East Coast of the United States. Qualitative and quantitative methodologies were used to conduct this study. The qualitative portion of the study consisted of interviews with the principal and the instructional technology resource teacher (ITRT) at each school. The quantitative portion of the study consisted of social network analyses (SNA) of the curricular support and technology support networks. The SNA software package of UCINET and NetDraw was used to analyze the data. Correlations were also examined between degree centrality and the teachers' technological, pedagogical and content knowledge (TPACK). 
Both principals were strong supporters of classroom technology integration, but they used different methods to put into place their respective visions. These differences seem to have affected the structures of the technology support networks that formed in the schools, with a highly centralized network efficient for exchanging routine information in one school, while in the second school, the technology support network was less centralized and took on a structure more closely identified with innovation and organizational change. As a result of this study, a number of leadership traits were identified, which include developing a vision that is subject-specific and pedagogicallyfocused as well as empowering the ITRT and others as technology leaders. 
Department of Educational Leadership, Policy and Foundations

Curry School of Education

University of Virginia

Charlottesville Virginia

APPROVAL OF DISSERTATION

This dissertation, A Case Study of School Technology Support Networks, has been approved by the Graduate Faculty of the Curry School of Education in partial fulfillment of the degree requirement for the degree of Doctor of Education.

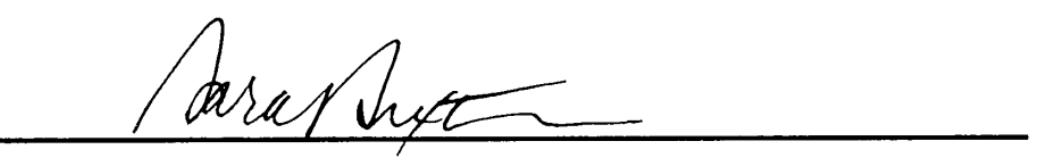

Sara L. Dexter, Chairperson

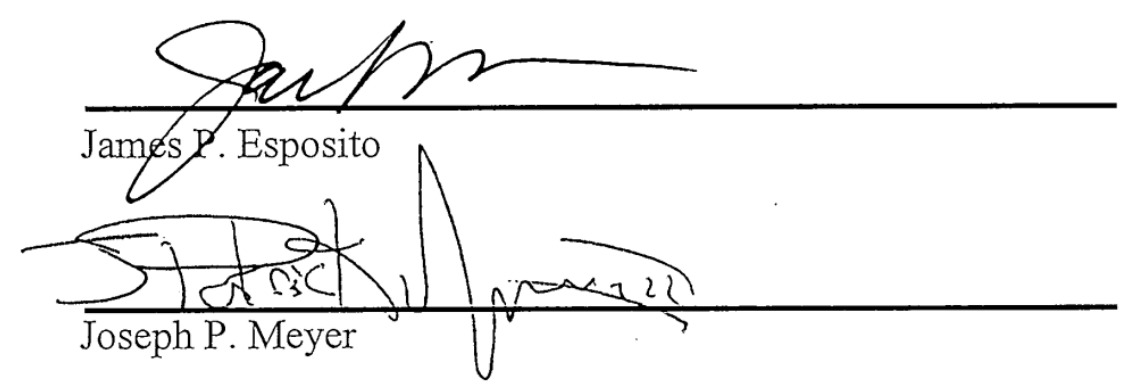




\section{Dedication}

My father entered Wilson Teacher's College in Washington, DC when he was 17

years old. He was an elementary school teacher and principal in the District of Columbia schools for 36 years. After his retirement from DC Schools, he became a Special Education teacher in Arlington County, Virginia and then after his retirement from that position, worked as a substitute teacher until he was 80 years old.

After WWII, he used his GI Bill benefits to enter a doctoral program at the University of Maryland. During one of these classes he met my mother and they eventually married. After completing his courses and passing his comprehensive exams, the duel demands of running an inner-city school during the early years of integration and raising a young family, prevented him completing his dissertation. He regretted not finishing his degree for the rest of his life. My father was overjoyed when I pursued a teaching career and was even more pleased when I obtained my Masters in Administration.

By the time I entered this doctoral program, he was suffering from Parkinson's disease and mild dementia. However, his one link to reality as the fact that I was now working on my doctorate. My telling him that this would be the doctorate that he was unable to finish was especially meaningful to him. During one visit, he continually congratulated me for finishing, telling me how proud he was at what I had accomplished. I could not convince him that I was not done, but decided to accept his congratulations in case he was not around when I actually did finish. Little did I know that he would pass away a few weeks after that at age 88 . 
After my father died, my mother underwent double heart valve replacement. A few years after that, she suffered a mild stroke. Despite all of these health problems, she repeatedly encouraged me to finish my degree, often saying that this was something she had to see before she died. Sadly, it was not to be. She died in her sleep two-weeks before my proposal defense. At least she knew that I was well on my way to completing my doctorate. Therefore, this dissertation is dedicated in memory of my parents:

Robert A. Hiltz, February 18, 1916 - July 2, 2004

Ruth H. Hiltz, June 12, 1924 - October 12, 2010 


\section{Acknowledgements}

One thing that I have learned is that earning a doctorate is a long journey and there have been many, many people who have helped me along the way. First is my dissertation chair, Sara L. Dexter. Within a week of working on the idea she gave me for a topic, I knew I had found my life's work. This study has been exciting and I was very fortunate to have her as my advisor. I am also very grateful for the help and guidance of the other members of my committee: Dr. J. Patrick Meyer and Dr. James Esposito. Their input at my proposal defense was invaluable to making this a much better study. I am deeply indebted to them for serving on my committee. I also have to thank Dr. Esposito for being my advisor in my M.Ed. program, as well as his work in putting together the Doctoral Cohort with Fairfax County Public Schools, my employer.

I also must thank Dr. Cheryl Henig and Dr. Bernadette Black of the Curry School for their help and guidance as well, especially the Dissertation Destination support group that Dr. Black ran at the Northern Virginia Center for many years. That group kept me going and without it I may have given up. I will also never forget Dr. Donald Ball. He taught me statistics in a way made it very easy for me to understand - and love. He is greatly missed.

In addition, I must thank my friend from high school, Wade Hinkle for suggesting that I come to the Curry School as a Third-Year transfer student, and the people in the Curry School who accepted my application for transfer as well as my Fourth-Year advisor, Dr. Cliff Bennett. Reconnecting with him many years after graduation inspired me to seek this degree. Most of all, the University Transit Service must also be mentioned, because if it were not for getting to drive the busses, I never would have come 
to UVA in the first place. As it turned out, my undergraduate education at UVA was truly the opportunity of my life.

I am overwhelmingly appreciative that Fairfax County Public Schools selected me to participate in the Doctoral Cohort. There are a number administrators who have supported on the way. I need to thank my current principal, Pamela A. Jones for her continual support, especially during the critical data collection phase. I have to thank Dr. John Banbury for helping me move to a position that allowed me to complete my dissertation. I also have to mention my two doctoral mentors during my coursework: Dr. Donald Weinheimer and Dr. Debra Tucker, both formerly of McLean High School. Dr. Evan Glazer, principal of The Thomas Jefferson High School for Science and Technology also give me help in understanding reciprocal relationships and their importance in the spread of technology innovation, an important construct in this study.

I must also thank Dr. Punya Mishra of Michigan State University for connecting me with the TPACK survey, which he played a part developing. That whole exchange of information occurred by way of Facebook and I greatly appreciate his willingness to quickly respond to a request for help from a grad student in a distant university. Another prime example of the power of social networking!

Finally, I have to mention the SOHO Tea and Coffee Shop at $22^{\text {nd }} \&$ P Streets NW, Washington, DC, where much of this document was written. It was great to have a place to work late into the night with other grad students. Several of the grad students I met during my many nights at the keyboard understood social network analysis as a methodology and were able to provide confirmation of my findings. Others were just willing to listen which helped me to clarify my ideas as I analyzed my data. 
TABLE OF CONTENTS

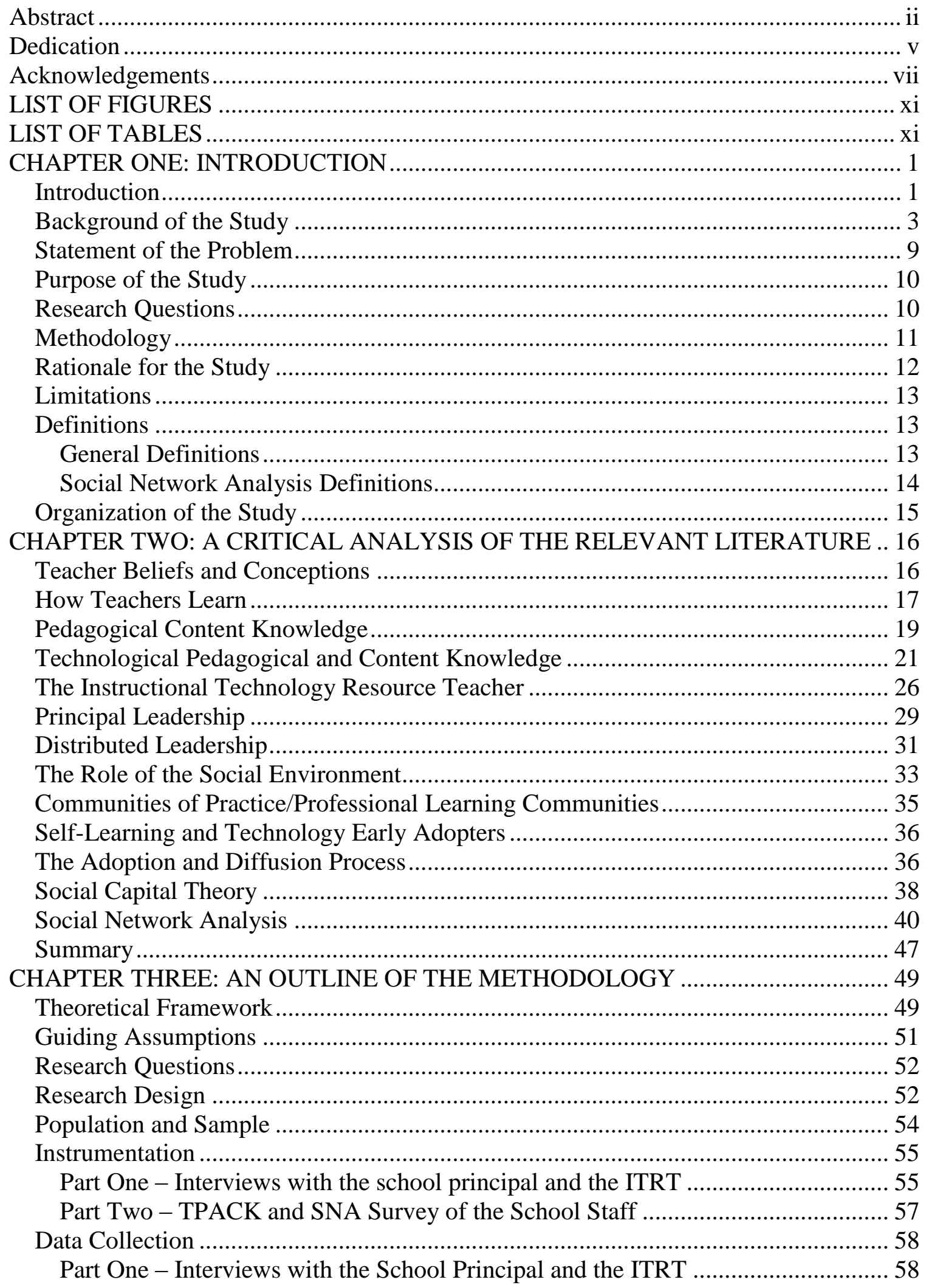


Part Two - TPACK and SNA Survey of the School Staff .................................. 59

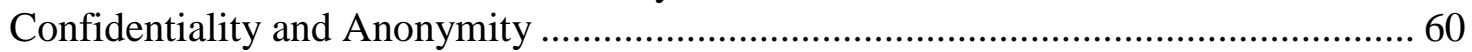

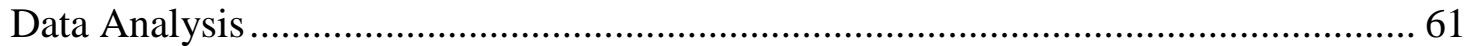

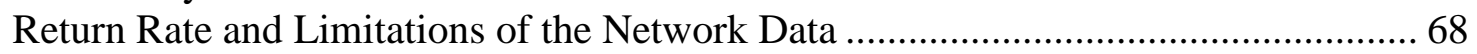

CHAPTER FOUR: PRESENTATION AND ANALYSIS OF THE DATA .................. 70

Baldon County Public Schools ................................................................................ 70

The Social Networks Studied ................................................................................ 72

Question 1: How Is Technology Leadership Conducted in the School on the Part of the

Principal and of the ITRT? ............................................................................. 75

Question 2: What Was the Structure of the Curriculum Support Network at Each

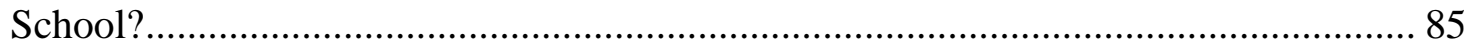

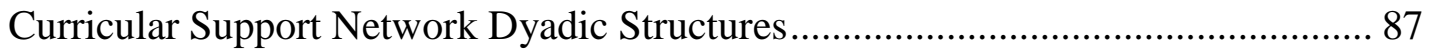

Curricular Support Network Macro Structures ..................................................... 90

Curricular Support Network Micro-Structures ...................................................... 94

Curricular Support Network Summary .......................................................... 101

Question 3: What Was the Structure of the Technology Support Network at Each

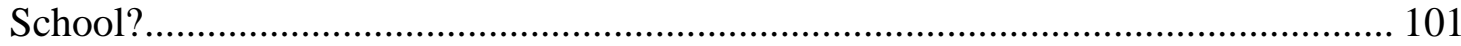

Technology Support Network Dyadic Structures ........................................... 103

Technology Support Network Macro-Structures.............................................. 105

Technology Support Network Micro-Structures ............................................... 107

Summary of Technology Support Networks ....................................................... 109

Question 4: The Position of the ITRT in the Technology Support Network............. 110

Question 5: What Is the Relationship between In- and Out-Degree Centrality and

Teacher Demographics? ............................................................................ 111

Question 6: How much of the Technology Support Network Was Composed of Ties

Created Specifically for Technology Support?....................................................... 113

Reinhart Technology-only Core and Periphery Structure and Node Removal....... 116

Filz Technology-only Core and Periphery Structure and Node Removal .............. 118

CHAPTER FIVE: SUMMARY AND CONCLUSIONS ...................................... 120

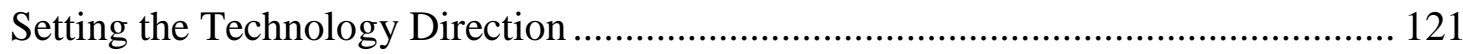

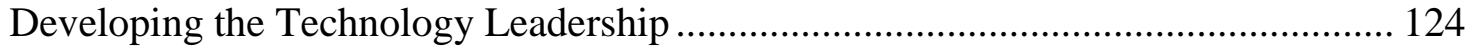

Technology Support Networks ........................................................................ 129

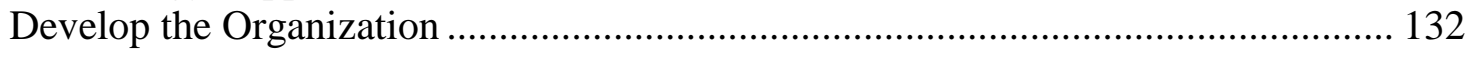

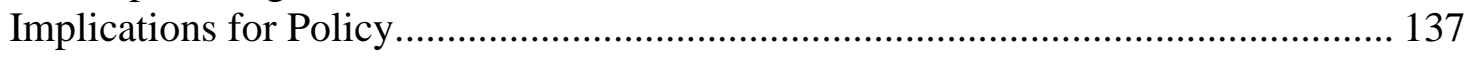

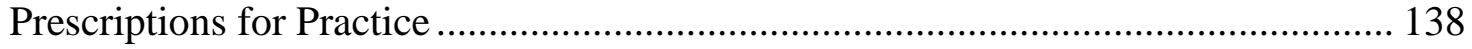

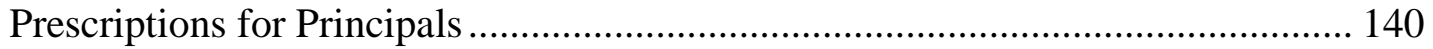

Prescriptions for School Systems Central Offices .......................................... 140

Prescriptions for Principal Preparation Programs ............................................ 141

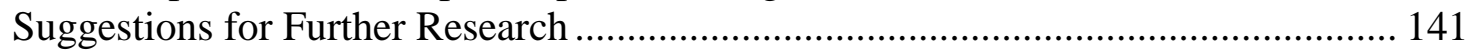

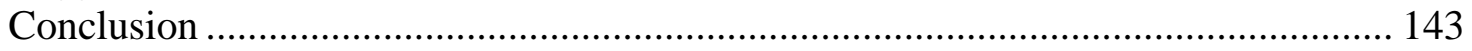

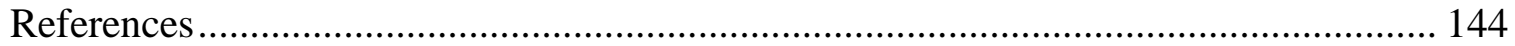

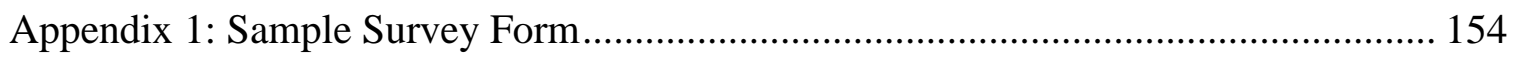




\section{LIST OF FIGURES}

Figure 2-1: Pedagogical Content Knowledge ............................................................. 21

Figure 4-1: Reinhart Knowledge Network Sociogram ........................................... 73

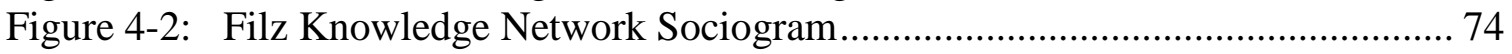

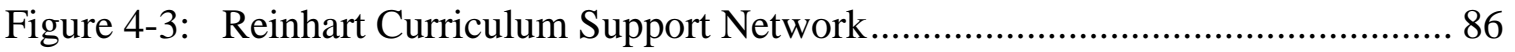

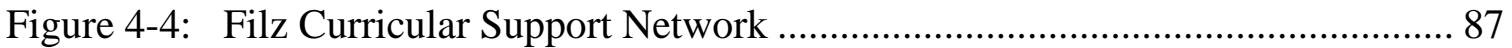

Figure 4-5: Reinhart Curricular Support Reciprocal Tie Substructure ......................... 95

Figure 4-6: Filz Curricular Support Reciprocal Tie Substructure ............................... 97

Figure 4-7: Reinhart Curricular Support Network Cliques........................................ 99

Figure 4-8: Filz Curricular Support Network Cliques ............................................. 100

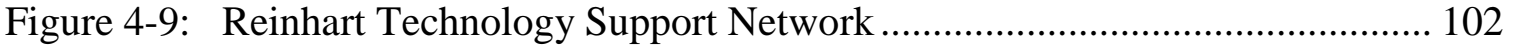

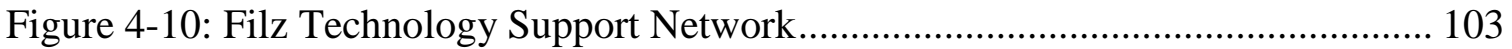

Figure 4-11: Reinhart Technology Reciprocal Ties................................................... 108

Figure 4-12: Filz Technology Reciprocal Ties ......................................................... 109

Figure 4-13: Reinhart Technology-only Network ................................................. 115

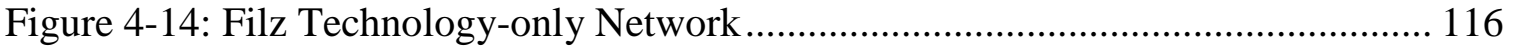

Figure 4-15 Reinhart Technology-only Top Three Actors Removed........................... 118

Figure 4-16: Filz Technology-only Top Three Actors Removed ................................ 119

\section{LIST OF TABLES}

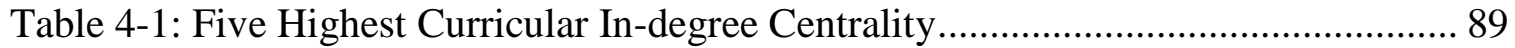

Table 4-2: Curricular Departmental Group Centrality................................................. 93

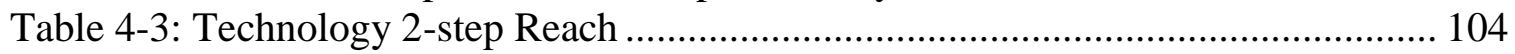

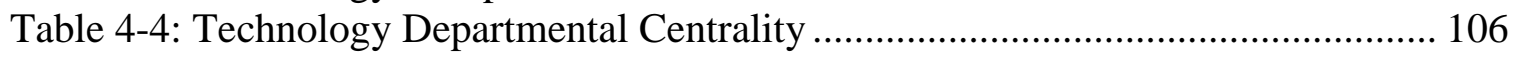

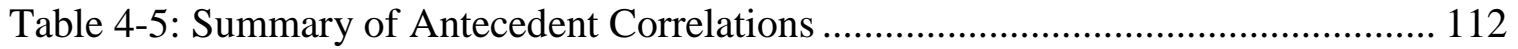




\section{CHAPTER ONE: INTRODUCTION}

\section{Introduction}

In recent years, a great deal of school funding has been spent creating a technological infrastructure in our nation's schools, with public school teachers now having near universal access to computers. Despite this, there has been an ongoing concern that teachers are resisting this effort and have not embraced technology as a significant tool in their instruction (Cuban, Kirkpatrick, \& Peck, 2001; Sandholtz \& Reilly, 2004). In some ways this resistance to technology has been so intense that is has been likened to a new species invading an established ecosystem (Zhao \& Frank, 2003).

Contributing to this resistance is the way that technology has been introduced into schools. In many instances, teachers have not been included in the planning and implementation of integration initiatives. Rather than take into consideration teachers' long-standing instructional beliefs, many policymakers act as if simply providing a technological infrastructure in schools will change practice and that all teachers need is a good attitude along with some staff development in building technological skills (Niederhauser \& Stoddart, 2001; Zhao, Pugh, Sheldon, \& Byers, 2002).

Research has shown that the introduction of technology and technological systems into schools has a far-reaching impact on the structure of the organization. In addition to changes in instructional practice, demands are also placed on the social systems within schools. This causes changes in the social interactions between teachers and teachers as well as teachers and administrators. New roles have had to be created and changes have to be made in leadership practice (Davidson \& Olson, 2003). 
Many of the state and national instructional technology standards teachers have been expected to meet do not promote belief change. Instead, they focus on teachers' technical or instructional expertise with hardware and software. Likewise, much of the training teachers receive is typically generic in nature. It centers on how to demonstrate technical knowledge about individual software programs, essentially what the software can do. However, for effective changes in practice to occur, teachers need staff development on how these software programs can be effectively integrated in a pedagogically sound way (Cuban, et al., 2001; Hatala \& Fleming, 2007; Hew \& Brush, 2007).

Teachers also need support to help them learn how to effectively implement technology into instruction. A job position, generically known as an Instructional Technology Resource Teachers or ITRT has been created to help teachers in this task (Davidson, 2003). Recognizing the role of technology in our modern society, the Virginia Department of Education requires that an ITRT be assigned to each school in the Commonwealth (Virginia Department of Education, 2008). However, the integration of technology into instruction is a dynamic process that involves much more than the creating of a new position in the organization chart to guide teachers. There are other factors involved in the successful integration of instructional technology that need to be understood by policymakers.

It is now being suggested that for teachers to successfully integrate technology into instruction, they need to develop a specific form of knowledge to develop their lessons that combines knowledge of the content with knowledge of technology. This form of knowledge has become known as Technological Pedagogical Content 
Knowledge (Mishra \& Koehler, 2006). It is also being understood that much of the learning about instructional technology occurs by way of teacher-to-teacher interactions, where teachers who have already developed expertise integrating technology into instruction help their novice colleagues (Glazer \& Hannafin, 2006). These interactions result in the formation of social networks composed of teachers seeking technological support. More and more it is being understood that these teacher networks are a powerful force in schools (Deal, Purinton, \& Waetjen, 2009) and that these teacher networks play an important role in the type of belief change necessary for effective instructional technology integration to occur (Ertmer, 2005).

The problem is there is little information about the dynamics of the technology support networks in schools. It is not known how they form, nor is it known what role the ITRT plays in these networks. This study was conducted to: (1) learn about the social networks teachers form in order to support technology integration in the classroom, (2) learn about how the ITRT is positioned in these social networks and to see if the instructional background of the ITRT affects that position, and (3) learn how technology leadership on the part of the school principal and the ITRT affects the structure of these networks. This mixed-methodology descriptive case study, in part, used social network analysis (SNA) techniques to generate lines of further inquiry, which has helped to expand the knowledge base of this topic.

\section{Background of the Study}

The arrival of the digital age has had a dramatic effect on all aspects of our society (Mishra \& Koehler, 2006). Today's school students live in an interactive, virtual world where information is accessed and exchanged on a regular basis (Jacobsen \& Lock, 
2004). This knowledge era has placed technological demands on educators as they prepare today's students for the emerging information age. Unfortunately, our nation's schools have not met this challenge. Although access to technology has expanded greatly in recent years, there has been a lag in teachers' abilities to apply these new technologies to instruction (Sandholtz \& Reilly, 2004).

Part of this lag in adopting technology has to do with the culture within schools. Schools are inherently resistant to change, in that there is a strong cultural predisposition to preserve existing practice (Zhao \& Frank, 2003). Teachers in specific content areas tend to have an "institutionalized" way of teaching that has been built up over many years of school practice. This has resulted in resistance to adopting instructional technology methods in ways that are incompatible with their long-standing beliefs about instruction (Hew \& Brush, 2007).

Teacher beliefs about instruction can be thought of as form of "personal truth" that impacts their approach to instruction. These beliefs are extremely individualized and are developed through personal experiences. They are also deeply held and are often formed before individuals enter teacher education programs. The earlier they are formed, the more difficult they are to change (Pajares, 1992). Throughout their careers, teachers will filter new information through their previous experiences and beliefs, in most cases rejecting what conflicts with their prior experiences and already established belief system (Joram \& Gabriele, 1998; Pajares, 1992).

For teachers to successfully assimilate new knowledge, they have to make adjustments to their current belief system. This involves something akin to a Gestalt shift, where old beliefs prove unsatisfactory and are replaced with these new beliefs (Pajares, 
1992). It tends to occur after beliefs are challenged in a way that causes teachers to integrate this new knowledge into their existing belief system. Few of today's teachers had experience with computers during their own schooling, which is when many of their beliefs about instruction were formed. This becomes a barrier to changing their instructional belief system since there are no preconceived ideas on how to integrate technology into instructional (Ertmer, 2005).

Policymakers have recognized that technology is constantly evolving and that teachers need continual staff development, translated into their content area, to keep up with the ever-changing nature of technological applications. One type of translator now being found in schools is the educational technologist. Often referred generically as an Instructional Technology Resource Teacher (ITRT), this individual's role is to provide ongoing staff development and assistance to teachers as they try to apply new technology to their instruction (Davidson, 2003; King, 2002).

The Commonwealth of Virginia has recognized the role of technology in economic development and wants to ensure that today's students have the technological skills necessary to excel in the emerging knowledge-based economy. Thus, the Virginia Department of Education (VDOE) has mandated one site-based instructional technology resource teacher for each of the schools in the Commonwealth. The ITRT is to assist teachers with integrating and embedding technological applications within their instruction (Virginia Department of Education, 2003).

Initially, the Commonwealth offered few guidelines to Virginia schools on how to implement this position, aside from requiring one position per 1000 students (Virginia Department of Education, 2008). However, in 2008, a detailed handbook for the ITRT 
was issued. This document provided guidelines for the duties that the ITRT was to be assigned, along with how much time this person should be spending on each of the duties. The handbook also recommended a very specific 5-step procedure that the ITRT was to follow in helping teachers integrate technology into instruction (Virginia Department of Education, 2008).

This approach of adding a position into the organizational chart is not uncommon. Often times, policymakers think in terms of a "task network," and believe that information about an innovation will take an orderly flow through organizational chart (Deal, et al., 2009). However, the actual process teachers take to integrate technology into instruction is much more complex, with multiple factors involved.

A number of studies indicate that many teachers learn about technology informally, through friends, family members, colleagues, or through their own study (Angers \& Machtmes, 2005; Markauskaite, Reimann, Reid, \& Goodwin, 2006). This is especially true of the "early adopters," which are the first teachers to recognize the value of technology in promoting student learning (Angers \& Machtmes, 2005). It has also been shown that teachers who effectively use technology in their classrooms have developed a new level of knowledge. From this knowledge, the technology has become integrated pedagogically into their instruction. A way to understand this is through the concept of Technological Pedagogical Content Knowledge (TPCK), more recently referred to as TPACK, which stands for Technological Pedagogical and Content Knowledge (Mishra \& Koehler, 2006).

TPACK is an extension of Shulman's (1986) work with Pedagogical Content Knowledge (PCK), which describes the special form of knowledge teachers use to 
present their content knowledge in a manner that students can understand. TPACK is a way to understand the distinct form of knowledge teachers need to successfully incorporate technology into instruction. Recognizing the complex nature of integrating technology into the classroom, TPACK serves as a grounded framework for understanding the interrelationships between technology, content and pedagogy (Mishra \& Koehler, 2006).

Under this framework, teachers build a distinct pedagogical knowledge based upon their knowledge of both technology and content. It has been graphically described as the intersection of content knowledge, technological knowledge and pedagogical knowledge. TPACK is very specific to the content area of the teacher. Therefore, a teacher with strong TPACK in English would not necessarily have the same level of TPACK in Social Studies or Science (J. B. Harris, Mishra, \& Koehler, 2007).

Research has also shown that principals play an important role in the degree to which technological innovations are accepted in a school (R. E. Anderson \& Dexter, 2005). Principals have to enact a vision for technology usage and encourage teachers to adopt technology in their instruction (Davidson \& Olson, 2003). In addition, principals who see themselves as active technology innovators have a greater impact on sustaining technological innovations within their schools than do principals who hold a neutral attitude towards this change (Owston, 2007). The introduction of technology and the creation of the ITRT position can also result in a redistribution of leadership roles in the school because of a need for interdependence, as opposed to the traditional isolated leadership structure (Davidson, 2003; Davidson \& Olson, 2003; Leithwood, et al., 2007). 
Distributed leadership is an analytical framework for understanding how leadership is practiced within a school, with a focus on the interactions between individuals in both formal and informal leadership roles. It is a perspective in which leadership is conceptualized as a practice rather than a collection of assigned roles and has been shown to contribute to constructive organizational change (A. Harris \& Spillane, 2008). In this way, principals recognize that the complexity of certain tasks outstrip the capacity of any one individual in the organization to manage. This leads to an understanding that many people in the organization have areas of expertise not held by others, thus, leadership is shared between multiple individuals, both formally and informally (A. Harris \& Spillane, 2008; Leithwood, et al., 2007). The collective expertise that is held by members of the organization is referred to as social capital (Penuel, Riel, Krause, \& Frank, 2009).

According to social capital theory, valuable resources and expertise can be found within the membership of social networks, with the resources being accessed by way of the social ties between the members (Frank, Zhao, \& Borman, 2004; Penuel, et al., 2009). Research has shown that mass behavioral changes occur within groups of socially connected people (Christakis \& Fowler, 2007, 2008). This is part of the logic behind establishing Professional Learning Communities (DuFour, 2004) and Communities of Practice (Koliba \& Gajda, 2009).

Research indicates there is a very pronounced social component in the case of instructional technology adoption, as teachers will react to the introduction of a technological innovation as both individuals and as members of the social systems within a school (Zhao \& Frank, 2003). The diffusion process is largely driven by the early 
adopters by way of interactions with their colleagues. These early adopters will mentor novices, who then go on to mentor other colleagues as they become more proficient. Over time, reciprocal interactions will occur throughout the network as greater numbers of teachers develop proficiency (Glazer, Hannafin, \& Song, 2005). This process serves as an illustration of how much of the actual work in a school occurs by way of the information that flows through the social networks that form between different staff members (Deal, et al., 2009).

Social network analysis is a quantitative technique used to uncover the information networks that exist in an organization. By conducting a social network analysis, a greater understanding of the information flow through the organization can be established, as well as the role that different members play in contributing to or hindering this flow of information (Coburn \& Russell, 2008; Otte \& Rousseau, 2002).

Understanding these social networks can then be used to gain greater insights as to how the information flow through these networks contribute to the success or failure of an innovation (Coburn \& Russell, 2008; Hawe \& Ghali, 2007; Penuel, et al., 2009). Information from the social network analysis can also be used to aid a "reform expert" such as the ITRT, in functioning more effectively within the school (Deal, et al., 2009).

\section{Statement of the Problem}

The problem is that not much is known about the dynamics of the technology support networks schools. It is not known how they form, or the degree to which they are based on other already established support networks in the school. Also unknown is an understanding of the characteristics of the prominent players, such as departmental membership. In addition, where the ITRT fits into these networks remains unknown. In 
some cases, ITRTs have not been universally accepted by the classroom teachers they are expected to be helping. This is because the ITRT is sometimes viewed as lacking sufficient content expertise to be of any true help (Davidson, 2003). It is also not known if teachers who have already adopted technology into instruction, essentially the teachers with highly developed TPACK, will play a complementary or competitive role with the ITRT within these social networks (Frank, et al., 2004). Finally, the effect of technology leadership on the part of the principal and the ITRT on the structure of the technology support network is also unknown.

\section{Purpose of the Study}

The purpose of this study was to: (1) learn about the social networks teachers form in order to support technology integration in the classroom, (2) learn about how the ITRT is positioned in these social networks and to see if the instructional background of the ITRT affects that position, and (3) learn how technology leadership on the part of the school principal and the ITRT might affect the structure of these networks. It was assumed at the onset of the study that TPACK is present in teachers who value the use of technology in their instruction to support student learning. There was also the assumption that school leaders are motivated to act in ways that promote the use of technology in the classroom. These assumptions were found to be true. Thus, the results of this study have generated lines of further inquiry to help expand the knowledge base of this topic.

\section{Research Questions}

The research questions that guided this study were as follows:

1. How is technology leadership conducted in the school on the part of the principal and of the ITRT?

2. What is the structure of the curriculum support network at the dyadic, the macro and the micro levels at each school? 
3. What is the structure of the technology support network at the dyadic, the macro and the micro levels at each school?

4. Where is the ITRT located in the technology support network, as measured by in-degree centrality? Was there any connection between the ITRT's instructional background and the backgrounds of the teachers who sought her help?

5. What is the relationship between in-degree centrality, out-degree centrality, TPACK level, age, years in the school and years teaching?

6. How much of the technology support network is composed of ties created specifically for technology, i.e., ties not also found in the curricular support network?

\section{Methodology}

This study used a mixture of quantitative and qualitative data collection in a case study using an operational construct purposeful sample (Patton, 2002). The case was each of the schools studied and the unit of analysis was teachers in the school. The sample schools were chosen because they were known to have high rates of integration, but with differences in factors surrounding this integration.

The quantitative data collection was in the form of a self-assessment on instructional technology competence each teacher filled out, as well as a social network analysis (SNA) of the ties teachers in the schools made with their colleagues. Social network theory is a concept that sheds light on the social structures embedded in an organization (in this case the school) and the effect these relationships have on the beliefs of its members (Hatala \& Fleming, 2007). As a quantitative technique, social network analysis is used to analyze interactions between the group members. One of its uses is to reveal which group members teachers will access for technical expertise, which then reveals which members are playing critical roles in this transfer of knowledge (Hatala \& Fleming, 2007). Therefore, SNA proved to be an effective technique to generate 
hypotheses for further research on the process of technological integration throughout a school.

The qualitative data collection consisted of in-depth interviews with the school principals and the ITRTs at the two schools. Principal leadership has been shown to be a critical factor in the success or failure of a technology integration reform. The Principal also plays a key role in the deployment of ITRT. Thus it was necessary to know about the principals' own philosophies about technology in instruction as well as the degree to which they empowered shared leadership in the individual schools. To help more fully understand the ITRTs' position in the network, it was also important to learn the instructional background of these individuals to learn if that had any bearing over who used the ITRT for technological help. Overall, the qualitative data was used to provide a more in-depth understanding of the quantitative analysis (Penuel, et al., 2009).

\section{Rationale for the Study}

The results of this study will prove valuable to a number of stakeholders. At the university level, principal preparation programs can help prospective school leaders develop the skills necessary to successfully lead technology integration efforts. At the school division level, the value of these results can be two-fold. First, staff development based on the finding of this study can be implemented to help existing school principals improve technology integration in their schools. Second, these findings can be used to help central office personnel devise interview questions for new principals in order to find principals who already possess the knowledge to successfully lead technology integration in schools. At the school level, principals and ITRTs can use the results from this study to assess and improve their own efforts to effectively help teachers successfully 
integrate technological methodologies into their individual instructional programs.

Finally, the study has provided valuable information about how technology leadership in a school affects the structure of the technology support networks. Several areas for further research have also been identified, which are discussed in Chapter 5.

\section{Limitations}

This study was conducted at two middle schools in one school district. The results may or may not be applicable to other similarly sized schools or school systems.

\section{General Definitions}

\section{Definitions}

Pedagogical Content Knowledge (PCK): The special knowledge that teachers possess that allows them to present their knowledge of a subject area in a way that school students can comprehend (Shulman, 1986).

Technological Pedagogical Content Knowledge: An extension of PCK that adds a teacher's knowledge of technology into the mix and allows the teacher to integrate technology into instruction in a pedagogically sound manner (Mishra \& Koehler, 2006). Recently, TCPK has been reacronymed as TPACK, which stands for Technological Pedagogical and Content Knowledge. This change was made to put greater emphasis on the interrelatedness of these domains (Thompson \& Mishra, 2007). This study will primarily use the updated acronym.

Distributed Leadership: A way of examining leadership practice that recognizes how sources of expertise are utilized from different levels within the school. In this model, leadership is shared between multiple individuals and is focused upon the interactions between individuals in formal and informal leadership roles (A. Harris \& Spillane, 2008). Instructional Technology Resource Teacher (ITRT): Resource teacher with technological expertise deployed to assist classroom teachers with integrating technology into 
instruction. The ITRT often plays a number roles in the school, some instructional, some administrative and some as a staff developer (Davidson, 2003).

\section{Social Network Analysis Definitions}

(Christakis \& Fowler, 2007; Hawe, Webster, \& Shiell, 2004)

Actors: Individuals who are members of the network

Alter: a person who possibly influences the ego through their connection

Bounded List: This is the list of people the focal actors are asked to identify

Centrality: used to identify key players. These actors are extensively involved with many other actors in the network. This is related to:

Degree Centrality: The sum of the actors who are directly connected a specific actor (ego).

Group Centrality: Used to identify which groups within the network exert influence in the network by way of their collective social capital.

Cliques: a subgroup of actors connected to one another but with no other actors directly connected to all members of the group.

Cohesion: This is how the interconnectedness of actors is described. In this study, it is expressed in terms of

Density: The number of relational ties divided by the total possible number of ties, expressed as a percentage.

Connected component: A portion of a social network where each actor has at least one tie to another actor and all actors are connected by way of their ties with others.

Ego: A focal actor such as the ITRT.

Graphs: A visual representation of how the actors are all interconnected. Also referred to as a Sociogram. 
Isolates: Actors not connected to any other actor in the network.

Name Generator: Names of people an actor could be connected to.

Nodes: How each actor is displayed on the graph.

Relational Ties: Connections between members within the network.

\section{Organization of the Study}

This study will be described further in the following chapters:

Chapter Two: A CRITICAL ANALYSIS OF THE RELEVANT LITERATURE

pertaining to teachers beliefs, the role of the Educational Technologist, Technological

Pedagogical Content Knowledge, distributed leadership and Social Network Analysis.

Chapter Three: AN OUTLINE OF THE METHODOLOGY including the

instrumentation, how the data was collected and how the data was analyzed.

Chapter Four: ANALYSIS OF THE DATA including a presentation of the findings organized by the research questions.

Chapter Five: SUMMARY AND CONCLUSIONS which will include a discussion of the implications of the findings ending with recommendations for areas of further study. 


\section{CHAPTER TWO: A CRITICAL ANALYSIS OF THE RELEVANT LITERATURE}

The purpose of this chapter is to review the relevant research associated with this study. The chapter begins with a discussion of teacher beliefs and how teachers learn in ways that promote belief change. This leads to the idea of successful teachers needing a well developed pedagogical knowledge. This concept has its roots in the educational literature of the late $19^{\text {th }}$ Century, which eventually led to Shulman's (1986) theory of pedagogical content knowledge. Mishra and Koehler (2006), in turn, used this concept as the foundation of their own theory of technological pedagogical content knowledge. The review will continue with a discussion of the instructional technology resource teacher (ITRT) and the many complexities associated with that position.

The role of the school principal and how the leadership practices of the principal are integral to the success of the ITRT then follows. The discussion will then move onto the important role social interactions play as teachers adopt new techniques as part of their instructional strategies. The review will conclude with a detailed discussion of Social Network Analysis, and how this analytical construct can be used to reveal how information flows through a school by way of established social networks.

\section{Teacher Beliefs and Conceptions}

Research has shown that teachers hold very strong beliefs and conceptions concerning instruction (Joram \& Gabriele, 1998). Beliefs can be thought of as form of "personal truth" that all people possess. They are extremely individualized and are developed through personal experiences (Pajares, 1992). Conceptions can be thought of as the set of guiding beliefs that influence the decisions teachers make concerning 
instruction (Entwistle, Skinner, Entwistle, \& Orr, 2000; Koballa, Glynn, Upson, \& Coleman, 2005).

Oftentimes, these beliefs and conceptions are formed long before teachers enter their teacher education programs (Mellado, 1998). Beliefs and conceptions tend to be stable, causing teachers to resistant changing them (Joram \& Gabriele, 1998). Research has also shown that the earlier these beliefs are formed the more difficult they are to change (Pajares, 1992). Thus, beliefs and conceptions about teaching and learning tend to guide a teacher's practice in the classroom (Foss \& Kleinsasser, 2001). Part of the problem of increasing teachers' integration of technology into instruction is that the most experienced teachers had no experiences with technology in their own schooling. Therefore, teachers' beliefs about technology are affected by the fact that they have no conceptions for using it in their own practice.

For changes in practice to occur with integrating technology into instruction, teachers need to acquire new beliefs and conceptions concerning its use (Ertmer, 2005). This type of acquisition will only occur when teachers are presented with new beliefs that are both plausible and cause dissatisfaction with the beliefs to be replaced, often with an actual shift in Gestalt having to occur (Pajares, 1992). Therefore, policymakers need to take into account the ways teachers learn, then provide opportunities for teachers to explore the connection between these new conceptions and their own practice in the classroom (Koballa, et al., 2005).

\section{How Teachers Learn}

There are a number of ways that teachers learn in order to improve their practice. First, they learn in terms of their own practice, by way of monitoring, analyzing and 
adjusting as a result of their experiences. A second way that learning by teachers takes place is by way of interacting with other teachers. This can include formal interactions, such as an experienced teacher mentoring a novice teacher, or through informal means, such as conversations between various teachers within the school setting (Bransford, Brown, \& Cocking, 2003).

Teacher learning can also take place by way of teacher education programs within schools. Effective programs have been found to include a combination of learnercentered and knowledge-centered approaches. Learner-centered approaches take into account the attitudes and beliefs that the teachers bring to the educational program and how each individual's current knowledge and beliefs are connected to their instructional program (Bransford, et al., 2003). A critical reflection of beliefs, which come as a result of the tensions and dilemmas that result from new information being introduced, is recognized as having the potential to support transformative learning (Webster-Wright, 2009). Thus, learner-centered instruction should be designed so that it will challenge preconceptions, allowing the learners to internalize the new material so as to readjust their beliefs and step away from the "taken-for-granted" instructional paradigm (Bransford, et al., 2003; Webster-Wright, 2009).

Bransford, Brown and Cockling (2003) state that the learner-centered staff development environment should help teachers adjust their beliefs, while a knowledgecentered environment will cause teachers to adjust their instructional practice. Staff development following this approach will cause teachers to rethink their knowledge of their subject matter in order to develop new pedagogical techniques. Subsequently, teachers will end up with a much deeper understanding of their content along with a new 
understanding on how to effectively deliver that knowledge to students. They further suggests that knowledge centered approaches be focused on the teachers' pedagogical content knowledge, as articulated by Shulman (1986).

\section{Pedagogical Content Knowledge}

In the 1890s, the modern the public high school was coming into existence and expanding. This expansion led to an increased need for high school content area teachers, which, in turn, led to discussions in the literature concerning what knowledge base these teachers needed in order to succeed in the classroom. This was at a time when most teacher exams were heavily focused on the content knowledge a teacher held (Shulman, 1986). While there was this prevailing belief in that high school teachers only needed a thorough knowledge of the subject matter they were to teach, Walter Jacobs (1897) argued that an additional skill was needed: the ability of teachers to translate their knowledge of the content in a manner that high school students could comprehend, a skill now known as pedagogy.

The suggestion that content teachers needed pedagogical as well as academic understanding gained traction in the years that followed (Bullough Jr., 2001). This concept was frequently addressed in the historic Report of the Committee of Seventeen on the Preparation of High School Teachers (Halleck, 1907b), presented at the 1907 meeting of the National Education Association (NEA). Several of the committee members, in their individual papers, made clear that successful teachers not only had to know their subject matter but also had to be well versed in pedagogy so that they could teach the subject material to high school students in a manner in which the students could understand (Bolton, 1907; Brooks, 1907; Halleck, 1907a; Hanus, 1907). 
This belief that successful secondary teachers needed some combination of pedagogical as well as content understanding continued to be discussed in the literature during the decades that followed (Bullough Jr., 2001). There was a slow evolution of thought away from the idea set out in closing decades of the $19^{\text {th }}$ Century that teachers merely needed a thorough understanding of the content. By the 1980s, the focus in the literature had moved in a direction that was opposite from where it had been in the $19^{\text {th }}$ Century, as teacher research had moved entirely away from advocating a foundation in content. Instead, the research was focused almost entirely on the process of teaching, e.g., the structure of assignments, the relative level of questions, how student understanding was judged (Shulman, 1986).

It was within this context that Shulman (1986) began raising questions about the "missing" role of content. His primary research interest was in finding the sources of teacher knowledge. He was also interested in how teachers acquired new knowledge, retrieved old knowledge and how an entirely new "knowledge base" was formed through the combination of this new and old knowledge. Despite this interest in the "missing" content, he recognized that content knowledge alone would be as "useless pedagogically as content-free skill” (p. 8) Thus, he saw it was necessary to study both aspects of instruction, content and process, in order to discover how they should be properly blended for effective instruction.

Shulman (1986) defined content knowledge as "the amount and organization of knowledge per se in the mind of the teacher" (p.9). He concluded that content knowledge was more than knowing the facts of a subject area. Furthermore there were several distinct facets of content knowledge that teachers possessed. This form of knowledge 
encompassed not only the accepted truths of the subject area, but why these truths were accepted. Beyond this simple form of content knowledge was what he termed "Pedagogical Content Knowledge" or PCK (Shulman, 1986).

Shulman (1986) concluded that PCK comprised a separate form of knowledge that could be thought of as occurring at the overlap of content knowledge and pedagogical knowledge (see Fig. 2-1). This form of knowledge was made up of an understanding of the important aspects for teaching the subject material. It is the knowledge teachers draw upon when they try to represent the subject material in a manner that students can comprehend. PCK also included an understanding of what made learning a subject difficult or easy for students as well as all of the tools and strategies teachers employ in effectively presenting lessons (Shulman, 1986). In the decades that followed Shulman's introduction of the concept, PCK has become widely accepted in teacher education (Segall, 2004).

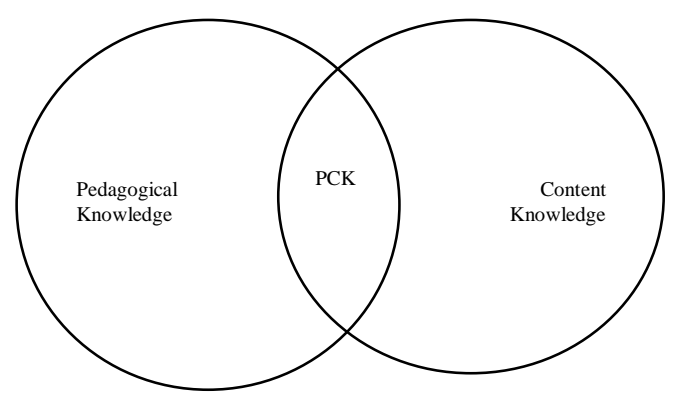

Figure 2-1: Pedagogical Content Knowledge From Mishra and Koehler (2006). This shows pedagocical content knowledge (PCK) at the intersection of pedagogical knowledge and content knowledge

\section{Technological Pedagogical and Content Knowledge}

Beginning in the mid-1990s, a major investment was made in creating a technological infrastructure for teachers to access in order that they may integrate technology into their instruction. By the turn of the $21^{\text {st }}$ Century, virtually all public 
school teachers had access to computers and the Internet. Despite this, instructional use of this technology continued to lag behind this infrastructure investment (Sandholtz \& Reilly, 2004). Part of this lag can be attributed to the approach that had been taken in preparing teachers to use computers in their instruction. Interestingly, there are some parallels to the situation that occurred a hundred years earlier, when the modern high school was introduced into the education system.

In the late $19^{\text {th }}$ Century, there was a prevailing belief that content teachers simply needed a college degree in their subject matter in order to teach. By solely having this content expertise, these teachers would be able to effectively teach in the classroom with no additional training in pedagogy (Bullough Jr., 2001). Policymakers at the end of the $20^{\text {th }}$ Century took a similar approach when introducing technology usage into the classroom. The prevailing belief at that time was that teachers simply needed training in the mechanics of computers and computer programs, which could be thought of as a type of content knowledge. Once teachers were trained on computers and provided with access to hardware and software, it was believed that creative instruction using these technological tools would automatically occur (Cuban, et al., 2001).

Subsequently, much of the technology training teachers received took a "one-size fits all" approach, centered on the technical side of computer applications. However, this type of training, devoid of specific context, content or pedagogy, left teachers on their own to figure out how to integrate these programs into their instruction. Many academics have concluded that this approach has failed (Jacobsen \& Lock, 2004; Niederhauser \& Stoddart, 2001; Zhao \& Frank, 2003). According to adult learning theory, it is necessary for adult learners to have transformational experiences in order to integrate new 
knowledge into their belief systems. This occurs through a process where their present values assumptions and beliefs are challenged in a manner that transforms their individual practice (King, 2002).

It has also been shown that teachers need to recognize the value of technology in supporting their instructional programs. Therefore, if the goal is for teachers to develop technologically-rich pedagogies, then content-based staff development experiences need to be made available (Hughes, 2005). This idea that technology training for teachers should be focused more on how applications can specifically be integrated into instruction has frequently appeared in the literature in recent years (Cuban, et al., 2001; Hatala \& Fleming, 2007; Hew \& Brush, 2007; Koehler, Mishra, \& Yahya, 2007; McVee, Bailey, \& Shanahan, 2008; Niederhauser \& Stoddart, 2001; Sandholtz \& Reilly, 2004; Zhao, et al., 2002).

Among those who have recognized that the introduction of technology in itself would not steer educational change are Mishra and Koehler (2006). They concluded that research needed to be focused on how teachers effectively use technology in their instruction rather than being focused on what technological competencies teachers need to demonstrate. To this end, they conducted a multi-year design experiment to gain a better understanding of the process by which teachers developed "rich uses of technology" in their classrooms (Mishra \& Koehler, 2006, p. 1019).

Mishra and Koehler (2006) employed a process they termed Learning by Design. Under this approach, participants were organized into design teams and placed in authentic situations where the participants had to develop solutions within contentspecific situations. They saw this process as being "riddled with contradictions and 
tensions" (p. 1040). Through this constructivist process, teachers were able to change perceptions that technology, pedagogy and content operate independently of each other and thus recognize the complex interactions between these three domains (Koehler, et al., 2007; Mishra \& Koehler, 2006). This challenging of prior conceptions that Mishra and Koehler employed is consistent with the processes identified by other researchers for belief change to occur in adults (Hughes, 2005; Pajares, 1992).

Mishra and Koehler (2006) further discovered that teachers draw upon three knowledge domains as they learn how to apply technology into their instruction. The first domain is the knowledge of content, which is the specific subject that is to be taught. The second domain is pedagogical knowledge, which encompasses the whole collection of teacher knowledge about how to teach the content to specific students. The third domain is the teachers' knowledge of modern collections of available technologies, which can range from something as simple as a blackboard to something as complex as computers and the Internet. They concluded that teachers develop a complex situational knowledge which drawn upon as technology is integrated into instruction. This knowledge is comprised of the varying interactions between the teacher's knowledge of technology, pedagogy and content. For example technological content knowledge describes how a teacher applies knowledge of technology to transform the subject material, while technological pedagogical knowledge describes how pedagogical goals can be supported by technology (Mishra \& Koehler, 2006).

From their work, Mishra and Koehler produced the concept of technological pedagogical content knowledge (TPCK) as a grounded framework to conceptualize what technological knowledge teachers need to acquire, as well as how this knowledge is 
developed by teachers into effective instructional strategies (Mishra \& Koehler, 2006). In this way, Mishra's and Koehler's framework became an extension of Shulman's (1986) theory of pedagogical content knowledge (Mishra \& Koehler, 2006). To further emphasize this interaction of domains, TPCK was re-acronymed to TPACK, which stands for Technological Pedagogical and Content Knowledge (Thompson \& Mishra, 2007). This dissertation will use the updated acronym from this point forward.

Technological pedagogical and content knowledge (TPACK) thus exists at the intersection of a teacher's technological knowledge, pedagogical knowledge and content knowledge (see Figure 2-2). Effective professional development programs must treat the three domains as an integrated unit, with successful staff development programs employing strategies that focus how to teach with technology rather than instruction on how to use the various technologies. It is only through this dynamic web of interactions that successful teaching with technology will occur. Thus, training which focuses on hardware and software skills in isolation of content and pedagogy will be ineffectual (Koehler \& Mishra, 2005; Koehler, et al., 2007).

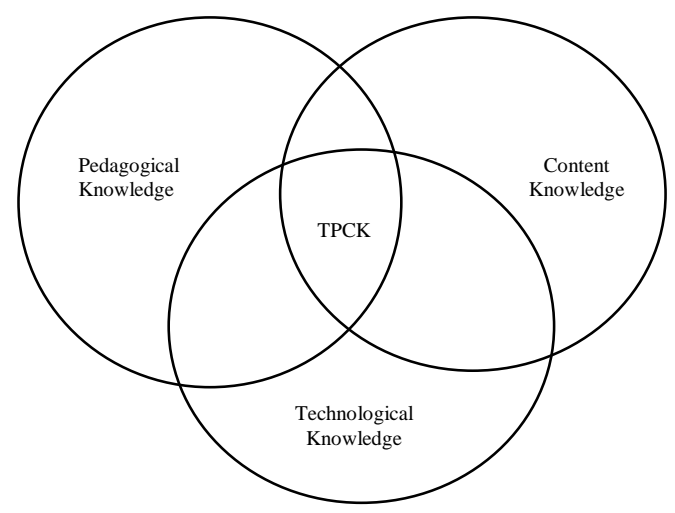

Figure 2-2: Technological Pedagogical Content Knowledge From Mishra and Koehler (2006). This shows TPCK at the intersections of the three knowledge domains of pedagogical knowledge, content knowledge and technological knowledge. 


\section{The Instructional Technology Resource Teacher}

Providing quality technological support has been identified in the literature as a key factor for teachers to successfully integrate technology into their instruction. To this end, new roles, such as the ITRT, have been created as a way to support teachers through this process (Dexter, Anderson, \& Ronnkvist, 2002; Ertmer, 2005). Despite the recognized importance of this role, the research base remains sparse (Davidson, 2003). This could be due in part to the newness of the role (Davidson, 2003), the ill-defined nature of the role including no clear consensus on the job title (Hofer, Chamberlin, \& Scot, 2004; Shoffner, 2001) and the lack of state certification requirements (Goetzel, 2008). There is however, a clear understanding that additional research on this role is needed (Davidson, 2003; Virginia Department of Education, 2003). Notwithstanding the thin literature record, some things are known.

The introduction of computer technology into instruction has been a multifarious process. Technical applications are complex and in some ways out of the realm of traditional instruction, causing teachers to need "translation" assistance, the role for which the ITRT position was created (Davidson \& Olson, 2003). This translation can take the form of either technical support or instructional support. Technical support focuses on the operational and troubleshooting aspects of software or hardware while instructional support is focused on how the technology can be integrated into the instructional program (Dexter, Seashore, \& Anderson, 2003). The predominant focus the ITRT plays in a school, either technical or instructional, is not inconsequential and can have an effect on how readily teachers embrace computers in instruction. 
Research has also shown instructional support makes a difference in the classroom. Teachers are not computer technicians and if they become overwhelmed with the technical aspects of hardware and software, they tend to revert to traditional practices. Thus there is a desire on the part of teachers for support activities centered on instructional issues (Sandholtz \& Reilly, 2004). Moreover, it has been found that when the type of support experiences teachers receive is focused on content-based learning, there is a greater integration of technology into classroom instruction (Hughes, 2005).

This is especially true when the activity is providing teachers with the opportunity to learn technology in conjunction the subject matter, including modeling instructional practices using the technology (Lee, Suharwoto, Niess, \& Sadri, 2006). Additionally, support experiences that provide opportunities for teachers to be learners as well as instructional designers has been associated with high-quality technical support programs (Dexter, et al., 2002). All of these ideas are consistent with the TPACK framework developed by Mishra and Koehler (2005).

There has also some thought that the background of the ITRT influences the perceptions of classroom teachers, which can affect the acceptance of individuals in this role. Davidson (2003) observed that content-area teachers saw themselves as specialists in their field regarding instructional matters. This led to questions concerning whether or not a whole-school generalist ITRT had sufficient "professional skills" to work with teachers in a specific content area, despite holding a teacher certification in a different content area.

The ITRT can also play multiple leadership roles within the school. However, this leadership function can be complex, with the ITRT having both formal and informal 
leadership responsibilities. In more informal settings, such as working directly with teachers, leadership occurs simply through the act of translating technology (Davidson \& Olson, 2003). In this function, the ITRT must understand the needs of adult learners as well as be cognizant of the widely varying technological abilities of the staff. Leadership is exerted in the ways that the ITRT crafts staff development to meet these varying needs, as well as facilitating the acceptance and implementation of technology in classroom instruction (Dexter, et al., 2003). In more formal settings, the ITRT oftentimes will be part of a larger technology leadership team, which can include administrators and teachers. Although not being a positional leader, the ITRT assumes a leadership role in these settings by holding expertise other team members might lack (Dexter, et al., 2003).

These multiple functions influence how the role of the ITRT in the school is ultimately defined (Davidson, 2003). The technical expertise held by the ITRT, as well as the responsibilities the ITRT is assigned, can affect perceptions teachers have of the individual in their school. For example, having responsibility over computer lab schedules, or being the only person permitted to perform simple maintenance, such as changing printer cartridges, leads to the perception that the ITRT is more of a technical resource rather than an instructional resource. In other instances, the ITRT can be seen as being "overburdened" by the multitude of responsibilities, leaving teachers reluctant to go to this person for instructional support (Goetzel, 2008; Pusey, Sadera, \& Kenton, 2007). However, holding a non-positional role, the eventual effectiveness of the ITRT is directly influenced by the leadership style of the school principal. 


\section{Principal Leadership}

Technology leadership has been found to have a greater impact on technology goals then either the funds spent on technology or the technology infrastructure that has been put into place (R. E. Anderson \& Dexter, 2005). Research has also shown that leadership on the part of the principal is a key factor in change efforts (R. E. Anderson \& Dexter, 2005; Dexter, et al., 2003). In addition, how power is distributed related to a change or new initiative influences the ultimate success of that initiative (Lindahl, 2007). Thus, it is necessary to understand the attitudes and practices of the school principal, since directly or indirectly, the principal will shape the leadership role and subsequent impact of the ITRT.

Leithwood (2005) has identified three core functions of successful leaders: "setting direction," "developing people" and "developing the organization." Setting direction includes articulating an unambiguous vision of the future which inspires the staff to adopt this vision as their own. This in turn leads to the staff working collaboratively in order to achieve the newfound common goal. A part of the leader's role in this process is to develop the expectation for high performance by setting goals which are challenging yet achievable (Leithwood \& Riehl, 2003).

The second function of successful leaders is to "develop people." This includes providing support to individuals as they navigate through the changes in practice. One way successful leaders facilitate the development of their staffs is to model the new expectations themselves (Leithwood, 2005). The third function of successful leadership is to "redesign the organization." This modification of the organizational structure is 
accomplished in part by developing new processes for accomplishing the goals of the organization (Leithwood, 2005; Leithwood \& Riehl, 2003).

Principals can also apply leadership through their attitudes towards integrating technology into the classroom. In the case where there is a lack of support on the part of the principal, technology integration into the classroom will be restricted, as teachers will not sense the importance of adopting the new instructional paradigm (Hew \& Brush, 2007). Conversely, the most influential principals are those who have become keenly involved in the innovation. These principals can become "the visionary behind the school's innovation" by way of their personal identification with technological integration. In this case, it can become a personal goal of the principal to get others within the school to adopt this vision (Owston, 2007, p. 71). How school leaders set the direction of a technology innovation can affect the degree to which teachers integrate it into instruction, where a focus on curricular and pedagogical uses leads to increased teacher involvement in using technology around learning (Dexter, 2011).

How the role of the ITRT is defined by the principal will have direct bearing on how the ITRT is utilized within the school. It is the principal's responsibility to designate the role of the ITRT and to publicize that role to the school staff. In this way, principals serve as gatekeepers in the way they choose to structure the ITRT role. According to how this role is defined, the ITRT could have the freedom to create appropriate professional development programs that helped teachers develop TPACK. Conversely, the ITRT could be used more to oversee the technical aspects of the infrastructure, such as being involved in maintenance of equipment or assigned as the individual in charge of a 
computer lab (Davidson \& Olson, 2003). Clearly defining the role is also important to prevent resentment by other teachers (Leithwood, et al., 2007).

Another impact on the role of the ITRT is the ways in which the principal chooses to distribute the leadership function throughout the school. The initial introduction of technological systems has had a profound effect on the traditional culture of schools. Since modern technology is complex and ever-changing, principals have had to increase their reliance on others who hold this expertise. This reliance in turn has required principals to redistribute their leadership capital to others (Davidson \& Olson, 2003). A way of examining this reallocation of responsibility is by way of what is being termed distributed leadership (A. Harris \& Spillane, 2008).

\section{Distributed Leadership}

In recent times, the world of education in general has become increasingly complex. This makes it necessary for leaders, such as principals, to adopt flexibility within the leadership structure to tap a diversity of expertise to help deal with the increasing complexity (Lindahl, 2007). Distributed leadership is part of an evolution of leadership theory away from the "Great Man" characteristics of the past to the more current transformational or servant leadership styles. It is an alternative way of looking at the relationship between leaders and followers, while recognizing that the interactions of the "followers" with the "leaders" may be a key element in how leadership is defined in the school (A. Harris \& Spillane, 2008).

Under this perspective, there is a distribution of leadership across the organization that is not limited to the positional leaders, such as the principal or assistant principals. Individuals within the organization become identified as leaders due to the personal 
resources they possess that are valued by others in the organization. Thus, leadership activity is situated within the realms of the knowledge and expertise individuals possess that is valued by others (human capital), the ways they interact with others (cultural capital) and the connections they make with others that allows the transmission of knowledge (social capital). This distribution of leadership is contextual to the type of advice being sought, where the leadership activity results from the advice-givers' influence on those seeking the advice (Spillane, Hallett, \& Diamond, 2003).

A holistic form of distributed leadership encompasses the idea that there is a synergy between all sources of leadership within an organization (Leithwood, et al., 2007). This is not the idea of looking at leadership itself, but looking at leadership as a practice. As a result, the study of distributed leadership is an analytical tool for examining leadership practice within a school that includes the interactions of the leader, the followers and the situation in which they are interacting (A. Harris \& Spillane, 2008; Spillane, Halverson, \& Diamond, 2001). Consequently, the work of non-positional leaders, such as the ITRT, will be affected by the relationship with the principal as well as the context in which they are operating (Spillane, Halverson, \& Diamond, 2004). Examining leadership activity from this perspective implies a situation where leadership activity will be socially constructed i.e., more interactive by continually engaging the group members with the culture of the organization. This recognizes that schools are not monolithic organizations but are made up of individuals. Influencing members of the school community is therefore accomplished by more than just the principal (Lindahl, 2007). There is also an implied social interdependence associated with leadership activity, as the principal will draw upon specific expertise held by others, such 
as the ITRT, to advance the goals of the school (Leithwood, 2005; Lindahl, 2007). According to Fullan (2002), "Information only becomes knowledge when it is socially processed" (p. 410). For this reason, principals and other school leaders, such as the ITRT, need to have an understanding of the social environment and its effect on the flow of information. Otherwise, deterioration of the organization will eventually occur (Fullan, 2002).

\section{The Role of the Social Environment}

Oftentimes there will be initial excitement on the part of teachers when acquiring new knowledge and skills. However, this excitement can quickly wane because of a lack of support among peers in the workplace (Hatala \& Fleming, 2007). In schools, institutionalized subject culture is an example of the kinds of relational barriers that can inhibit the implementation of a new initiative (Hew \& Brush, 2007). A lack of collaboration between teachers as well as innovations that are too far afield of the traditional norms within a school are other examples of relational barriers that can negatively impact a newly introduced innovation (Zhao, et al., 2002).

Schools are composed of complex social structures. Social interactions take place between teachers and others for various purposes, causing networks to form - all of which have their own characteristics (Zhao \& Frank, 2003). One important network centers on the friendships that develop between teachers. Research has shown that having three or more friends in the workplace can increase job satisfaction by as much as 50 percent. Much of the real work of schools will occur within these various friendship networks (Deal, et al., 2009). 
Teachers tend to find friends that are have classrooms near their own classroom, known as proximity or who share similar background characteristics, known as homophily (Deal, et al., 2009). How these relationships form and how information flows through them can be affected by the physical layout of the school. For example, when individual academic departments are clustered in their own section of the building, social networks tend to form within departments. On the other hand, when schools are configured into "houses" or teams, such as with many middle schools (Conley, Fauske, \& Pounder, 2004), teachers from different departments will be clustered together according to the group of students they teach. In this latter case, networks develop centered on groups of students taught rather than on the departmental membership of the teachers. These different configurations subsequently impact the flow of information in the school (Deal, et al., 2009).

Another type of social network can form around the concept of "reciprocal altruism" where teachers will work together for the common good of the school (Zhao \& Frank, 2003). In general, when an innovation is introduced, it is the early adopters who recognize the value of the innovation. They then give help to, as well as exert pressure upon others within the school to adapt to the new strategy (Zhao \& Frank, 2003). As part of this process, a reciprocal benefit occurs for the expert as the novice adopts and integrates the new knowledge. This benefit for the early adopters takes the form of a growing conformity to the new innovation. Benefit is received by teachers when adopting the norms of the group in order to remain in good standing. As this process unfolds, members of the school will draw upon others who already have developed expertise, so 
as to gain the necessary knowledge to become part of the reform movement (Frank, et al., 2004).

\section{Communities of Practice/Professional Learning Communities}

One way that policymakers and school leaders have attempted to tap into this collective knowledge of a school staff has been through creating opportunities for teachers to work together on common instructional issues. These have taken the form of such structures as communities of practice or as professional learning communities (PLCs). This concept is based on the idea there is a collective knowledge held by the educators within a school, and that school improvement and reform can occur through greater collaboration (Stoll, Bolam, McMahon, Wallace, \& Thomas, 2006). The benefits of successfully established learning communities include increased collaboration, improved professional relationships and ongoing support networks. This type of collaboration has been shown to be important during technology integration initiatives (Glazer \& Hannafin, 2008).

There have been mixed results regarding the establishment of PLCs within schools. At the high school level, problems have occurred as a result the tradition rigid departmentalization and hierarchical management (Giles \& Hargreaves, 2006). Although middle schools are also departmentalized, this type of redesign has been more effective at that level. This could be due in part to the establishment of interdisciplinary teams that work with specific groups of students that is one of the characteristics of the middle school movement (Conley, et al., 2004). When these redesign efforts are forced and do not take into account the social environment of an organization, fiefdoms can develop and the effectiveness of the community is greatly reduced (Deal, et al., 2009). These 
problems notwithstanding, schools that accept innovation exhibit a pattern of collaboration and social interaction among the staff (Giles \& Hargreaves, 2006).

\section{Self-Learning and Technology Early Adopters}

Studies have shown that between $69 \%$ and $88 \%$ of teachers report being selftaught regarding their knowledge of computer technology (Angers \& Machtmes, 2005; Markauskaite, et al., 2006). This concept of self-taught can be thought of as not having learned through formal coursework, since it can include learning from friends, from a spouse or at work (Markauskaite, et al., 2006). In addition, the teachers who are "early adopters" of instructional technology have been shown to have a higher level of selflearning, coupled with a higher level of confidence in their ability to learn independently (Jacobsen, 2000; Markauskaite, et al., 2006).

The early-adopters are the teachers who exhibit a strong commitment to integrating technology into their instruction. These individuals also exhibit a risk-taking attitude that helps them to embrace the concept of technological integration (Angers \& Machtmes, 2005). These teachers, who have integrated technology into instruction, have developed what Mishra and Koehler (2006) refer to as TPACK. The early adopters also have a much higher level of learning on their own, as evidenced by self-reflection as they try to improve their own skills and instructional delivery (Angers \& Machtmes, 2005; Jacobsen, 2000). While they will tend to give help to others, they tend not to seek help because of their own perceived high level of expertise (Frank, et al., 2004).

\section{The Adoption and Diffusion Process}

Help and talk between teachers in the school has also been shown to be a significant factor in the adoption and diffusion of technology (Frank, et al., 2004). 
Adoption refers to the decision a single individual makes regarding accepting and integrating an innovation. When individuals observe others adopting the innovation, they tend to feel internal pressure to adopt the innovation themselves. Adoption - Diffusion theory, therefore, describes the spread of an innovation and its collective adoption within an organization over a period of time (Straub, 2009).

The Concerns-Based Adoption Model (CBAM) is one adoption-diffusion theory that is frequently applied to educational innovations (S. E. Anderson, 1997; Straub, 2009). Part of this model describes various levels of use of an innovation by teachers. The fifth stage of this six-stage process is referred to as integration. One of the characteristics of teachers who have reached this integration level is the desire to share what they are doing with their peers (Straub, 2009). Research has shown that these early-adopters play an important role in the diffusion process by taking a leadership role in assisting and mentoring colleagues who are in earlier stages of applying technology to their instruction (Glazer \& Hannafin, 2008; Zhao \& Frank, 2003).

Social Contagion Theory describes the social process by which knowledge of an innovation is transferred from one individual to another. Under this model, early adopters are observed by others using the innovation. In this way, non-users are able to make judgments about the value of adopting the innovation into their own practice (Burt, 1987). As the diffusion process unfolds, these experts begin helping their novice colleagues. Frank, Zhao and Borman (2004) describe the constructs of "help, talk and social pressure" (p. 162) coming together as process to facilitate the adoption and diffusion of the innovation. 
Glazer, Hannifin and Song (2005) depict a diffusion process where reciprocal interactions are a key part of successful technological adoption built around communities of practice. In their process, more experienced teachers support novices working to master new technological skills. As the novices gain more experience and confidence, they too become mentors to other less experienced colleagues. In an organization where large numbers of teachers have achieved mastery, different advice-giving roles are assumed according to individual areas of expertise. Accordingly, a teacher may being giving advice to a colleague in one situation while receiving advice from the same colleague at a different time, with the interactions driven by the contextual factors of the given situations (Glazer, et al., 2005).

It is through the varying processes described in this section that peer pressure is exerted for teachers to either adopt or reject an innovation. Over time, mass conformity to the new norms occurs, which marks the transition from the micro-level actions of distinct individuals (adoption) to a macro-level school-wide shift in culture (diffusion). At the macro level, this diffusion process can be thought of as a function of the knowledge base (social capital) that exists within a school (Deal, et al., 2009; Zhao \& Frank, 2003).

\section{Social Capital Theory}

In any organization, the internal structure, the culture, and much of the work occurs by way of social interactions between its members. Reform efforts often involve changes in the established patterns of social interaction requiring different connections between members of the organization (Daly \& Finnigan, 2011). Formalized structures and formalized exchanges of information can tend to inhibit or enhance the flow of 
information However, when the existing social capital is identified, it can be drawn upon by those trying to implement an innovation or reform (Frank, et al., 2004).

Social capital theory has its roots in studies of sociology and political science (Penuel, et al., 2009). In general, social capital refers to the resources and expertise that exist within an organization. This expertise is not something that is openly available to everyone. Members of the organization can only gain access by way of their social interactions with others. The degree to which members are able to tap into this expertise also depends in part on their position within the organization (Coburn \& Russell, 2008; Frank, et al., 2004; Penuel, et al., 2009). For example, a climate supportive of innovation and change has been shown to develop where teachers have ready access to multiple exchanges of information (Moolenaar, Daly, \& Sleegers, 2011). Thus, without an understanding of these group dynamics, change will be stymied as the organization is trapped in a never-ending cycle of paralysis (Kahn, Cross, \& Parker, 2003).

Compounding this is the fact that upper level leaders often view the information flow in schools in terms of the "task network." This is not a true social network, but the network based upon the organizational chart. The expectation is that information and expertise will flow through the organization by way of the individuals placed in specific positions on the organizational chart. Subsequently, a new initiative might mean a new position added to the flow chart as a resource for implementing the reform (Deal, et al., 2009).

The ITRT position in Virginia is such a position, as it was mandated from above to help teachers change instructional practice, in this case from the state level. Very detailed responsibilities were proscribed, right down to a five-step procedure the ITRT 
was recommended to follow when working with teachers to create technologically rich lessons (Virginia Department of Education, 2008). Yet, research has shown that educational change often occurs outside the formal organization structure through already established social networks (Frank, et al., 2004; Straub, 2009). These social interactions allow teachers to access the human capital embedded within the school, which in turn fosters their construction of a leadership framework around the innovation (Spillane, et al., 2003). Therefore change agents need to identify, cultivate and facilitate these established social structures in order to have a positive impact on the reform effort (Frank, et al., 2004).

\section{Social Network Analysis}

The problem in identifying social capital and how information flows through an organization is that these networks are often not readily apparent to change agents (Kahn, et al., 2003). Different information networks can form as a result of having similar backgrounds, working with physical proximity or how the organization is structured (Brass, 1995). Social network analysis (SNA) is a quantitative method used to study the social structures within a population (Borgatti, Mehra, Brass, \& Labianca, 2009). The map of social interactions that is created from the SNA can reveal patterns of informal communication that can help change agents by revealing how expertise (human capital) is channeled throughout an organization. Primarily SNA focuses on relationships between network members. However, when examining these relationships, it can also be used to study how these social ties influence the behaviors of the members as a whole (Hatala \& Fleming, 2007; Otte \& Rousseau, 2002). Understanding the internal structure of a school 
community is especially valuable when the reform initiative involves using nonpositional leaders such as the ITRT (Penuel, et al., 2009).

In a pair of studies widely reported in the news media, Christakas and Fowler $(2007,2008)$ used social network analysis to show how social connections affected behaviors related to personal health. In the first study, the authors used longitudinal data from the Framingham Heart Study to demonstrate that individuals become obese according to their social connections. In other words, the more connections an individual has with people who become obese, the greater the chance that person would also become obese (Christakis \& Fowler, 2007). In a separate study using the same data source, the authors learned that smoking cessation had a social component, with entire groups of socially connected individuals quitting smoking in concert (Christakis \& Fowler, 2008). In both cases, the authors concluded that changes in perceived social norms of the group had an effect on the behaviors of the individual group members (Christakis \& Fowler, 2007, 2008).

One of the most common aspects a social network analysis attempts to uncover is the identity of the prominent individuals (actors) in a social network (Borgatti, et al., 2009). Deal, Purinton and Waetjen (2009) referred to these individuals as "stars," because the connections they had with others resembled a star on a social network graph. In SNA terminology, these "stars" are central actors, and are said to have a high degree of centrality. A study of centrality seeks to identify the prominence of an individual in the network, such as the ITRT (Borgatti, et al., 2009). Mapping centrality is not used to evaluate the effectiveness of an individual; rather it is used to learn from whom members of the organization are being influenced. By mapping "the reality" and comparing this to 
"the expectation," school leaders can learn to what degree the established chains of command exert influence within the organization (Deal, et al., 2009).

Another group of individuals (actors) examined in a social network analysis are those who are found on the shortest path between other actors in the network. These individuals are referred to as having betweeness centrality. Actors who are found with this type of centrality have the potential to wield power by serving as a gatekeeper of information to others whose path they lie upon. They can speed up or slow down the flow of information, as well as distort what is passed on, in order to further their own individual interests (Borgatti, et al., 2009).

Hatala and Fleming (2007) conducted a case study which used betweeness centrality, in part, to study the transfer climate of an organization prior to initiating a training program. They surveyed the individual members of a workgroup concerning who they went to for help after a training session, as well as those whom they sought for company gossip. By examining these two networks, the authors were able to identify potential information flows that could affect the success of the training initiative. By knowing who the "go-to" people were for both technical support and company gossip, the managers were able to see that these employees were provided with accurate information about the training initiative. In this way, the actors who served as "brokers of information" could be prepared in advance of the training so as to become part of an effort to bring other members onboard quickly (Hatala \& Fleming, 2007).

While SNA has a long history of being used in sociology, its application to research in schools and with school technology integration is relatively new (Frank, et al., 2004; Hawe, et al., 2004; Penuel, et al., 2009). Hawe and Ghali (2007) conducted a SNA 
study at the onset of a "whole-school health promotion intervention." A five-level hierarchy of relationships was studied. At the lowest level the staff was asked to indicate whether or not other staff members were known to them by name. The highest level of the hierarchy studied which staff members socialized outside of the school. Each of the five networks was analyzed to learn how many people each staff member was connected to by way of the staff members with whom they were directly connected. Through this analysis (called a two-step reach), the authors were able to learn how well each staff member was able to reach out to other colleagues to convey information. This was then used to develop a comprehensive understanding of the social relationships and the various flows of information within the school (Hawe \& Ghali, 2007).

The advice-seeking network was used to identify cliques, gatekeepers and members that many staff members sought for advice (those having high degrees of centrality). They found the principal and vice-principal (as expected) to be highly central and thus desirable champions of the intervention. The SNA was also able to identify marginal members of the staff - actors with only one or two connections. This knowledge could then be used to target which staff members interacted with these marginalized individuals. The targeted staff, in turn, could be recruited as helpers to draw loosely connected actors more closely into the initiative. The authors believed this to be important information when introducing a health promotion initiative, since by using SNA to understand the flow of information in the school, the probability that the initiative would be successful was increased (Hawe \& Ghali, 2007).

Penuel, Riel, Krause and Frank (2009) used SNA as part of a systems approach to studying a literacy reform initiative. The initiative included using reform experts to help 
guide teachers in adopting the new instruction techniques. The authors focused on two schools which were involved in the initiative: Glade and Crosswinds. Social network analysis was used to examine the flow of information in the two schools as part of an effort to uncover why the initiative was more successful at Crosswinds than at Glade. One conclusion drawn from the study was that differences between the structures of the social networks, as well as how central a role the reform expert played in the respective networks, affected the flow of information in the individual schools, (Penuel, et al., 2009).

At Glade, the social groupings were not cohesive, with less likelihood that there would be interactions of the different social groups. In addition, the Glade social groups were more aligned by years of teaching experience, where the most expert teachers tended to group separately from less experienced teachers. Subsequently, some social groups had mostly veteran teachers while other groups were made up of novice teaches early in their careers. In addition, information flowed through the established hierarchy, where the principal was the primary source. This information was then passed on to other teachers by way of their grade-level leaders. Sharing from outside staff development rarely occurred. The reform expert was perceived as an "enforcer" and thus played a much less prominent role (less centrality) in the various networks (Penuel, et al., 2009).

The situation at Crosswinds was much different. That school had more cohesive social groups, aligned by grade-level, and composed of both novice and experienced teachers. Subsequently, expertise between teachers flowed more freely. A great deal of sharing occurred when individual teachers attended staff development outside the school. In addition, the reform expert held a more central position in each of the groups. This was 
because she was seen as a resource, thus many teachers sought her advice, which in turn resulted in her having a relatively high degree of centrality (Penuel, et al., 2009).

Through the social network analysis conducted at the two sites, the researchers were able to identify differences in teachers' access to expertise (social capital). These differences in the flow of social capital through the schools contributed to the level of success of the program in the respective schools. Additionally, how the role of the reform expert was defined by the principal had direct effect on the role that expert played in the various teacher networks. Overall, the study uncovered a relationship between how the flow of social capital within a school will impact teacher change (Penuel, et al., 2009).

An ego network is a way of examining the direct ties to a specific individual (actor) in the organization (Borgatti, et al., 2009). In a study of ego networks surrounding mathematics coaches, Coburn and Russell (2008) touched on many of the issues discussed in this chapter, including taking a pedagogical versus technical approach to staff development activities; and the role the principal plays in the success of the nonpositional leader. In their study, they examined the ego networks surrounding mathematics coaches to learn how school district policy affects the social networks of teachers. They compared two school districts, Greene School District and Region Z, which were both implementing a new elementary mathematics curriculum (Coburn \& Russell, 2008).

The two districts took different approaches in the selection and uses of the mathematics coaches, who were hired to help teachers implement the mathematics programs in their classrooms. Greene district hired coaches with high levels of expertise, while the coaches in Region $\mathrm{Z}$ mostly had low levels of expertise, with the exception of 
one coach who held moderate expertise. This level of expertise, along with the directions set by the school district and the individual school principals, affected the positions these coaches held in the social networks of the teachers (Coburn \& Russell, 2008).

The authors discovered that the directions set by the principals in the schools had a direct effect on "tie-strength," which measures the frequency of interaction and the social closeness between the teachers (the players) and the mathematic coaches (the egos). For example, in the Green School District, the expectation was that the mathematics coaches would meet with the teachers on a weekly basis as well as conducting twice-monthly whole-school staff development. The principals supported this plan, which resulted in frequent interactions (strong tie-strength) between the mathematics coaches and the teachers (Coburn \& Russell, 2008).

By contrast, the Region $\mathrm{Z}$ school system was not as specific regarding the role the mathematics coaches were to take. Principals had more latitude as to how to use these coaches. Not only would the reform coaches work with teachers, but they would also work with groups of students. Principals would pull the coaches from regularly scheduled coaching duties to deal with other problems in their schools, for example working with a new teacher on classroom management issues. Subsequently, none of the teachers were found to have a strong tie-strength with the mathematics coaches (Coburn \& Russell, 2008).

The differences between the deployments of the mathematics coaches extended into the focus of their respective professional development programs. In the Greene School District, the coaches took a pedagogical approach to the activities related to the mathematics program. They would explain the activities as well as work with teachers on 
how the activities could be integrated into their instruction - in effect helping the teachers develop pedagogical content knowledge around the new program (Coburn \& Russell, 2008).

By contrast, the coaches in Region $\mathrm{Z}$ took a more technical approach, explaining to the teachers how the activities worked, and then leaving it up to the teachers to figure out how to integrate the activities into their own instruction. Subsequently, the pedagogically-centered approach of Greene School District resulted in more detailed information flowing through the social networks of teachers than in Region Z, where the staff development centered on the teachers gaining technical knowledge about the new program (Coburn \& Russell, 2008).

\section{Summary}

This chapter illustrates that the process of fostering technological integration into instruction is complex. Many factors have to be taken under consideration, including how teachers acquire new knowledge and change attitudes about an instructional reform. Much of the learning and acceptance of the innovation takes place by way of informal interactions of teachers, with support networks forming by way of these interactions. This must be taken into account when policymakers place a person into a new non-positional leadership role to guide the reform, such as with the ITRT.

Both Penuel, Reil, Kraus and Frank (2009) and Coburn and Russell (2008) looked at issues associated with how central a role non-positional leaders played in the social networks of their schools. In the Penuel, et al., study (2009), teacher perceptions of the reform expert affected the flow of expertise throughout the school. When the reform expert was perceived as a valuable resource to the teachers, that person was able to serve 
as a bridge between different sub-groups. This subsequently contributed to a better flow of information (social capital) in the school, which contributed to the success of the initiative (Penuel, et al., 2009).

Coburn and Russell (2008) reported that there were a number of additional variables that affected how central a role the reform coaches played. These variables included differences in how the reform coaches were selected as well as the role the principals played in defining the role of the reform coach in their individual schools. In addition, the coaches themselves took different approaches to their own staff development programs. The coaches in one district helped the teachers develop pedagogical content knowledge around the new instructional materials, while the coaches in the other district only provided technical information about the activities in the new program materials. The different approaches to staff development helped to explain differences in the respective success of the reform efforts as well as the role the reform coaches played in the effort (Coburn \& Russell, 2008).

These last two studies (Coburn \& Russell, 2008; Penuel, et al., 2009) touched on many of the topics discussed in this chapter. In both cases, the social network analysis revealed how effectively (or ineffectively) information and social capital were flowing through the networks in the various schools. By conducting the social network analysis, the researchers were able to uncover additional factors that helped or hindered the success of the initiatives being studied. 


\section{CHAPTER THREE: AN OUTLINE OF THE METHODOLOGY}

The purpose of this study was to provide insights into teachers' technology support networks in schools. Subsequently, this study was conducted to: (1) learn about the social networks teachers form in order to support technology integration in the classroom, (2) learn about how the ITRT is positioned in these social networks and to see if the instructional background of the ITRT affects that position, and (3) learn how technology leadership on the part of the school principal and the ITRT affects the structure of these networks.

\section{Theoretical Framework}

As Chapter 2 has shown, the integration of technology into instruction is a complex phenomenon. The attitude of the school principal towards technology in instruction has been shown to play an important role in this new instructional paradigm (R. E. Anderson \& Dexter, 2005). This is especially true when a principal implements a new technology innovation with which he or she is particularly identified (Owston, 2007). The principal can also serve as a gatekeeper through the allocation of resource and support personnel, such as the ITRT (Davidson \& Olson, 2003).

In the Commonwealth of Virginia, the ITRT is a new position created to help teachers use technology with their instruction (Virginia Department of Education, 2008). However, such support positions are not always accepted by the teachers they are expected to help, especially when the individuals in the positions do not share a common instructional background with the teachers (Davidson, 2003). In addition, taking a "task network" approach of placing a new individual into the organizational chart is not shown to be effective (Deal, et al., 2009). This is because acceptance or rejection of an 
innovation in schools often occurs by way of the social interactions between teachers (Zhao \& Frank, 2003).

Learning about technology often takes place informally by way of interactions between teachers (Frank, et al., 2004). Interactions such as these can cause technology support networks to form. Working in nearby classrooms (proximity) or being members of the same academic department (homophily) are some of the ways these technology support networks are believed to form (Deal, et al., 2009). In addition, early adopters of instructional technology are thought to have a leadership role in these networks (Angers \& Machtmes, 2005). Theoretically, having a high number of connections in these networks (centrality) allows an individual to amass power by controlling access to information and resources (Brass, Galaskiewicz, Greve, \& Tsai, 2004).

What is not known are the antecedents to, or the factors that create, the connections between the teachers constituting these networks. For example, the degree to which teachers seek new ties with colleagues for technology support, versus relying on established ties from other support networks within the school is unknown. It is also not known what role the ITRT actually plays in the varying support networks. Also unknown is how the principal's leadership practice that involves others, along with his or her relationship with the ITRT, impacts the position of the ITRT in these technology support networks. In addition, while the principal's role is known to be important, it is not clear how his or her emphasis on instructional technology affects the structure of the resulting technology support networks. 


\section{Guiding Assumptions}

Based on the review of the literature, a number of assumptions were made concerning technology leadership and the resulting integration by classroom teachers. The research questions were generated by these guiding assumptions. First of all, high levels of high-quality instructional technology integration take place where teachers receive strong organizational support. In these types of organizations, there is a vision from the school principal regarding classroom technology use. There is also a welldeveloped working relationship concerning technology leadership between the principal and the ITRT so that the ITRT is deployed strategically to support that vision.

Furthermore, the ITRT offers staff development for teachers that is pedagogically grounded. It is also believed that the instructional background of the ITRT influences teacher acceptance of the ITRT.

Technological pedagogical and content knowledge (TPACK) is a content-specific understanding of how instructional technology can support instruction. It is assumed that TPACK is present in teachers who use and value technology-supported instruction. TPACK is developed through formal and informal learning. Much of the informal learning comes by way of colleague-to-colleague interactions. These interactions are believed to result in the development of technology support networks that are distinct from the already existing curricular support networks. However, the degree to which these technology networks differ from the curricular support networks is unknown.

Early adopters (teachers presumed to have higher levels of TPACK) can play an important role in these networks if they then mentor and assist their colleagues. Homophily, which are connections made between actors with a common background, 
such as the academic department or the instructional team, is believed to affect the structure of these networks, with teachers with similar backgrounds clustering together. The relative power of individuals in the network can be measured by the number of incoming links from others in the network, a network characteristic called in-degree centrality.

\section{Research Questions}

This study will answer the following research questions. The questions have been organized along the themes presented in the guiding assumptions.

1. How is technology leadership conducted in the school on the part of the principal and of the ITRT?

2. What is the structure of the curriculum support network at the dyadic, the macro and the micro levels at each school?

3. What is the structure of the technology support network at the dyadic, the macro and the micro levels at each school?

4. Where is the ITRT located in the technology support network, as measured by indegree centrality? Was there any connection between the ITRT's instructional background and the backgrounds of the teachers who sought her help?

5. What is the relationship between in-degree centrality, out-degree centrality, TPACK level, age, years in the school and years teaching?

6. How much of the technology support network is composed of ties created specifically for technology, i.e., ties not also found in the curricular support network?

\section{Research Design}

A case study approach to research is carried out to understand complex social phenomena. The ensuing results from a case study can then be used to generate both hypotheses and propositions for subsequent investigations (Yin, 2009). Social network analysis is used to study interactions between individuals in an organization with the objective of providing insights to the flow of information through the organization. The 
resulting exposure of these relationships can be used to enhance the capacity of a person to function in the organization. For this reason, social network analysis (SNA) is a vibrant measurement technique well suited for use in descriptive studies which are designed to comprehend theoretical questions around organizational change (Hatala, 2006).

This research took the form of a multi-site case study conducted in a pair of middle schools. The schools were the unit of analysis for the case study. A mixed-model approach was employed using both qualitative and quantitative data collection and data analysis methods. The results were then used to gain insights into the research questions. Part One of the study used qualitative methodologies to learn about technology leadership in the school by way of interviews with the principal and ITRT at each school. Part Two of the study used quantitative methodology to learn about the social networks teachers formed in the school. The entire staffs of each school were surveyed about the staff members they knew in the building. The teachers were also surveyed as to whom they sought help for curricular matters and then with whom they sought help for technology assistance. Social network analysis techniques were used to analyze the data. Looking at a variety of networks in the school has been shown to help develop a fuller picture of how information flows throughout the organization for various purposes (Hatala \& Fleming, 2007).

This research approach recognized the dynamic, complex and interdisciplinary reality of the present time, as well as allowing the best qualities of both qualitative and quantitative designs to be incorporated into the research project (Johnson \& Onwuegbuzie, 2004). Practically speaking, the qualitative data was expected to contribute to a greater depth of understanding of the quantitative data, allowing for more 
robust research results (Johnson \& Onwuegbuzie, 2004; Penuel, et al., 2009).

Specifically, information from the interviews of the individual school principals and ITRTs revealed how they set direction and developed others which was critical in understanding of the redesign of the organization (Leithwood \& Riehl, 2003) as illustrated by the differences between the two technology support networks.

\section{Population and Sample}

The participants in this study were the principal, ITRT and staffs of two middle schools that are both part of a large suburban school system located in the Mid-Atlantic States. The researcher, with the help of other school district personnel, identified several middle schools known be instituting technology integration initiatives. Several principals were contacted and asked to participate in the study. Two principals agreed to participate. Both principals were strong supporters of instructional technology integration, with well defined visions for the use of technology in their schools. However, it turned out there were distinct differences in how they enacted these visions. Also different were the instructional backgrounds of the two ITRTs.

There were a number of reasons for conducting the study at the middle school level. Like high schools, middle schools have multiple academic departments. Having multiple departments allows research into the instructional discipline background of the ITRT to see if there is a connection with a common academic department in the school. In addition, since TPACK is based on pedagogy and content, it would be reasonable to assume that the technological support network would form according to departmental membership. However, at this level, there is less fragmentation within the core academic departments (English, Science, Mathematics and Social Studies) when compared to the 
high school. For example, in the middle school, there are only two types of science courses offered, one for seventh grade and one for eighth grade. At the high school level, there will be Earth Science, Biology, Chemistry, and Physics among possible others. Thus the middle school reduces the departmental complexity issue which permits a less cumbersome study of how departmental membership affects these networks.

There are additional reasons that make an investigation at the middle school level appealing. Research has shown that workplace networks can form because people work nearby, because they have frequent interactions or because they share some type of common background (Brass, et al., 2004). In addition to having departmental membership, middle school teachers have membership in interdisciplinary academic teams for teaching a common group of students. These factors present a unique opportunity to learn how some of these other factors might play a role in network formation.

\section{Instrumentation}

\section{Part One - Interviews with the school principal and the ITRT}

Part One of the study consisted of qualitative data collections consisting of separate interviews with the principal and the ITRT at each school. The purpose of the principal interviews was to learn about her technology vision for the school, the role of the ITRT in helping to achieve that vision and the manner in which the ITRT was deployed and empowered to carry out that role. The goal of the ITRT interview was to learn how she viewed and implemented her technology leadership position within the school.

According to Yin (2009), interviews are a vital source of information in a case study. Furthermore, Yin suggests that case study interviews should also be along the lines 
of a "guided conversation." Therefore, the questions for the principal and the ITRT were designed to be opened-ended and promote the characteristics of a conversation rather than a rigid interview (Yin, 2009). The questioning protocol was developed to guide the conversations with the principals and the ITRTs with the questions designed to gain insights on the core leadership practices of setting direction and developed others (Leithwood \& Riehl, 2003)

\section{Questions for the Principal}

1. First, tell me some about how technology is currently being used in classrooms around your school?

2. How has this evolved in your school in recent years?

3. Tell me some about your role in this process.

4. What are some things you would like to seeing happening with technology applications in your school in the future? Are you looking to some new initiatives?

5. How do you see your role in enacting this vision?

6. Tell me about the role of the ITRT in your school? What are the duties and responsibility you have assigned to this person?

7. How has your relationship with this individual come about over the years?

8. I'm curious about who you might see as some other key people in the school who some responsibility over technology use in the school. Are there others who you have assigned, or have taken on a leadership function regarding classroom technology? This can be a formal or informal role. What can you tell me about them?

\section{Questions for the ITRT}

1. How long have you been in this position?

2. What were you teaching before you assumed this role?

3. What led you to pursue this career path?

4. Describe some of your duties and responsibilities? 
5. What is a typical day like? If I were to spend a day with you, what things would I observe you doing?

6. Tell me some about how you work with individual teachers. Who tends to come to you for help? What kinds of help do teachers tend to seek?

7. What are some of the ways you have worked with groups of teachers? Can you describe one or two activities you have put together for groups of teachers or for the entire school?

8. How have you seen your role in the school evolve over the years?

9. I'm curious about who you might see as some other key people in the school who have some responsibility over technology use in the school. Are there others who have been assigned, or have taken on a leadership function regarding classroom technology? This can be a formal or informal role. What can you tell me about them?

\section{Part Two - TPACK and SNA Survey of the School Staff}

Part Two of the study consisted of quantitative data collection. Separate surveys were developed for the teachers and instructional assistants, the professional staff (assistant principals, guidance counselors, librarians, etc.) and support staff (secretaries and other clerical personnel). The data sought consisted of demographic information, self-reported TPACK level and social network information.

The entire school staff was asked to fill out a demographic information sheet. Information sought included the number of years in the school, the position held (teacher, secretary, etc.), gender and age range. The instructional staff was also asked about the subjects they taught and their number of years teaching. The instructional staff, guidance counselors and assistant principals were asked to fill out modified versions of the Survey of Preservice Teachers' Knowledge of Teaching and Technology (Schmidt, Baran, Thompson, Koehler, Mishra, et al., 2009). The validation of this survey has been described in two recent conference presentations (Schmidt, Baran, Thompson, Koehler, 
Punya, et al., 2009; Shin, et al., 2009). Teachers were also asked to give examples of some technology applications they use related to their instruction.

Social network data was sought for three social networks in the school: the knowledge network, the curricular support network and the technology support network. A grid was created where the rows contained a bounded list of all staff members in the school (excluding custodians and cafeteria workers). Bounded lists have been found to provide more accurate data than allowing those surveyed to provide the names of whom they seek help (Daly \& Finnigan, 2009). The column headings listed the social network relationships. Respondents were asked to place a mark in the column next to the names of the staff members with whom they had the specific relationship. The column headings were as follows:

1. Who do you know in the school? (Knowledge Network)

2. Who have you gone to, or collaborated with, regarding advice or ideas about instruction in your classroom? (Curricular Support Network)

3. Who you have gone to for advice or ideas about using instructional technology in your classroom? (Technology Support Network).

Teachers received surveys that contained all three columns. Non-teachers received surveys that only contained Column 1.

\section{Data Collection}

\section{Part One - Interviews with the School Principal and the ITRT}

Data was collected during the spring of the 2009 - 2010 school year. Separate interviews were conducted with each principal and each ITRT at a location of their choice. The school principals were both interviewed in their offices. One ITRT chose a quiet section of the school library. The other ITRT was interviewed in a computer lab/office she shared with the Network Specialist. Interviews were recorded using a Sony 
PX820 digital recorder in an mp3 format. Transcriptions of the interviews were transcribed into a Microsoft Word document by the researcher. In addition, each of the interviewees completed a survey which included some demographic information and their self-assessed TPACK level. They also filled out the knowledge network survey. The demographic, TPACK and knowledge network information were entered into Microsoft Excel spreadsheets for use with UCINET.

\section{Part Two - TPACK and SNA Survey of the School Staff}

Staff surveys were distributed during this same time period. Staff lists at each school were generated from the Baldon County Public Schools email system. Initially, virtually all professional and clerical staff members were listed on the staff rosters, since it was not known where technological expertise was distributed throughout the staff. Later, some non-instructional staff members, such as the county police officers assigned to the schools, were eliminated from the study. Staff members had received an email message a few days prior to the distribution of the surveys alerting them that the surveys would be arriving in their mailboxes. The surveys were personalized, with each staff member's name pre-printed on the survey. A piece of candy was taped to each survey as an incentive to complete the survey.

The surveys were placed in staff mailboxes at each school and a box was placed near the mailboxes in each school where completed surveys could be deposited. Two email reminders to complete the surveys were sent to teachers prior to the end of the school year. At the suggestion of one of the schools, a digital copy of the survey was attached to the second email reminder. The digital copy could be filled out by respondents on their own computers and returned to the researcher as an email attachment. A second digital copy was emailed during the summer to teachers who had 
not completed a survey. Approximately $16 \%$ of the surveys from each school were returned in the digital format. Examples of the surveys can be found in Appendix A.

\section{Confidentiality and Anonymity}

All identifying information was removed from the collected data. Pseudonyms were used for the names of the school system, the schools, the school principals and the ITRTs. The names of the other actors in the social network analysis section were replaced with letter and number combinations, with the letter being the same as school name (" $F$ " for Filz and "R" for Reinhart). In some cases, the positions of an actor was included if this was needed to provide some level of clarity, for example "F-91 AP" was used to identify an Assistant Principal at Filz Middle School.

All copies of the returned surveys were destroyed after the successful completion of the dissertation defense. Recordings and transcriptions of the interviews were able to be accessed only by the researcher and were kept in a secure location. The recordings were deleted after the dissertation was successfully defended. Data from the surveys and transcriptions of the digital recordings will be held for three years from the date of the successful defense of the dissertation.

The analysis of the data has been included in the dissertation document. In exchange for permitting the study, the school system where the study was conducted required that a summary report be presented to the school system and the principals of the schools where the study was conducted. These reports will use the same name format as the dissertation and will be consistent with the confidentiality statement that was printed on the consent forms. That statement is as follows:

Confidentiality: Because of the nature of the data, it may be possible to deduce your identity; however, there will be no attempt to do so and your data will be reported in a way that will not identify you. 


\section{Data Analysis}

In case study design, it is important to understand the difference between the unit of data collection and the unit of data analysis (Yin, 2009). In this case study, the units of data collection are the staff members who were surveyed and interviewed. Collectively, these individuals compose the unit of data analysis, and the technology support network to which they contribute is the phenomenon occurring in the school as a whole. The research questions were used to guide the analysis and interpretation of the data. The use of both qualitative and quantitative methodologies permitted data triangulation, where each line of inquiry was used to collaborate the others (Patton, 2002; Yin, 2009). The dissertation report has followed a linear-analytic structure, which resulted in the uncovering new hypotheses for further study (Yin, 2009).

The qualitative data collected in Part One was transcribed, analyzed and coded for themes. The data collected in this section revealed each principal's vision for technology usage, the working relationship between the principal and the ITRT, how the ITRT was deployed in the school, and they ways in which the ITRT supported teachers in their use of technology in instruction. From this information, it was possible to create rich descriptions of the organizational support the staffs of each school received concerning instructional technology.

Information from the Baldon County Public Schools' email directory was used to determine the job assignment and department membership for staff members who did not return a survey (for example, a staff member listed as a Social Studies teacher was coded as a teacher and assigned to the Social Studies department). Many of the teachers left the team membership field blank; however, one school provided the researcher with a team 
membership roster. At the other school, team membership was posted in school's public website. It was at this point that teacher names were replaced with the letter/number alias. The demographic information spreadsheets from the individual schools were then loaded into UCINET (Borgatti, Everett, \& Freeman, 2002) and saved as attribute files.

The information provided by those surveyed on the three networks for each school was entered as a binary matrix into Microsoft Excel spreadsheets. The teacher names were listed in the first column and along the top row. The names checked off by the staff members in each network are called "nominations." When entering data, a " 1 " (one) was placed in the column for the staff member nominated along the row of the staff member doing the nominating. If a staff member was not nominated, then a " 0 " (zero) was entered into the corresponding cell. Rows for staff members not completing a survey were left blank. When the data entry was complete, looking across a row showed who people went to for help (out-degree centrality), while looking down a column showed who was coming to each staff member for help (in-degree centrality).

The data from the spreadsheets was then loaded into UCINET 6 for Windows (Borgatti, et al., 2002) for analysis. NetDraw (Borgatti, 2002) was used to create sociograms displaying the knowledge, the instructional support and the technological support networks. These analyses took the form of directional ties as opposed to merely showing that links exist. In this study, it was necessary to know the direction in which the information is flowing since the goal was to learn who teachers go to for technology support (Hatala, 2006).

Social network analysis (SNA) is used as a methodology to provide an understanding of how information exchanges occur within an organization (Daly, 
Moolenaar, Bolivar, \& Burke, 2010). The focus of the analysis is understanding the patterns of ties between network members (actors), rather the characteristics of the individual actors (Daly \& Finnigan, 2009). Looking at multiple networks helps to gain a broader understanding of the social climate in the organization (Hatala \& Fleming, 2007; Hawe \& Ghali, 2007). While simply knowing the name of a staff member (knowledge network) may seem superficial, it gives an indication as to the overall climate in the school, as well as how isolated or not the staff is. According to Hawe and Ghali (2007), people are more inclined to answer seemingly innocuous questions with more accurate information than questions that seem more intrusive.

The analysis of the knowledge and curricular networks revealed structural similarities between the two schools, which allowed more robust conclusions about the differences between the structures of the technology networks in the two schools. When examining network data, it is not possible to assume that the relational ties are independent of each other. Therefore, the normal methods for determining Pearson Correlations between the various networks within the schools will not work (Daly, et al., 2010). With SNA data, a quadratic assignment procedure (QAP) must be conducted instead. Under this process, a Pearson correlation coefficient is calculated between the matrices. Next, a random permutation of the rows and columns of one matrix is conducted thousands of times, each time correlating the new matrix to the second matrix. The number of times the new correlation is equal to or greater than the original correlation is calculated, providing a $p$-value. With a $p<.05$, there is strong evidence that the original correlation between the two networks is not a result of chance (Daly, et al., 2010). 
Quadratic assignment procedure (QAP) analyses were conducted between the curricular networks and the technology networks of the two schools. A .400 correlation was found between the Reinhart curricular support network and the Reinhart technology support network. This meant that if there was a tie between two actors in one network, there was a $40 \%$ chance there would be a tie between the same actors in the other network. There was a .352 correlation between the two networks at Filz Middle School, meaning a $35.2 \%$ chance of tie between the same two actors in both networks (Hanneman \& Riddle, 2005). The QAP procedure in UCINET (Borgatti, et al., 2002) ran 5000 permutations for the two schools' networks. In both cases, the $p$-values were .0000 , providing a high rate of confidence that none of these networks had formed due to connections between actors occurring at random. The relatively weak correlations suggest that the curricular support and the technology support networks are not measuring the same facets of collaboration at each school (Daly, et al., 2010).

Multiple SNA indices were used to analyze the structure of the social networks in the two schools at the dyadic-, macro- and micro-levels. The first examination at the dyadic level was network density. Network density is one measurement of cohesion in the organization. Network density shows the actual number of connections in a network divided by total number of possible ties and is expressed as a percentage (Hawe, et al., 2004). Take for example the knowledge network in this study. If every staff member indicated that they knew of every other staff member in the school, then the network density would be 1.00 (100\%). This would indicate a high potential for information flow, since everybody knows everybody else, and nobody is left out. On the other hand, a 
network density of .1 (10\%) would indicate a lack of connections between individuals with a corresponding low potential for information flow (Hatala, 2006).

The second dyadic-level analysis was of centrality. Centrality is used to learn who the most prominent individuals are in the organization. Simply put, the greater the number of ties an individual has with others in the organization, the more central that individual is (Hawe, et al., 2004). When examining the flow of information, those with greater centrality hold power, since they are able to control which pieces of information will be distributed to those with whom they are connected (Hatala, 2006). Out-degree centrality is a measurement of the degree to which actors are seeking help or advice from others. It is an indication of influence, since those with high out-degree centrality are able to make their views known to others (Hanneman \& Riddle, 2005). In-degree centrality is a measurement of which actors in the network are sought for advice and is a measurement of power, since actors with high in-degree centrality can control what information is provided to others (Hanneman \& Riddle, 2005). Both in-degree centrality and out-degree centrality measure the direct connections to any one individual.

A two-step reach measures how many people an actor is connected to through his or her direct connections to others. Someone with a high two-step reach has to ability to spread information by way of those with whom there is a direct connection (Hawe \& Ghali, 2007). All of these analyses were used in this study. Additionally, traditional Pearson correlations were conducted to examine the relationship between in- and outdegree centrality and the demographic variables of TPACK level, age range, years in the school and the total years teaching, in order obtain the clearest picture of the network phenomena. 
The macro-structures of the networks were examined using the Group Centrality function of UCINET (Borgatti, et al., 2002). In both schools, the teachers were organized into professional learning communities (PLCs) according to their departmental membership. Some teachers were also assigned to an instructional team based on groups of students they taught. Group centrality measures were conducted on both of these PLC groups for the curricular and technology networks at both schools. This examination uncovered which departments were seen as possessing high or low amounts of social capital. Looking at these ties between groups resulted in a clearer understanding of the overall organizational structure (Brass, et al., 2004). This also provided greater understanding when comparing the network structures between the two schools.

The micro-structures of reciprocal ties and cliques were also examined for the curricular and technology support networks at each school. In reciprocal relationships, there is a two-way exchange of information, where advice is both given and received. In general, these bidirectional ties between network members are an indication of open communication, which is essential for the organization to excel as a whole (Hatala, 2006). In school communities of practice, reciprocal interactions indicate that multiple teachers have reached a level of competence in their use of technology. When this occurs, true collaboration is able to take place (Glazer \& Hannafin, 2006). It has also been suggested that reciprocal ties contribute to a climate of innovation (Moolenaar, et al., 2011).

A clique is a subgroup which is built upon the reciprocal ties. Cliques have a minimum of three members, where all members have reciprocal ties with each other, and where no other member of the larger network has connections to all the members of the 
clique (Hawe, et al., 2004). Information is able to flow more quickly through cliques because of its more tightly interconnected structure (Jamali \& Abolhassani, 2006). In addition, cliques provide a measure to resolve conflict between members, have been found to be more stable than reciprocal ties, and tend to form due to specific actions on the parts of the members (Bellotti, 2009).

The interest in studying the reciprocal tie and clique structures in these schools was to further understand why these sub-groups have formed. Reciprocal ties and cliques are seen as the "building blocks" of the networks (Hanneman \& Riddle, 2005).

Subgroups such as reciprocal ties and cliques have been shown to have a strong influence on the attitudes and behaviors of teachers. Subgroup members are known to exert a greater influence on each other than the influence by others in the network outside their subgroup (Penuel, et al., 2009).

NetDraw (Borgatti, 2002) was used to create sociograms of all networks and substructures analyzed in this study. It was also used to visually analyze the structures of the reciprocal ties and cliques by examining the membership characteristics of department and team membership. This was done by changing node labels and colors according to department and team membership of the actors. As a result, clear patterns emerged that could not be identified by way of the raw data alone. NetDraw (Borgatti, 2002) was also used to remove the ties in the technology support networks that also existed in the curricular support networks of each school, making it possible to further understand the formation and structure of the social network that was created specifically for teachers to obtain technology support. 


\section{Return Rate and Limitations of the Network Data}

The return rates between the two schools were fairly comparable. Initially, 106 surveys were distributed to teachers, instructional assistants, administrators, guidance counselors and office assistants at Reinhart Middle School. Teachers on leave, the school resource officer (a Baldon County Police uniformed officer assigned to the school), a public health training assistant and a security specialist were removed from the study group, leaving 98 staff members in the study. Ultimately, 45 surveys were returned, for a return rate of $45.9 \%$.

Surveys were also prepared for the 146 staff members listed as working at Filz Middle School. The names of staff members on leave, as well as the school resource officer were removed from the study, leaving 140 network members. In due course, 68 surveys were returned, giving a return rate of 48.6 percent. The difference in the return rates equates to 3 surveys, meaning if three more surveys had been returned by Reinhart, or there had been three fewer surveys returned by Filz, the return rates would have been virtually identical.

There had been long-standing assumptions by researchers using social network analysis methodology that there needed to be $100 \%$ return rate to accurately understand the network (Borgatti, Carley, \& Krackhardt, 2006). Using this standard, the return rates for this study would be considered problematic. However, research in the past decade has shown this assumption of $100 \%$ return necessity to not be accurate. Costenbader and Valente (2003) found that in-degree centrality, the primary measure in this study, to be highly stable for a $50 \%$ response rate, with the correlation coefficient greater than $85 \%$ in all but one of their cases studied (Costenbader \& Valente, 2003). 
In cases of "edge removal" (lines between nodes missing because of nonrespondents), the accuracy of in-degree centrality has been found to increase as the density of network decreases (Borgatti, et al., 2006), a finding important for this study, with low network densities for the curricular support networks and the very low densities for the technology support networks. Although the return rates in this study are a limitation, the Costenbader and Valente (2003) and Borgatti, Carley, and Krackhardt (2006) studies provide reason to have confidence with the results of the in-degree analyses conducted here. 


\section{CHAPTER FOUR: PRESENTATION AND ANALYSIS OF THE DATA Baldon County Public Schools ${ }^{1}$}

Baldon County Public Schools is a large school system near a major city situated in the Mid-Atlantic States. It educates close to 200,000 students in approximately 200 schools. The school system has become increasingly diverse, with no single ethnic group in the majority. Overall, $22 \%$ of the students receive free and reduced lunch, a common measure of socio-economic status. However, the distribution of these students is not uniform, with some schools having very high rates of students on free and reduced lunch, and other schools with very few students coming from low-income families (BCPS Web, 2010).

Baldon County Public Schools also two system-wide digital resources that classroom teachers are expected to use. The school system has contracted with Blackboard, Inc., (Blackboard Inc., 2010) to provide interactive instructional services for classroom use by every instructional employee. They have also developed The Digital Cupboard. This contains computerized test-banks and other resources for each of the courses where students have to take a state-mandated high-stakes test at the end of the school year. Teachers are expected to use these resources, especially the test banks, for ongoing formative assessments to gauge their students' understanding of the content covered by the high-stakes tests (BCPS Web, 2010).

The study was conducted at two middle schools that are part of Baldon County Public Schools. J. E. Reinhart Middle School is a seventh \& eighth grade middle school

\footnotetext{
${ }^{1}$ The name of the school system, schools and individuals participating in this study have been replaced with aliases.
} 
in a more affluent section of Baldon County. According to the most recent figures available, the student body is over $60 \%$ non-Hispanic white. The next largest ethnic group is Asians, who make up approximately $20 \%$ of the student body. The percentages of non-Hispanic black students, Hispanic students and students classified as "other" are all in the single digits. Slightly less than half of the students are in school-based gifted programs. The number of students who are English proficient approaches $90 \%$. Only seven percent of its students are on free and reduced lunch, a common proxy for poverty. All indications are that this is a school of high performing students, and, in fact, the pass rates on the high-stakes tests are just under 100\%(BCPS Web, 2010)

Susan Filz Middle School has a grade 6-8 program, one of three middle schools in the county to house the sixth graders in the school. It is located in a section of Baldon County that has seen vast demographic changes in the past 25 years. Although the school and the homes in the surrounding community are of the same vintage as Reinhart Middle School, it has experienced an influx of immigrant and lower income families. The school is a "majority minority" school, with approximately one-fifth of the study body composed of non-Hispanic white children. Hispanic student compose the largest ethnic group in the school (37.6\%), with Asian students the second largest group (25.0\%) and Non-Hispanic Black students comprising slightly more than $10 \%$ of the student body. Approximately half of the students in the school are identified as having Limited English Proficiency (LEP). Slightly more than half the students are eligible for free or reduced lunch. Pass rates on the state-mandated high-stakes tests for non-LEP students range from $60 \%$ to $94 \%$. There has been steady improvement in the pass rates of these tests during the past several years (BCPS Web, 2010). 
There are 98 members of the Reinhart Middle School staff or in SNA parlance, 98 actors in the Reinhart middle school network. Of the 98 actors in this network, 45 returned surveys for a return rate of $45.9 \%$. The median age range of the actors returning surveys was in the 46 - 55 years old range. There are 140 actors in the Filz network, with 68 actors returning surveys for a return rate of $48.5 \%$. The median age range of the actors returning surveys from this school was in the $36-45$ years old range. The staffs of both schools are approximately $70 \%$ female. The principal of Reinhart Middle School is Roberta Barnes and the principal of Filz Middle School is Becky Shapirio.

\section{The Social Networks Studied}

Although the purpose of this study was to learn about the social networks teachers form around technology integration, to provide points of comparison, a total of three social networks were studied at both of the schools. These were the knowledge network (discussed here), the curricular support network (discussed in the section on Question 2) and the technology support network (discussed in the section on Question 3). Looking at multiple networks allows for a greater understanding of interactions taking place at a school (Hawe \& Ghali, 2007). The purpose of examining the knowledge network was to find out how well connected the staff was in simply knowing who worked in the school. The analyses and comparisons of the curricular networks in the two schools make it possible to have a point of comparison for the technology support networks as well as to see the organizational differences in these two networks.

Only one measurement was made of the interconnectedness of the members in the knowledge network of each school. That measurement was for network density. This is the actual number of connections between network members (actors) divided by the total 
possible number of connections and is expressed as a density The higher the network density, the greater the potential information flow (Hawe \& Ghali, 2007). In the Reinhart knowledge network, there are 3615 connections, out of a maximum possible connections of 4074 , giving a network density of 88.7 percent. Thus, there is a high potential of information flow within the school since every member of the staff is connected to the network and there are no isolates (actors with no connections).

The sociogram of the Reinhart Knowledge Network (see Figure 4-1) provides a visual representation of the overall interconnectedness of the school staff at Reinhart Middle School.

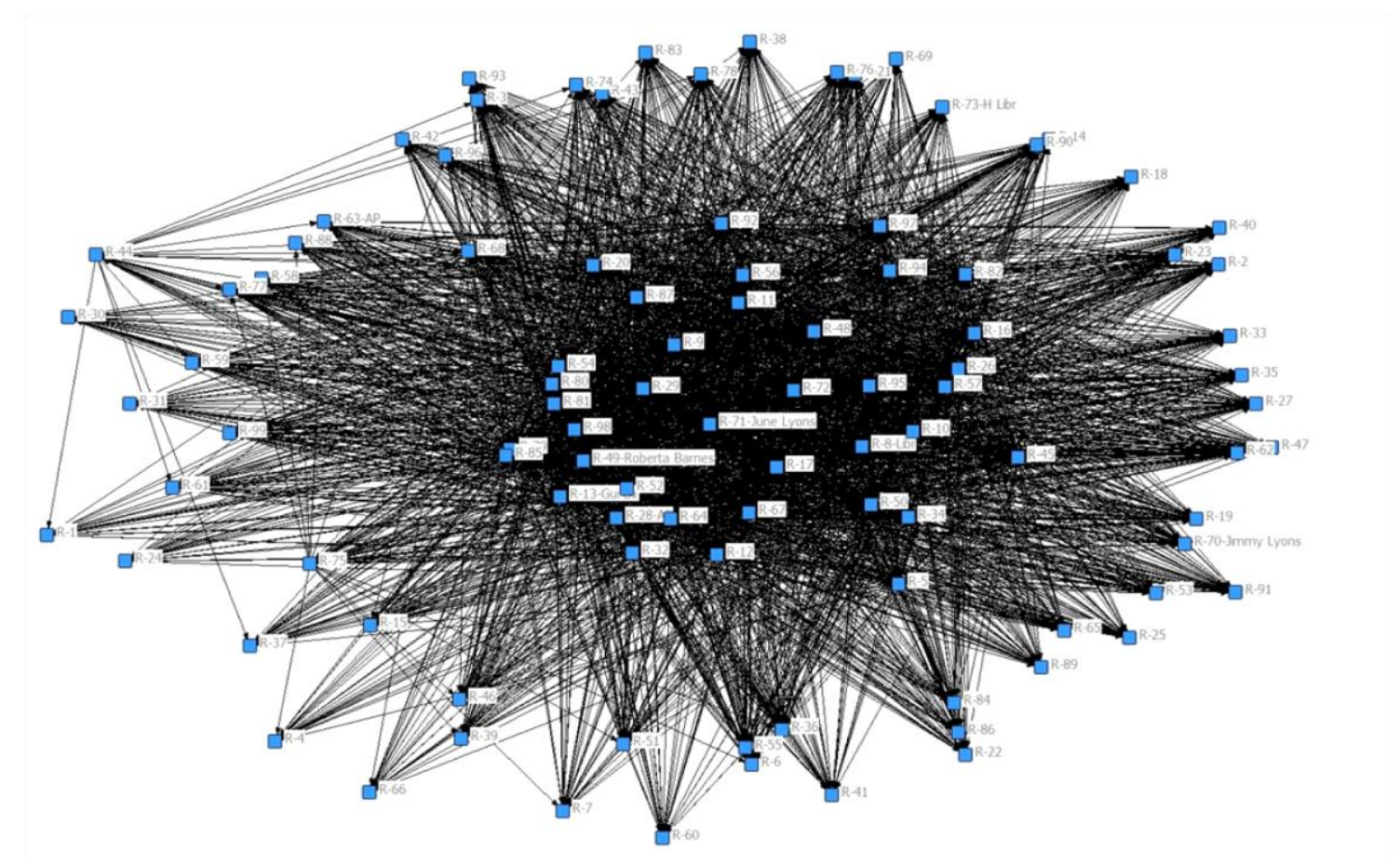

Figure 4-1: Reinhart Knowledge Network Sociogram Blue squares (nodes) represent individual actors in the network. Lines show connections between the actors.

At Filz Middle School, there are 7184 connections in the knowledge network, out of a possible 9452 connections for a network density of $76.0 \%$ (see Figure 4-2). Although the network density is lower than the $88.7 \%$ network density at Reinhart Middle School, 
it is still very high, and there are no isolates (actors with no network connections). This difference in the overall density for the knowledge networks of the two schools could also be a function of Filz Middle School being 1.43 times larger than Reinhart. As the size of the organization increases, it becomes more difficult for everyone to know everyone else (Hanneman \& Riddle, 2005).

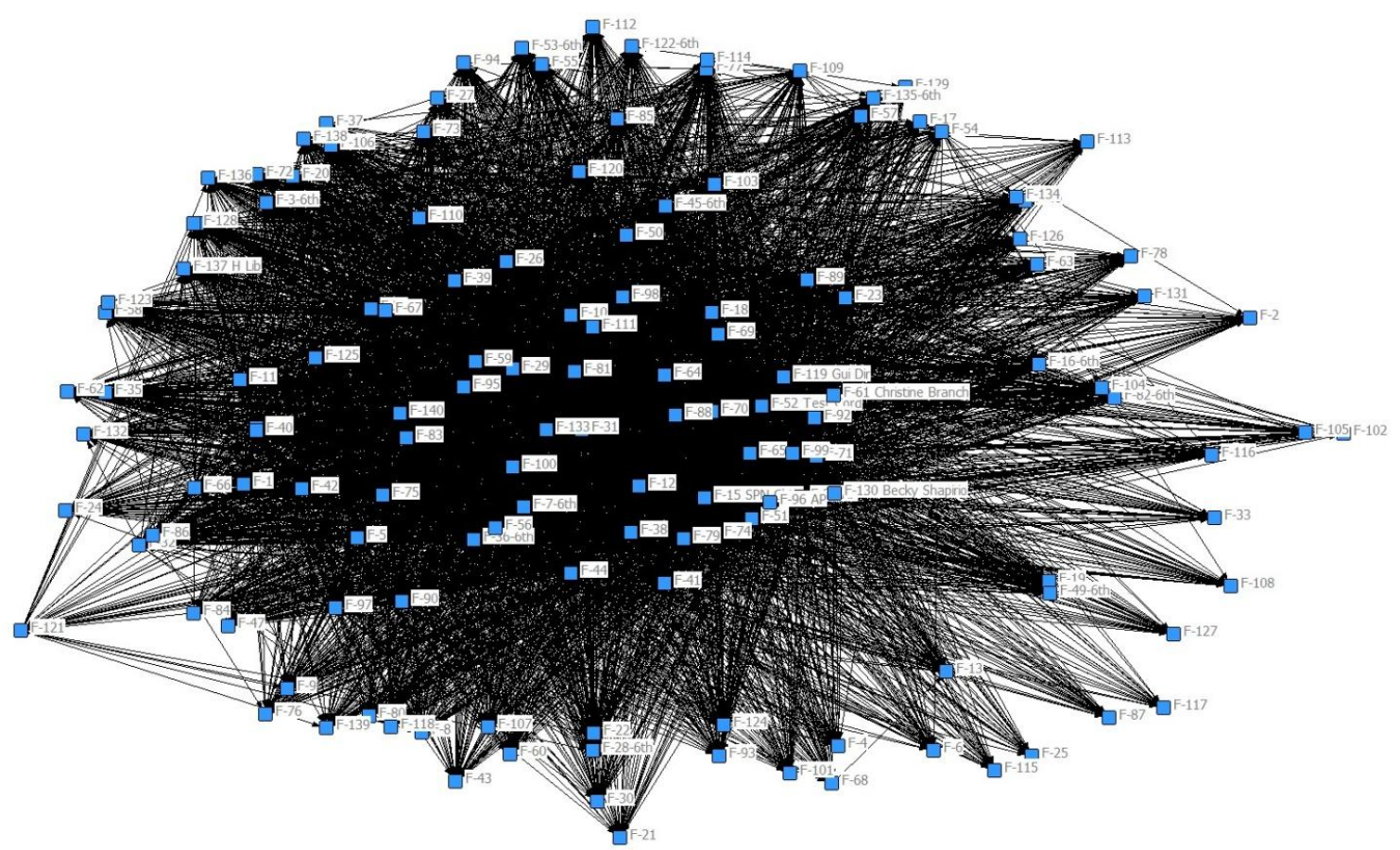

Figure 4-2: Filz Knowledge Network Sociogram

Since Filz is larger than Reinhart, there are more total connections. However, the actual network density is lower.

Overall, the high network density for the knowledge networks at both schools (89\% at Reinhart Middle School and $76 \%$ at Filz Middle School), suggests a high potential for information flow in each of the schools, since everyone was connected within these respective networks and there were no isolates (actors not connected to any other actor in the network). 


\section{Question 1: How Is Technology Leadership Conducted in the School on the Part of the Principal and of the ITRT?}

Principal leadership in technology has been identified in the literature to have a major impact on the success of technological integration in schools (R. E. Anderson \& Dexter, 2005; Dexter, et al., 2003). Factors such as having a shared technology vision, providing budgetary support for technology and the principal being an active user of technology have all been identified as being key components of successful technology leadership (R. E. Anderson \& Dexter, 2005). The principal being personally identified with technology integration is another factor in successful adoption efforts (Owston, 2007). In addition, the principal's relationship with the ITRT, and how that individual's role in the school is defined has also been shown to affect both the acceptance and leadership function of the ITRT (Davidson \& Olson, 2003; Dexter, et al., 2002).

The principals of the two middle schools positioned themselves to be strongly identified with increasing technology usage in their schools. Both believed that a shared vision on technology existed throughout their respective schools. They also saw their ITRTs as being key players in this effort, and expressed the desire that these individuals be instructional as well as technology leaders. They were active users of technology themselves, and they both mentioned allocating funds through their budgetary priorities as being one of the important roles they played as technology leaders in their schools. However despite both principals having the characteristics of successful school technology leaders, there were distinct differences in the way that they set direction and developed others around instructional technology (Leithwood \& Riehl, 2003). Ultimately, it will be shown that these differences impacted the redesign of the organization as shown in the differences in the structure of the technology support networks in the two schools. 
At Reinhart Middle School, Roberta Barnes believed that technology vision came from the top. When describing the technology direction she was setting, it was mostly about trying to "beef up" the technology in the school, which meant acquiring more equipment, such as 25 new SMART Boards, or seeing that all of the instructional teams had been issued sets of "clickers" for ongoing student assessments. She wanted there to be "solid use" of technology in the classrooms, thus she had a goal that all of the teachers in the school become comfortable with some type of technology. Yet, she offered no specifics about how the technology equipment could be applied to instructions other than the teachers using their laptop computers for lesson planning and PowerPoint presentations.

She believed that her excitement over technology was causing her faculty to become excited about technology as well, and reported that leadership in the school, from the assistant principals down through the department chairs and the team leaders were all on board with this idea. Overall, she saw technology as a way for teachers to develop "data-driven instruction." Once again, offering no specifics, she expressed the desire that each teacher become comfortable with some type of technology, thus she expected to see it being used when she or the assistant principals made classroom visits to observe instruction.

Filz principal Becky Shapirio had a similar vision for instructional technology in that it should be used throughout the school. Additionally, with her large international student population, many with Limited English Proficiency (LEP), she saw technology as a way to help these students get up-to-par with their "native" classmates. Thus, her vision was for technology to also be linked to instruction pedagogically in a purposeful manner. 
As an example, she used the term "ecosystem," which may be a new concept for many students in the school. She described how students can go onto a computer and see an image of an ecosystem, which gives them an idea of what the word means. Then they can be shown a short clip streamed from the Internet, for example of the Chesapeake Bay, which gives them a connection with the region where they now live. She saw this use of technology for scaffolding as helping the students understand the direction of their seventh grade Biology unit.

One of her concerns was that the scores on the high-stakes mathematics tests had been stagnant and were not rising. She recognized that her students were living technologically infused lives, with their iPods, cell phones and video games and that pedagogical applications of technology were a method of bringing instruction to the children in way they were already learning. Subsequently, math teachers began to video their lessons allowing the students to download the video from Blackboard onto an IPod or home computer for review when doing homework assignments.

A robotics class was also created in conjunction with the sixth grade mathematics program. During one class session a week, students would learn the mathematics curriculum by way of creating a robot. Helping with this effort have been high school students from the nearby Old Oak Tech, the high-technology magnet school. Also emphasized was the fact that these efforts were not only to improve test scores, but to try to get more students interested in applying to Old Oak Tech as well as pursuing the International Baccalaureate diploma offered at the high school Filz feeds into.

In order to gain "buy-in" from the faculty, she put out missives seeking teachers who were willing to try new instructional approaches or to help with the afterschool 
technology-based activities. She understood that these are new approaches to instruction and that teachers may be wary of trying them at first. She cited teacher fears that the students would just use the IPods or cell phones to listen to their music or text friends, rather than download information. However, she saw that as a risk that needed to be taken to see if these tools will help students improve academically. She found that there were teachers in the school willing to take these risks if it was for the betterment of the students.

Both principals cited their physical education (PE) teachers as an example of a department that had embraced technology. Roberta Barnes at Reinhart Middle School cited the "tremendous job" the teachers in the PE Department had done with technology during the past school year. She noted that each of the PE teachers had Promethean Boards that they used for the PowerPoint presentations they had developed for their lessons. She was especially pleased with how they had embraced these technologies in their classrooms.

The example Becky Shapirio at Filz Middle School gave showed her closer attention to detail for how technology should support instruction. She spoke of how the teachers from the PE Department wrote a grant for a computerized anti-obesity program. This program was to help the students become aware of using technology to become more physically active, which Mrs. Shapirio described it as being similar to a Wii. By using this application in their PE class, the students were then able to become of aware of how technology could be used to help them become more physically active.

These examples of the PE Departments' use of technology are illustrative of the different approaches these two principals have taken towards instructional technology 
leadership. Roberta Barnes' approach could be summarized as hierarchical (meaning coming from her), teacher-centered and equipment oriented. Conversely, Becky Shapirio's approach was more student-centered and pedagogically focused. It was also geared towards developing her staff's integration of technology into instruction. These differences in style and substance were consistent with the relationships they had with their Instructional Technology Resource Teachers (ITRTs), which was triangulated with what the ITRTs reported in their interviews.

At Reinhart Middle School, the ITRT was June Lyons. Mrs. Barnes stated that she greatly respected June's technology knowledge and would have her attend the weekly administrative team meetings and give a technology report to the administrators. This meeting also gave June an opportunity to ask questions of the administrators. In these ways, Mrs. Barnes believed that she and June had quickly developed a close working relationship while sharing a vision for the technology needs of the school. However, this idea was not confirmed by June during her interview.

Overall, Mrs. Barnes recognized the critical need for there to be an instructional technology expert to work with the teachers, thus, she wanted June to be an instructional leader in the school. When asked if there were others in the school who had also taken on technology leadership, Mrs. Barnes explained that the various team and department leaders' job was to schedule June for training sessions for their teachers. To this end, June was expected to meet with the instructional teams and departments and work with the teachers on ways technology could be used in the classrooms. She also expected June to provide the teachers with training on new uses for the technology equipment they were bringing into the school. She was very satisfied with observations she had made of June 
working with teachers and students in the classroom. She saw this kind of working with students and teachers as June's primary role in the building.

One problem that arose in the school concerned the interactive white boards. Mrs. Barnes explained that June had a preference for the Promethean brand of interactive white boards. Initially she supported June and bought 25 of these for the school, in the process trading-in three SMART Boards, a different brand of interactive white board. However, the school system central office later entered into a contract with SMART Technologies (Smart Technologies, 2010) to install only SMART Boards throughout the system's schools.

As part of the ongoing school renovation, 50 more interactive white boards were scheduled to be installed in the school, and Mrs. Barnes was encouraged to go with the system's contract. Since the school system's Instructional Services Department would also be developing teacher training around the SMART Boards, Mrs. Barnes did not want her teachers having to attend training sessions for a technology they would not have in the school. For these reasons, she made the decision to switch to the SMART Boards. Apparently this decision was made without consulting June, since in her interview June indicated that she had no idea why this change had been made.

Filz Principal Becky Shapirio also greatly respected her ITRT, Christine Branch, and her knowledge of technology integration in the classroom. At one point Mrs. Shapirio described her as being "the greatest ITRT in the UNIVERSE!" Mrs. Shapirio saw Christine's primary role in the school as being an instructional leader. Similar to June Lyons at Reinhart Middle School, Christine was expected to meet with departments and teams to develop ways of integrating technology into instruction, and to provide 
regular staff development programs for the teachers. She would also have Christine teamteach with classroom teachers to directly help students use technology in their classrooms. However, to further empower and develop Christine as an instructional leader, Mrs. Shapirio made her a part of the leadership council, where she provided leadership on the school improvement plan. Christine was given a similar role with the testing team as well. In these ways, Mrs. Shapirio gave Christine involvement in the "whole instructional component" of the school.

Mrs. Shapirio believed that using technology in the classroom was critical for increasing student achievement, thus she would meet weekly with Christine to discuss ways that technology could be used to make connections with the students while enriching their learning. As a way of providing an example of her technology integration vision to the faculty, Mrs. Shapirio and Christine together developed an interactive podcast activity for the teachers at the opening faculty meeting. In this activity, the teachers learned of new school policies while simultaneously learning how to create podcasts for use with their own students.

When asked if there were others in the school who were providing technology leadership, Mrs. Shapirio described an evolution that had been occurring during the past several years. When she would first send out missives, it would be a case of "who wants to try this." As individual teachers began to develop expertise, it became a case of "these are the people who are good at technology." Later, a Forefront Team was created, made up of technologically-minded representatives from the various departments who would then work with ITRT Christine Branch on helping their colleagues with technology integration. 
Thus, contrasting leadership practices were evident in the ways the two principals defined the roles their ITRTs played in the school as instructional leaders and how these played out in the interactions between principal and ITRT. These differences in the way the two ITRTs were empowered by their principals seemed to influence the ways in which June and Christine provided technology support in their respective schools.

June Lyons at Reinhart Middle School, reported her primary role in the school as a provider of "Level 1 Technology Support," which she described as helping the teachers use the equipment they had been provided. In some instances, this involved helping teachers who were having some type of problem, such as being unable to log-on to their computers because the password has been forgotten. In other instances, it involved helping teachers with curricular projects, such as organizing a group of pictures into a movie. When meeting with teams, she tried to give the teachers ideas on how technology could be used to make their lessons "a little better." A portion of the teachers, she estimated it as being 25 percent, were trying activities such as wiki's and blogs, and she would help with those activities. However, she reported that most uses of technology in the school revolved around the testing function of The Digital Cupboard.

June also described a number of ways she had worked with the faculty as a group. This included putting together a presentation on what technology integration in the classroom looked like, so the teachers would have a way to gauge if they were using it effectively. Since the assessment function in The Digital Cupboard was extensively used in the school, she proved the teachers with training on how they could use the data from these assessments to track their students' progress over time. She was also working with groups of teachers on how the school would integrate technology in order to prepare the 
students for the future high-stakes state technology test the eighth grade students would have to pass.

Filz Middle School ITRT Christine Branch also reported having to spend some of her time with routine tasks, such as inventorying computers, ordering printer cartridges and helping teachers setup their digital grade books at the beginning of the school year. However, she reported the main element of her job was with working on instructional concerns with the school. In this capacity, she worked closely with other instructional leaders, such as the Instructional Coach, the International Baccalaureate Middle Years Programme Coordinator, and the members of the Instructional Council, on ways to prepare the Filz Middle School students "academically for the $21^{\text {st }}$ Century." This concept was then the focus of her work with teachers, both individually and within their teams and departments.

When the science teachers received new netbook computer carts for their classrooms, she developed an activity to help the teachers adjust their classroom management style for working with computers. She also arranged for these teachers to visit another school to observe and work directly with teachers who had successfully integrated the netbooks. Overall, her staff development activities related instructional technology to recognized best practices, so that when the technology was used in the classroom, it promoted higher-level thinking in the students. Working in collaboration with the science teachers and their netbooks, lessons were developed where the students created blogs, podcasts and Facebook-like pages around whatever unit was being studied. While she did work with the teachers on the assessment functions in The Digital Cabinet, they developed a plan in which the students themselves tracked their progress over time 
in a way that allowed to students to connect individual effort to gains in individual achievement.

The relationships between the principals and ITRTs at the two schools seemed to extend to some additional contrasts. Christine was very knowledgeable about the technology plans for the next school year and beyond. She spoke about efforts to retrofit classrooms with digital projectors and plans for additional netbook carts. June on the other hand made clear that she had no budget of her own, future plans were "made at a higher level" and she had no say in the matter. Her response when asked about the change made from Promethean Boards to SMART Boards was indicative of this, as she simply shook her head indicating she did not know why this change had been made.

Even more illustrative was the difference in the answer they both gave when asked to identify classroom teachers who were providing leadership to their colleagues. Christine was able to name many individuals who had mastered instructional technology and were sharing their knowledge with colleagues, some, but not all of whom, were members of the Forefront Team. When asked the same questions, June mentioned that she too had a Forefront Team but they were mostly focused on introducing into classrooms the National Education Technology Standards for Students (NETS-S) developed by the International Society for Technology in Education (International Society for Technology in Education, 2007). She further explained how they also shared what they had learned at the county-wide Forefront Team conference with the teachers in their departments.

These interviews showed there was a distinct contrast in how the principals set the technology direction in their respective schools. This extended to the way that the 
principals developed their ITRTs as instructional and technology leaders in the school differences that influenced how the ITRTs worked with and developed teachers as technology leaders in their own right. Overall, these differences in leadership style and substance proved predictive of the differences in the structure of the technology support networks, which are addressed in question three. The differences are all the more noticeable in light of the similarities between the curricular support networks of the two schools, described next.

\section{Question 2: What Was the Structure of the Curriculum Support Network at Each School?}

Curricular support networks were examined at the two schools. The data for these networks were collected from the second column of the teacher surveys, where the teachers were asked who they go to, or collaborated with, regarding advice or ideas about classroom instruction. Research has shown that the introduction of technology changes the structure of the social networks in organizations (Burkhardt \& Brass, 1990). The comparison of these networks with the technology support network, discussed in the next section, helped answer the question of whether or not teachers form a separate support network when seeking technological support, or if they simply build upon the already established curricular support network. A sociogram of the Reinhart curricular support network is shown in Figure 4-3. 


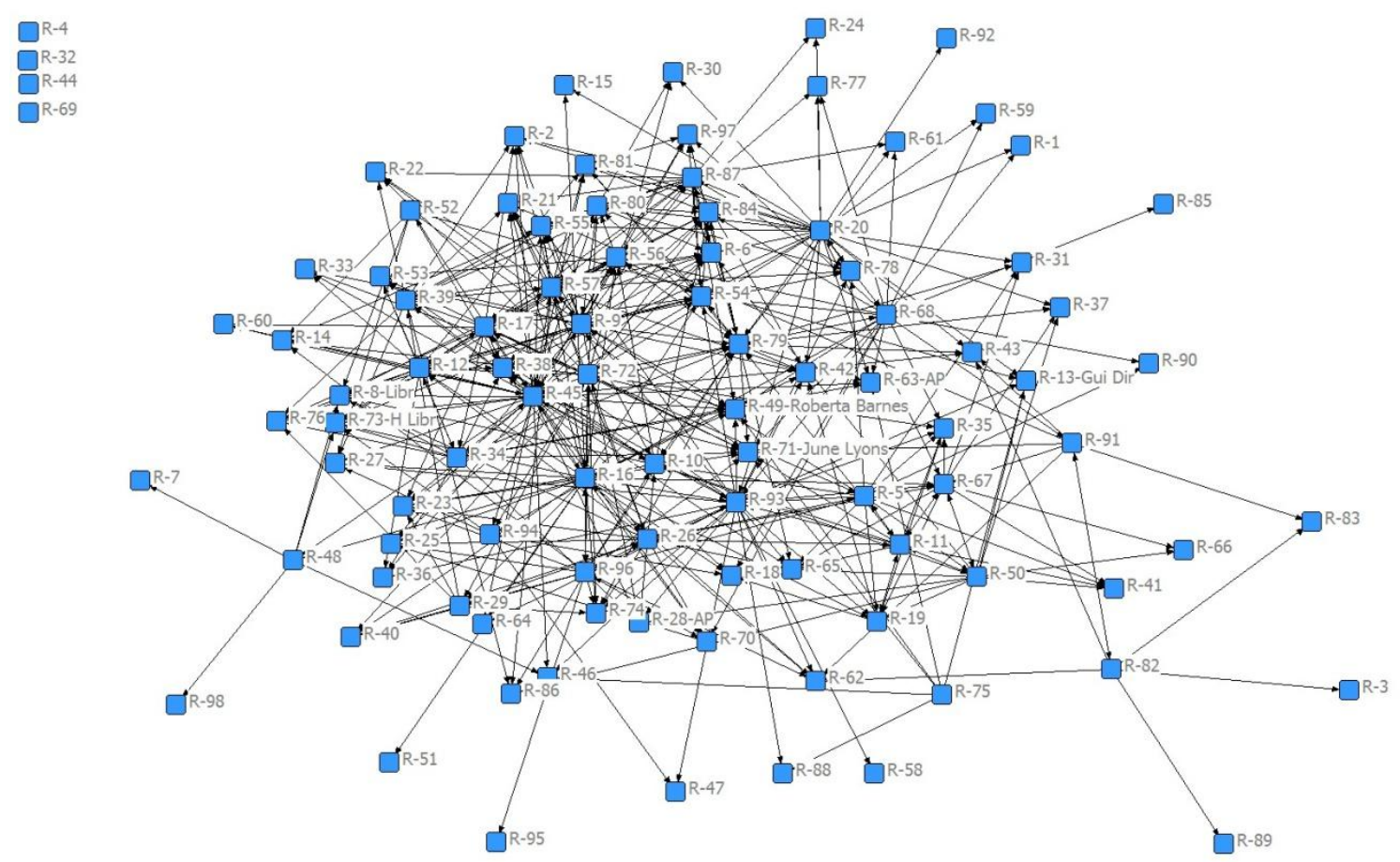

Figure 4-3: Reinhart Curriculum Support Network

This sociogram is showing the social network teachers at Reinhart Middle School showing who they went to for help or collaboration with instruction in their classrooms. Four actors in the network have become disconnected from all other actors and are shown as isolates on the left part of the figure.

It is clear that the sociogram of the Reinhart Curriculum Support Network looks much different than its Knowledge Network (Figure 4-1). There are fewer connections than in the Knowledge Network, and individual actors in the network become visible. It is also apparent that some actors have many more ties, both incoming ties and outgoing ties, than other actors. The Univariate function in UCINET reveals that there are 479 connections in this network, out of a maximum of 3298 possible connections, giving a network density of $14.5 \%$. This is less than the $88.7 \%$ network density in the Knowledge Network. This is not unexpected, since seeking a more narrowly focused network will result in fewer connections (Hawe \& Ghali, 2007). The curricular support network for Filz Middle School is shown in Figure 4-4. 


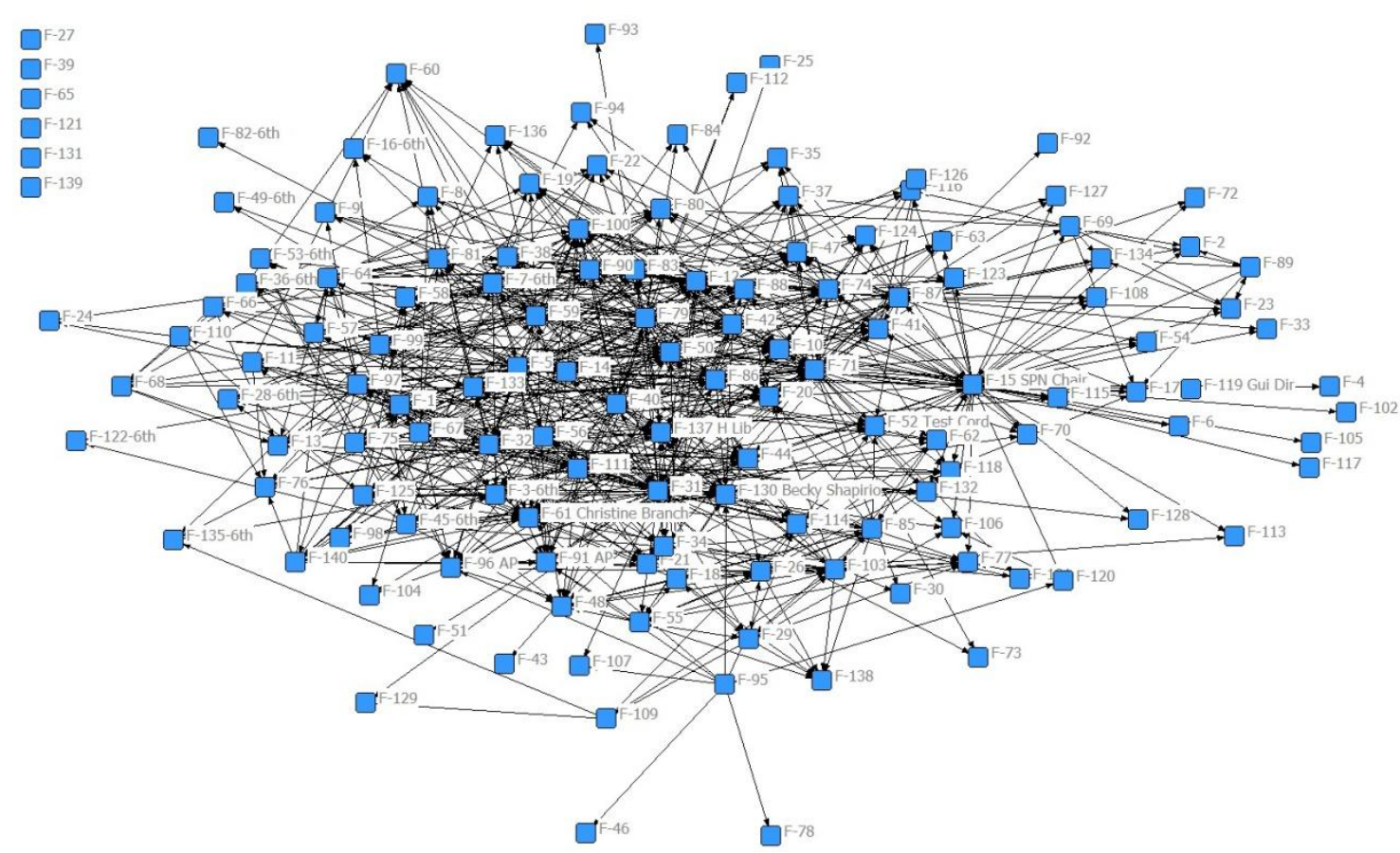

Figure 4-4: Filz Curricular Support Network

This sociogram shows the social network the Filz teachers formed around classroom help or collaboration. Six actors have become disconnected from this network and are shown as isolates on the left side of the figure.

It appears that this network could be denser than the Reinhart curricular support network; however, that is an illusion due to the larger size of the network. The Univariate function in UCINET indicates that there are 839 connections out of a possible 7506 connections giving a network density is $11.2 \%$, which is slightly less than the network density of the corresponding Reinhart network

\section{Curricular Support Network Dyadic Structures}

Since this study examined the direct exchange of information between individuals, the most precise social analysis measurement is with degree centrality (Huang \& Provan, 2007). Degree centrality is the number of ties network members, (known as actors) have with other actors (the actors nominated by the network members submitting a survey, also referred to as alters). Actors who send out large numbers of ties (out degree centrality) have influence since they are able to make their views known to 
others. Actors who receive a large number of ties (in-degree centrality) have power, since they possess the information others want (Hanneman \& Riddle, 2005). The interest here is with the actors' in-degree centrality since they are the ones being sought for help.

Since the networks in the two schools were different sizes, normalized scores were used in the analysis of the curricular support and the technology support networks. Normalized scores allow for different sized networks to be compared on a more equal basis (Hanneman \& Riddle, 2005). When UCINET (Borgatti, et al., 2002) produces a normalized score, it assumes that all members of the network (n) have been surveyed and have also submitted surveys. It then divides each raw score by the total number of actors in the network, minus 1 (n-1), since it is assumed each actor will not seek help from him or herself. In essence, the normalized score is a percentage of the total network members nominated by each actor.

In addition to the UCINET normalization, an alternative method was used to normalize the in-degree scores. Since only teachers were asked to submit a survey for the curricular support network, the total number of incoming ties was limited by the number of teacher surveys returned. The Reinhart teachers returned 34 surveys, so the maximum number of incoming ties any actor in the network could receive would be 34 ties if the actor did not return a survey and 33 ties if the actor did return a survey. Therefore, the score for an actor who returned a survey was divided by 33 (n-1) to obtain a normalized score. For all others, the number of incoming ties was divided by 34 to obtain a normalized score. At Filz, 54 teachers returned surveys, meaning that the maximum indegree score any actor in the network could receive would be 54 nominations if no 
survey was submitted and 53 nominations if a survey was submitted. This alternative method normalized the scores is a percentage of teachers making the nominations.

In all, the examination of the curricular support networks at the two schools revealed numerous similarities. Eleven actors received the five highest number of nominations at both of the schools. The normalized scores for in-degree centrality between the two schools for these actors were also similar. At Reinhart, the normalized scores for this group ranged from $26.5 \%$ to $42.4 \%$ of the teachers submitting nominations. Normalized against the total network, the range was from $9.2 \%$ to $14.4 \%$ of the total network. At Filz, the range was from $25.9 \%$ to $37.0 \%$ of the teachers submitting nominations, which equated to a range of $10.1 \%$ to $14.4 \%$ of the total network. A summary of these top nominations is shown in Table 4-1.

Table 4-1: Five Highest Curricular In-degree Centrality

\begin{tabular}{|c|c|c|c|c|c|c|c|}
\hline \multirow[b]{2}{*}{ Teacher } & \multicolumn{3}{|c|}{ Reinhart } & \multirow[b]{2}{*}{ Teacher } & \multicolumn{3}{|c|}{ Filz } \\
\hline & $\begin{array}{c}\text { In- } \\
\text { Degree }\end{array}$ & $\begin{array}{c}\text { Percent } \\
\text { of } \\
\text { Surveyed }\end{array}$ & $\begin{array}{c}\text { Percent } \\
\text { of } \\
\text { Network }\end{array}$ & & $\begin{array}{c}\text { In- } \\
\text { Degree }\end{array}$ & $\begin{array}{c}\text { Percent } \\
\text { of } \\
\text { Surveyed }\end{array}$ & $\begin{array}{c}\text { Percent } \\
\text { of } \\
\text { Network }\end{array}$ \\
\hline R-79 & 14 & 0.424 & 0.144 & F-100 & 20 & 0.370 & 0.144 \\
\hline $\mathrm{R}-45$ & 12 & 0.364 & 0.124 & F-137 H Libr & 20 & 0.370 & 0.144 \\
\hline $\mathrm{R}-54$ & 12 & 0.364 & 0.124 & F-20 & 17 & 0.315 & 0.122 \\
\hline R-71- Lyons & 12 & 0.353 & 0.124 & F-61 Branch & 17 & 0.315 & 0.122 \\
\hline $\mathrm{R}-84$ & 12 & 0.353 & 0.124 & F-31 & 16 & 0.302 & 0.115 \\
\hline R-38 & 11 & 0.324 & 0.113 & F-130 Shapirio & 16 & 0.296 & 0.115 \\
\hline $\mathrm{R}-80$ & 10 & 0.303 & 0.103 & F-12 & 15 & 0.283 & 0.108 \\
\hline R-6 & 10 & 0.294 & 0.103 & F-71 & 15 & 0.283 & 0.108 \\
\hline $\mathrm{R}-26$ & 9 & 0.273 & 0.093 & F-96 AP & 15 & 0.278 & 0.108 \\
\hline $\mathrm{R}-12$ & 9 & 0.273 & 0.093 & F-10 & 14 & 0.264 & 0.101 \\
\hline 49- Barnes & 9 & 0.265 & 0.092 & F-86 & 14 & 0.264 & 0.101 \\
\hline R-8-Libr & 9 & 0.265 & 0.092 & F-91 AP & 14 & 0.259 & 0.101 \\
\hline
\end{tabular}

There were also similarities with whom the teachers nominated most frequently at the two schools. At Reinhart Middle School, the teacher receiving the highest number of nominations (R-79) was the chair of the Special Education Department. Two of the actors 
with the second highest number of nominations were also Special Education teachers (R45 and R-84), with the Reading Specialist (R-38) in third place and another Special Education teacher (R-80) in fourth place. This top group also included four content area teachers, the Assistant Librarian and Roberta Barnes, the school Principal. ITRT June Lyons was tied for the second highest in-degree centrality. At Filz Middle School, Christine Branch also had the second highest in-degree centrality. However, unlike at Reinhart Middle School, there were no content area teachers. The two actors with the highest in-degree centrality were the Head Librarian and the Instructional Coach. The rest of the list was composed entirely of special education teachers or administrators.

\section{Curricular Support Network Macro Structures}

Research has shown a tendency for actors with similar backgrounds to interact within a network. Interactions between actors sharing similarities of some type or another are known as homophily. These interactions can occur by way of the established organizational structure, or by way of more informal, organic interactions (Brass, et al., 2004). It is through these interactions that the actors become embedded within microstructures, where the social interactions of individual actors cluster around these macrostructures (Hanneman \& Riddle, 2005). The examination of these macro-structures is used to uncover how some of these dimensions of similarities lead to connections between individual actors and their subsequent effect on the social structure in the organization (Hanneman \& Riddle, 2005).

Teachers in both schools were organized into professional learning communities (PLCs) as a way of fostering communication between teachers sharing designated similarities, with the overreaching goal of improving student achievement. All of the teachers were members of professional learning communities based on their academic 
department. Some teachers were also organized into grade-level teams based on teaching similar groups of students. However, these teams were set up differently at the two schools. At Reinhart Middle School, social studies, English and science teachers belonged to a team-based PLC. Each of these teams has one teacher from each of the three disciplines. At Filz these teams were not restricted to social studies, science and English teachers, but included teaches from other departments such as mathematics, ESOL and art.

At Reinhart Middle School, there were four eighth grade teams, all named after vegetables (Turnips, Rutabagas, Parsnips and Eggplants), four seventh grade teams, all named after fish (Carps, Tunas, Cods and Eels), and one seventh/eighth grade team called the GMO (Genetically Modified Organism) Salmon (half fish, half plant). At Filz Middle School, there were three sixth grade teams named after rivers (Amazon, Hudson, Nile), three seventh grade teams named after trees (Maple, Oak, Willow) and three eighth grade teams named after igneous rock types (Basalt, Feldspar, Granite). In addition, one team (Suns) was composed of special needs students with physical disabilities. There was another team composed of physical education teachers (Team Hercules).

These departmental and team professional learning communities met regularly at designated times throughout the school year for sharing and collaboration. By examining these substructures at the macro-level, it was possible to see which of these established chains of command exerted influence on the rest of the organization, which ultimately affect the flow of information throughout the entire network (Deal, et al., 2009). This inturn was used to help explain the substructures at the micro-level for both the curricular and the technology networks. 
There were similarities between the two schools with the macro-level curricular substructure regarding departmental group centrality. In most cases, departments had more ties with other departments (external ties) overall. At the same time, most departments had more ties within the department (internal ties), than ties with any other single department. External ties provide access to the knowledge of others, where internal ties permit the actors to work together as a group (Adler \& Kwon, 2002).

The E-I Index measures the degree of closure for the different subpopulations within the network, i.e. the degree to which actors tend to link with others inside their groups versus others outside their groups. This index is created by subtracting the number of ties to other group members from the ties to actors outside the group, then dividing it by the total number of ties. The index ranges from -1 to +1 , where positive values indicate more external ties and negative values more internal ties (Hanneman \& Riddle, 2005).

Higher positive E-I indices have been related to greater cooperation between departments and successful organizational change, while organizations with lower E-I indices have been found to be resistive to outside pressures and less successful change initiatives (Daly \& Finnigan, 2009). For Reinhart Middle School, the E-I Index was .257, while at Filz Middle School, the E-I index was .411. This indicates a slightly greater tendency for external departmental ties at Filz Middle School. Therefore, in the curricular network, teachers at Filz reach out more to members of other departments than the Reinhart teachers do.

Departmental group centrality was measured at both schools to reveal the patterns of interactions at the macro level that department organization represents. Table 4-2 lists 
the departmental centrality for both schools. The scores were normalized using a procedure derived from Everett and Borgatti (2005). The total number of external ties into a department was divided by the number of actors in the network, minus the number of members in the department. Normalizing the scores is necessary so that comparisons can be made of different groups that are comprised of the same set of actors (such as the curricular and technology networks) as well as comparing separate networks that are different sizes (Everett \& Borgatti, 2005).

Table 4-2: Curricular Departmental Group Centrality

\begin{tabular}{|c|c|c|c|c|c|c|c|}
\hline \multirow[b]{2}{*}{ Department } & \multicolumn{3}{|c|}{ Reinhart } & \multirow[b]{2}{*}{ Department } & \multicolumn{3}{|c|}{ Filz } \\
\hline & $\begin{array}{c}\text { External } \\
\text { In-ties }\end{array}$ & Size & $\begin{array}{l}\text { Normalized } \\
\text { Score }\end{array}$ & & $\begin{array}{c}\text { External } \\
\text { In-Ties }\end{array}$ & Size & $\begin{array}{c}\text { Normalized } \\
\text { Score }\end{array}$ \\
\hline Special Ed & 57 & 18 & 0.7125 & Special Ed & 125 & 34 & 1.1792 \\
\hline Social Studies & 48 & 9 & 0.5393 & Admin & 76 & 7 & 0.5714 \\
\hline English & 45 & 12 & 0.5233 & Eng & 55 & 9 & 0.4198 \\
\hline Admin & 23 & 4 & 0.2447 & Social Studies & 47 & 10 & 0.3615 \\
\hline Math & 18 & 10 & 0.2045 & ESOL & 46 & 12 & 0.3594 \\
\hline Guidance & 18 & 6 & 0.1957 & 6th-grade & 40 & 10 & 0.3077 \\
\hline Library & 17 & 2 & 0.1771 & Guidance & 33 & 6 & 0.2463 \\
\hline Science & 15 & 9 & 0.1685 & Math & 31 & 8 & 0.2348 \\
\hline ESOL & 13 & 2 & 0.1354 & Library & 27 & 4 & 0.1985 \\
\hline ITRT & 12 & 1 & 0.1237 & Science & 23 & 7 & 0.1729 \\
\hline PE & 8 & 7 & 0.0879 & Special Needs & 18 & 3 & 0.1314 \\
\hline World Lang & 5 & 5 & 0.0538 & ITRT & 17 & 1 & 0.1223 \\
\hline Performing Arts & 5 & 4 & 0.0532 & PE & 14 & 9 & 0.1069 \\
\hline Home Econ & 5 & 1 & 0.0515 & Business & 10 & 2 & 0.0725 \\
\hline Special Needs & 4 & 2 & 0.0417 & Performing Arts & 9 & 6 & 0.0672 \\
\hline Business & 3 & 3 & 0.0316 & World Lang & 8 & 4 & 0.0588 \\
\hline Art & 3 & 1 & 0.0309 & Office & 6 & 5 & 0.0444 \\
\hline \multirow[t]{2}{*}{ Office } & 1 & 2 & 0.0104 & Art & 6 & 2 & 0.0435 \\
\hline & & & & Home Econ & 1 & 1 & 0.0072 \\
\hline
\end{tabular}

Note. Ranked by Normalized Score

At both schools, the most central department was the Special Education

Department. The next three most central departments were the Social Studies

Department, the English Department and the Administrative Team, although not in the same order. At Filz Middle School, the ESOL Department and the sixth grade teachers 
were near the top, but their ESOL population is substantially greater than at Reinhart, and Reinhart does not have a sixth grade in the school. However, the other departments were in roughly the same order with similar normalized centrality scores. For example, the Science Department at Reinhart had a normalized score of .169, while the Science Department at Filz had a normalized centrality score of .172. Team centralities could not be compared because of the different ways they were configured between the schools.

\section{Curricular Support Network Micro-Structures}

There were also similarities with the reciprocal tie and the resulting clique substructures at the two schools. In a didactic relationship, reciprocal ties indicate that a form of collaboration is occurring between actors since there is a two-way information flow (Hanneman \& Riddle, 2005). This type of relationship has been shown to fuel professional growth, especially with regard to the adoption of instructional technology (Glazer, et al., 2005). The purpose of looking at the reciprocal ties in the curricular support network was to see if a similar phenomenon was occurring in the technology network.

Figure 4-5 shows the reciprocal tie substructure of the Reinhart curricular support network. There are two components of this subgroup: Component 1 and Component 2. Component 1 is subsequently divided into four factions. This diagram reveals that the isolated dyad (Component 2) consists of two physical education teachers. The blue faction at the bottom of Component 1 is composed of math teachers, while the green faction is made up of science teachers. The red faction at the top of Component- 1 is made up of English, social studies, ESOL (English for Speakers of Other Languages) and special education teachers. There is also a two-actor faction between a special needs teacher and a special education teacher that is shown in pink. 
Three reciprocal pairs serve the role of brokers. Brokers are actors that connect different groups within a network or sub-network. These connections can facilitate communication between groups (Parise, 2007). In this component, two dyads that connect the green faction to the red factions have members who belong to the same team. The two teachers in the social studies/science dyad are both members of the GMO Salmon team while the two teachers who make up the science/English dyad are both members of the Turnip team. These connections between departments, as well as the single department factions are illustrative of the homophily concept, which is the idea that actors will create ties based on shared characteristic (Brass, 1995).

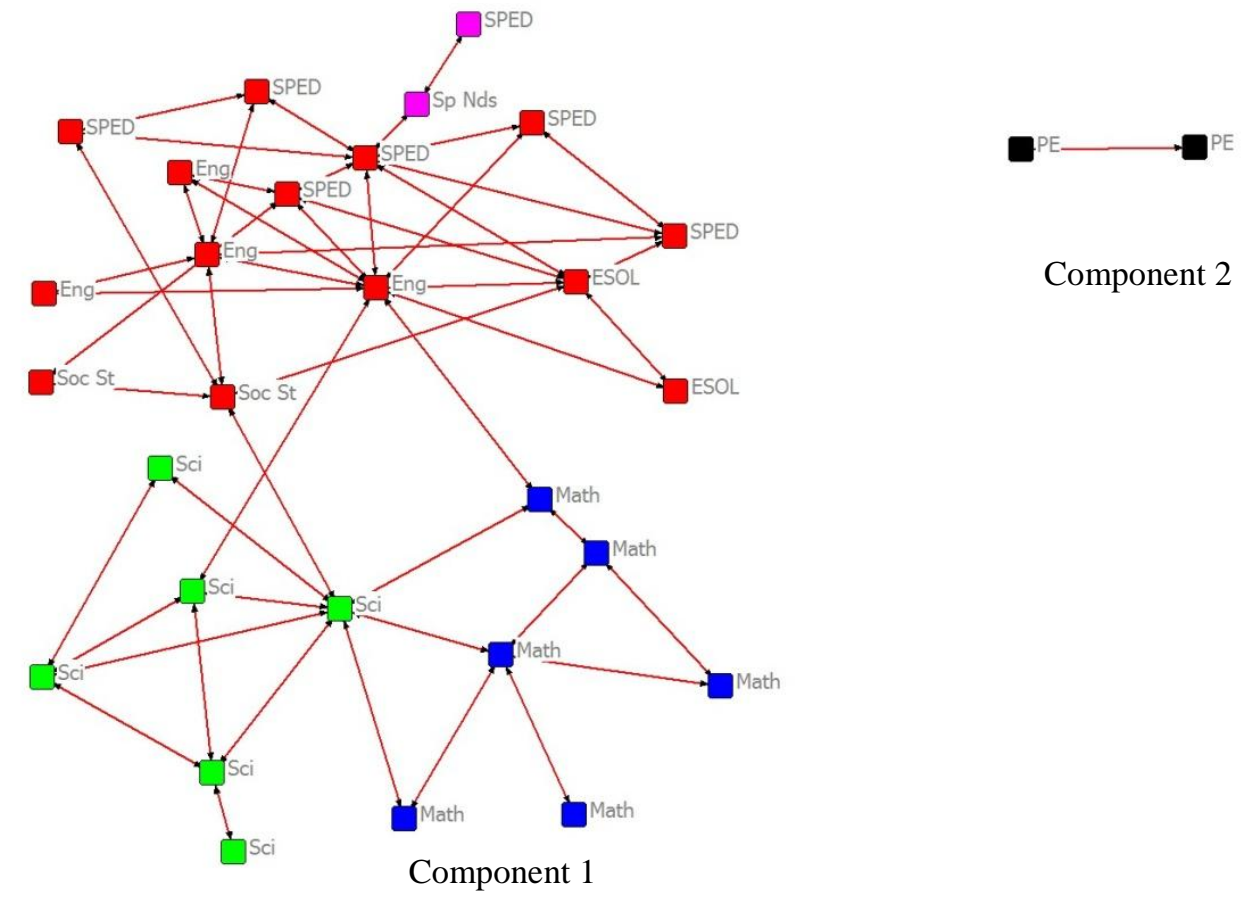

Figure 4-5: Reinhart Curricular Support Reciprocal Tie Substructure All ties shown are reciprocal ties. Node labels are showing department membership of the actors. Department labels show how much of the clustering is due to homophily. The colors represent factions, which illustrate patterns of more tightly interconnected groups of actors in the sociogram (Hanneman \& Riddle, 2005).

There are also two components of the reciprocal ties subgroup for Filz Middle School (see Figure 4-6). Component 1 is divided into five factions. The Gray Faction in 
Component 1 is made up art, English, ESOL, social studies, special education and teachers of special needs students. This composition is similar to the Green Faction in the Reinhart curricular support network. Since this is occurring at both schools, it suggests that at the middle school level, teachers in the Social Studies and English Departments have a greater need to work with ESOL and Special Education specialists than teachers in other academic departments.

Homophily seems to play an even larger role in the other factions surrounding the Gray Faction, with the different factions composed of math, ESOL, social studies, special education or PE teachers (although there is one world languages teacher connected to the PE grouping - the only apparent homophily being that the two teachers in that dyad share the same first name). The dyad that comprises Component 2 has as its members the Band and Orchestra teachers. Once again, an example of the role homophily plays in the formation of reciprocal ties. 


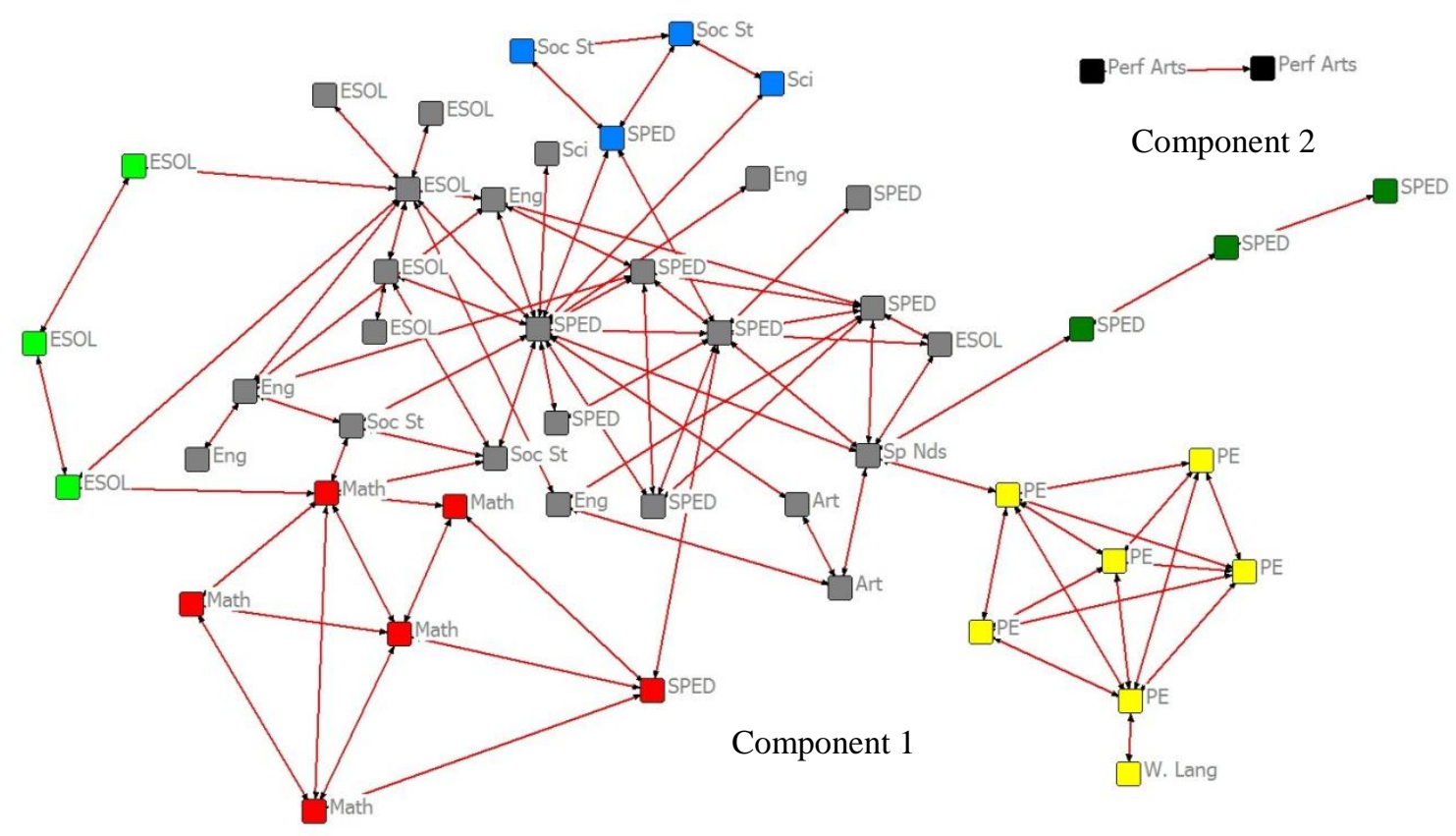

Figure 4-6: Filz Curricular Support Reciprocal Tie Substructure All ties shown are reciprocal ties. Node labels are showing department membership of the actors. The colors represent factions of more tightly interconnected groups of actors (Hanneman \& Riddle, 2005).

A clique is a cohesive subgroup within the network with a minimum of three members (triads) and where each members of the clique has a connection with all members of the clique (Hanneman \& Riddle, 2005). Cliques are of interest because of the norms that can be imposed by clique members. In addition, being a tightly connected substructure, information can flow back and forth more quickly through the members (Jamali \& Abolhassani, 2006). Although cliques are formed through reciprocal ties, there are distinct differences in the triadic structure. For example, in a clique, there are reductions in individuality and the subsequent individual power. A clique also provides a mechanism for moderating conflict among its members (Bellotti, 2009).

Cliques tend to form among network members who have some shared similarities. This may occur through the deliberate action of the members, or may occur spontaneously as a result of the shared similarities (Haythornthwaite, 1996). Clique 
relationships have been shown to be longer-lasting than reciprocal dyads and they tend to form "with greater frequency than would expected by chance" (Bellotti, 2009, p. 54). The structure of the cliques is also of interest. When cliques overlap, there is a greater potential for new information to spread throughout the entire network. When cliques are separated, diffusion can be slowed, and the disconnected groups can form unique traits (Jamali \& Abolhassani, 2006).

The sociogram of the cliques formed in the Reinhart curricular support network reveals that the cliques have formed into two disconnected components: Component 1 and Component 2 (see Figure 4-7). It becomes apparent the two components of the curricular clique network are actually more tightly bound substructures of the two factions that formed Component 1 of the reciprocal ties substructure. The blue faction, is composed of English, ESOL and (one) special education teachers, while the green faction is composed of entirely of special education teachers. In Component 2 , the red faction is composed of science teachers, while the black faction is composed of mathematics teachers. In addition, the flow of information between the two factions in this component is more constrained than in Component 1 , since there is only one broker between the two factions compared to three brokers connecting the factions in Group-1. 


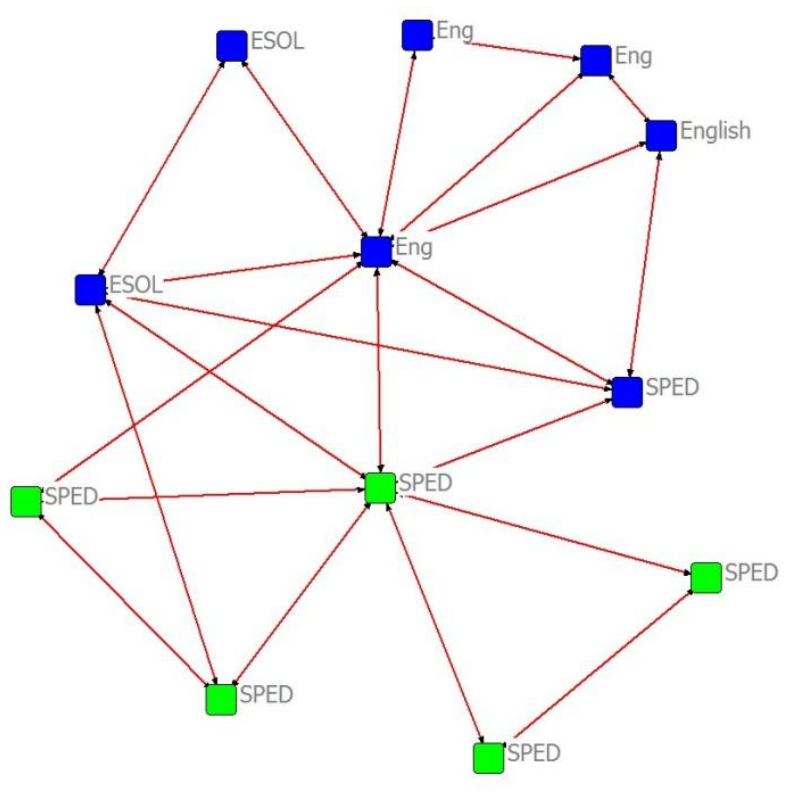

Component 1

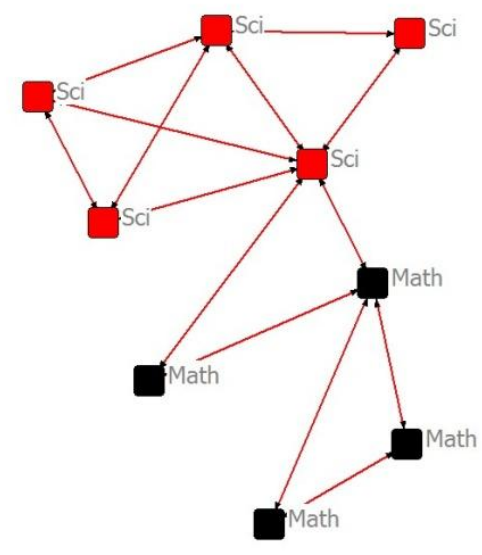

Component 2

Figure 4-7: Reinhart Curricular Support Network Cliques

All ties shown are reciprocal ties. Nodes labels are according to the department membership of the actor. The colors represent factions of more interconnected actors (Hanneman \& Riddle, 2005).

This sociogram for the Filz Curricular Cliques (see Figure 4-8) reveals that two disconnected components have formed. Component 1 in turn is divided into four factions. Both the Green and Blue Factions are centered on special education teachers. The Green Faction is primarily composed of special education teachers, while the Blue Faction is made up of social studies, English and ESOL teachers, all of whom, with one exception, are directly tied to a special education teacher. In the Gray Faction, the special education teacher who is connected to two social studies teachers is assigned to teach social studies and is on the Hudson Team with one of the social studies teachers in his faction. The Red Faction is made up of mathematics teachers, with one special education teacher who teaches mathematics. Component 2 has a tightly interconnected structure and is entirely made up of physical education teachers. There is only one tie missing between two of the PE teachers that prevents this from being a totally interconnected group. 


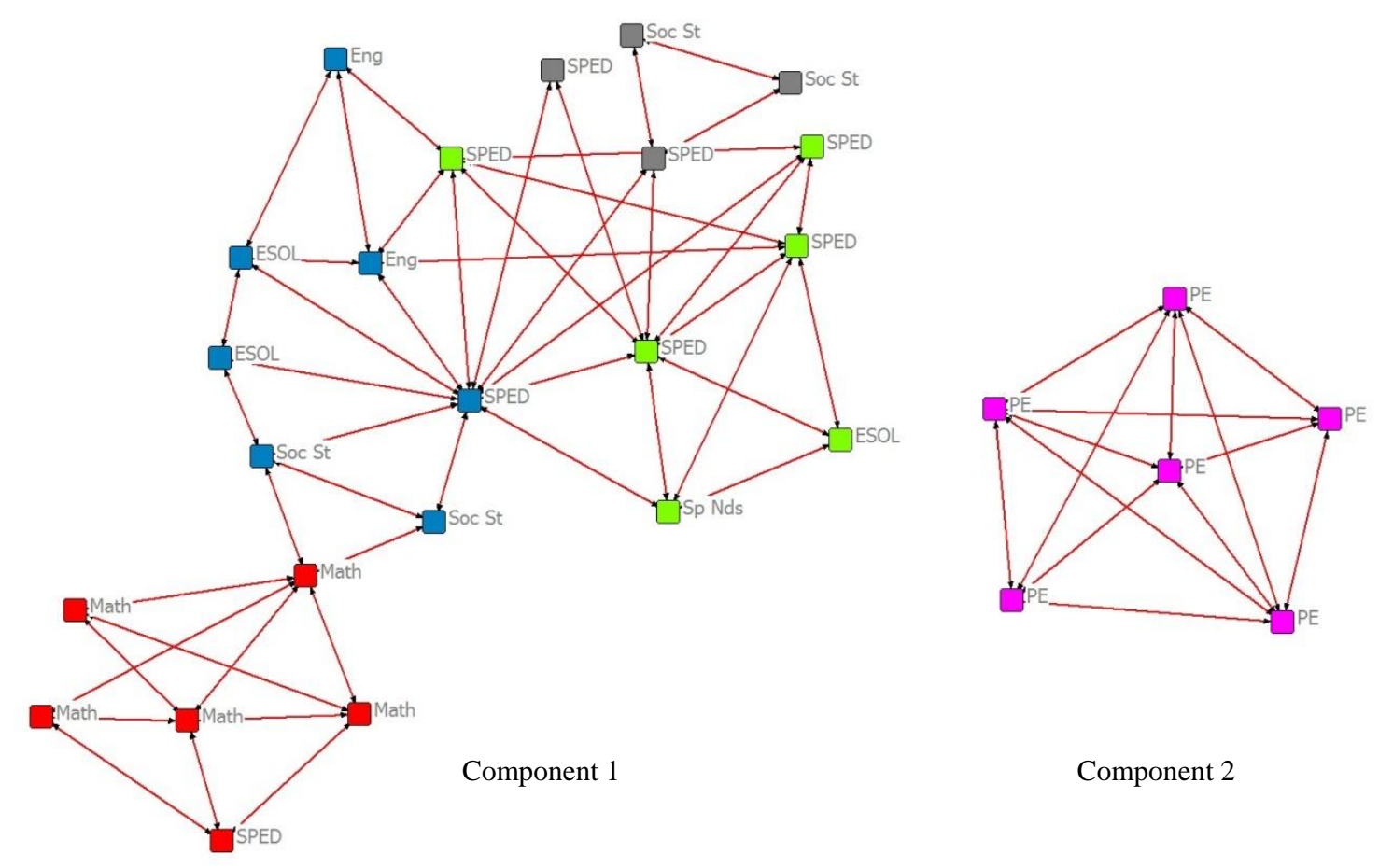

Figure 4-8: Filz Curricular Support Network Cliques

All ties are reciprocal ties. Nodes labels are according to the department membership of the actor. The colors represent factions of more interconnected actors (Hanneman \& Riddle, 2005).

Factions developed in the reciprocal tie and clique substructures largely as a result of departmental homophily. Both schools had factions that were composed of mathematics teachers and factions composed of special education teachers. English teachers, ESOL teachers and social studies teachers made their connections to the special education factions. In both schools, brokerage between the factions often occurred between teachers who were on the same teams (such as the GMO Salmon Team or the Hudson Team). Reinhart Middle School also had a large faction composed of science teaches, while Filz Middle School had large faction composed of PE teachers. This was due in part to differences in response rates of these departments from the two schools. However, it should be noted that while the two PE teachers who submitted surveys at Reinhart Middle School shared a reciprocal tie, the two science teachers who submitted surveys at Filz Middle School did not. 


\section{Curricular Support Network Summary}

In summary, the curricular support networks at both schools were largely similar. At the dyad level, there were a number of prominent actors for in-degree centrality for both schools. At Reinhart Middle School, this top group of in-degree centrality accounted for slightly more than one-quarter of the total number of ties in the network (26.9\%). At Filz Middle School, this top group of in-degree centrality accounted for slightly less than one-quarter of the total number of ties in the network (23.0\%). Special Education teachers and other specialists (such as the ITRT or librarian) tended to dominate those with the highest in-degree centrality scores at both schools.

At the macro level, the Special Education Department had the highest group centrality, with the English and Social Studies Departments, along with the Administrative Team the other top departments. At the micro-level, there were similar percentages of reciprocal ties, and the teachers forming the reciprocal ties and the resulting cliques tended to group into factions based on departmental membership. However, these structural similarities between the Curricular Support Networks in the two schools were not replicated in the Technology Support Networks.

\section{Question 3: What Was the Structure of the Technology Support Network at Each School?}

When examining the Technology Support Networks at the two schools, there were similarities between the two schools at the macro- and the micro-levels. There were also similar differences in the distribution of reciprocal ties at both schools when compared to the distribution of reciprocal ties in the respective curricular networks. However, while the ITRTs were the most central actors in both networks, there were 
overall structural differences in the Technology Support Networks in the two schools (see Figures 4-9 and 4-10).

The two technology support networks had similar network densities: $5.6 \%$ at Reinhart Middle School and 4.9\% at Filz Middle School. Beyond that, the differences in the distribution of social capital in the two technology support networks are apparent when examining the sociograms for the two schools. In the Reinhart technology support network (Figure 4-9) there is only one actor with many in-degree connections. That is ITRT June Lyons (shown in red). In the Filz technology support network (see Figure 410), ITRT Christine Branch (also shown in red) has the greatest number of in-degree connections, but several other actors are also visible who also have a large number of incoming ties.

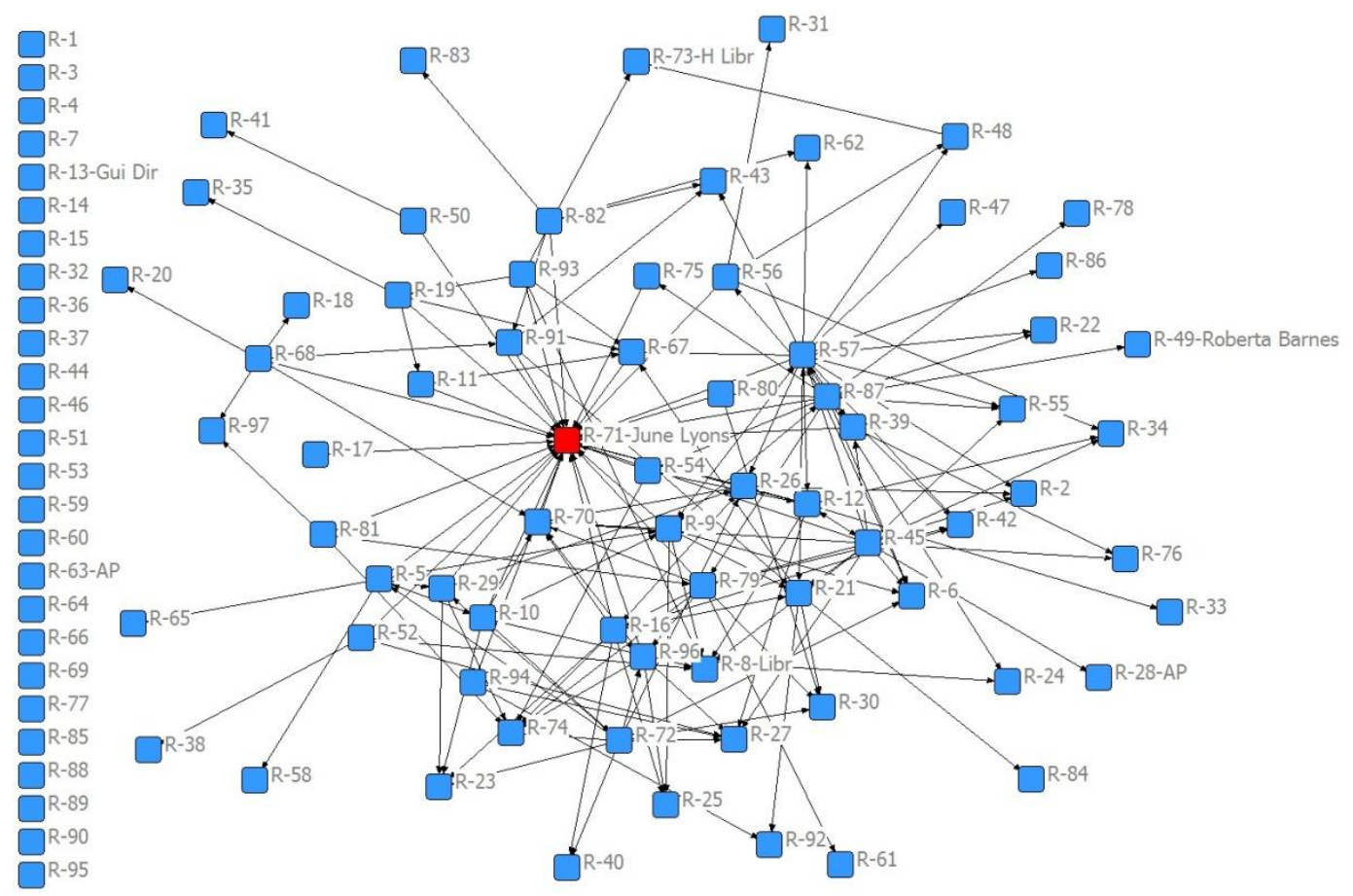

Figure 4-9: Reinhart Technology Support Network

This sociogram shows the ties Reinhart teachers designated for technology help. Actors appearing as a column on the left side of the figure are isolates - actors not connected to any other actor in the network. ITRT June Lyons is shown in red. 


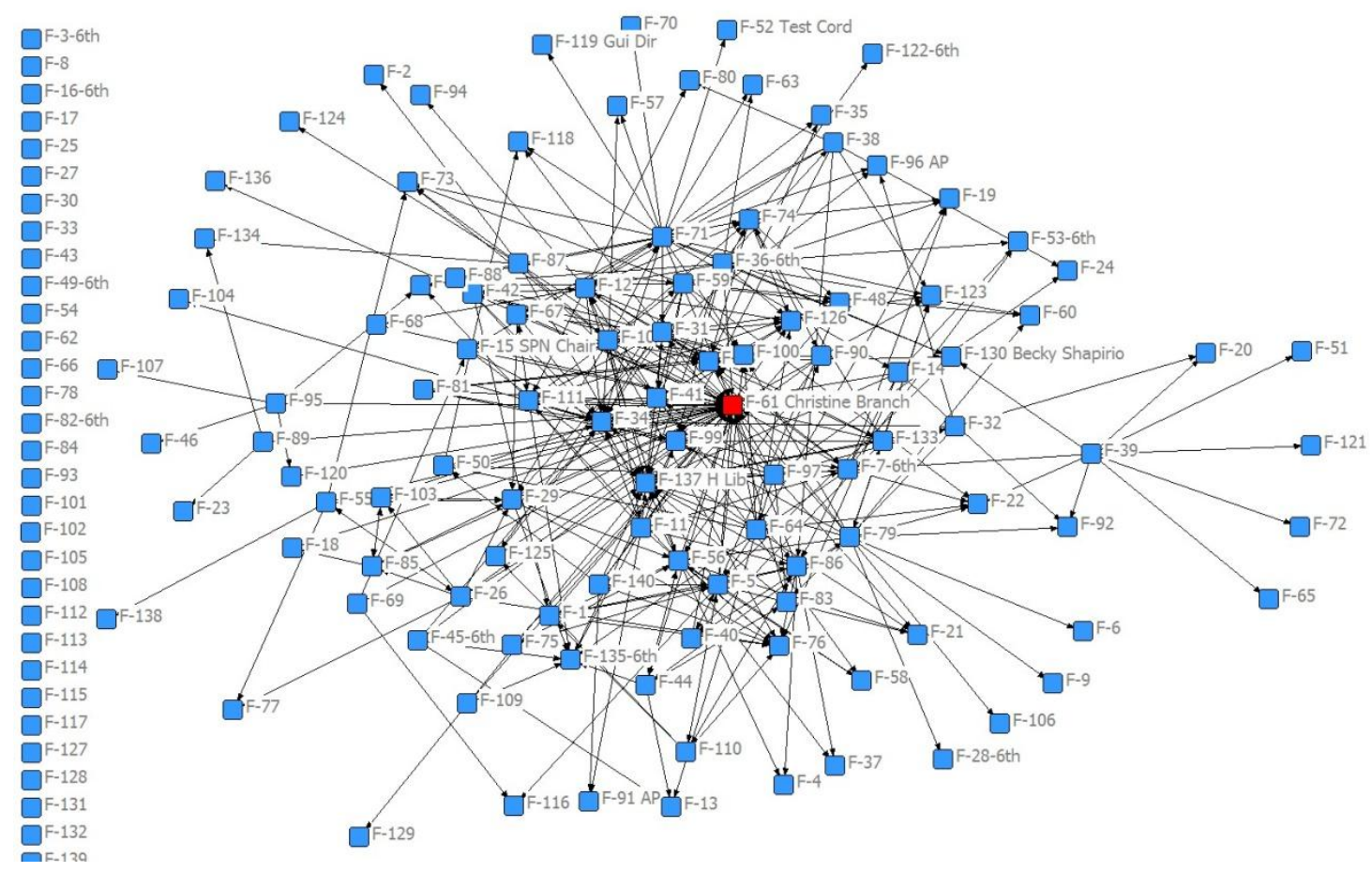

Figure 4-10: Filz Technology Support Network

This sociogram shows the ties Filz teachers designated for technology help. Isolates appear as a column on the left side of the figure. ITRT Christine Branch is shown in red.

\section{Technology Support Network Dyadic Structures}

In the Reinhart Technology Support Network, June Lyons had an in-degree centrality of $88.2 \%$ of the teachers sending out ties which meant that she had direct ties to $30.9 \%$ of the total network. The actor with the second highest in-degree centrality (Teacher R-70) received ties from $24.2 \%$ of the teachers sending out ties $(8.2 \%$ of the total network). This equated to $27.2 \%$ of number of incoming ties June received. The third place actor received ties from $20.5 \%$ of the actors sending out ties $(7.2 \%$ of the total network), which was $23.2 \%$ of June's normalized score. June Lyons was the person that people looked to for technology help in this school.

In the Filz Technology Support Network, Christine Branch had an in-degree centrality of $87.0 \%$ of the teachers sending out ties (33.8\% of the total network), similar to the normalized in-degree centrality for June Lyons. However, the actor with the second 
highest in-degree centrality (F-137, the head librarian) received ties from $44.4 \%$ of the teachers sending out ties (17.2\% of the total network), which was $51.0 \%$ of the Christine's normalized in-degree centrality. The actor with the third highest number of in-coming ties (F-34, the computer technology teacher) received ties from $38.8 \%$ of the teachers sending out ties (13.6\% of the total network), which was $41.1 \%$ of Christine's in-degree centrality. While Christine had the greatest number of direct ties, the teachers in this school also recognized other actors as having valuable technological expertise.

This difference in influential actors between the two schools was much more apparent when the two-step reach of the top actors was examined. Two-step reach is another measure of influence and information flow and is measured by looking at how much of the total network an actor can reach by way of one other person (Hatala $\&$ Fleming, 2007). A summary of the top actors with two-step reach is shown in Table 4-3.

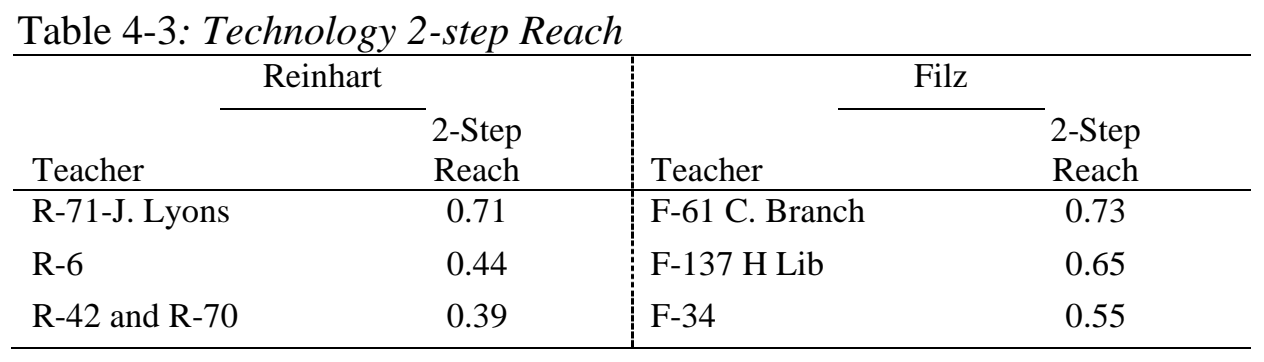

By way of two-step reach, June Lyons was able to reach $71 \%$ of the members in her network. At Filz Middle School, Christine Branch was able to reach $73 \%$ of the members in her network, not much different than June's two-step reach. The actor with the second highest two-step reach at Reinhart Middle School was able to reach $44 \%$ of the network, which is equal to $61 \%$ of June's reach. The two actors with the third highest two-step reach only had 55\% of June's two-step reach. By contrast, at Filz Middle School, the second place actor had a two-step reach that was $90 \%$ the size of Christine's 
two-step reach. The third place actor had a two-step reach that was $75 \%$ of Christine's two-step reach. These different measures of influence by direct and two-step connections revealed a different level of dependence between the two schools. This is one of the ways that illustrate how communicating technology information through the network would be much more difficult with the loss of the ITRT at Reinhart Middle School than it would be at Filz Middle school.

\section{Technology Support Network Macro-Structures}

Looking at the macro-level, at both schools, the teachers tended to have more ties with members of their own departments than they had with members of any other single department. However, as with curricular support networks, the teachers had more overall ties with members of other departments. At both schools, the E-I Index showed a slightly higher preponderance of external ties than there had been in the respective curricular networks. However, some differences were reveled when the most central departments were examined. Table 4-4 is a summary of the departmental centrality for both schools' technology support networks. 
Table 4-4: Technology Departmental Centrality

\begin{tabular}{lcc:lcc}
\hline & \multicolumn{2}{c}{ Reinhart } & & \multicolumn{2}{c}{ Filz } \\
\cline { 2 - 6 } Department & $\begin{array}{c}\text { External } \\
\text { In-ties }\end{array}$ & $\begin{array}{c}\text { Normalized } \\
\text { Score }\end{array}$ & Department & $\begin{array}{c}\text { External } \\
\text { In-ties }\end{array}$ & $\begin{array}{c}\text { Normalized } \\
\text { Score }\end{array}$ \\
\hline ITRT & 30 & 0.3093 & ITRT & 47 & 0.3381 \\
Social Studies & 20 & 0.2247 & Special Ed & 33 & 0.3113 \\
Special Ed & 13 & 0.1625 & Business & 28 & 0.2029 \\
Science & 13 & 0.1461 & Library & 27 & 0.1985 \\
English & 9 & 0.1047 & Admin & 24 & 0.1805 \\
Library & 8 & 0.0833 & Social Studies & 23 & 0.1769 \\
Math & 4 & 0.0455 & Science & 15 & 0.1128 \\
ESOL & 4 & 0.0417 & Math & 14 & 0.1061 \\
PE & 3 & 0.0330 & 6th-grade & 13 & 0.1000 \\
Guidance & 3 & 0.0326 & English & 12 & 0.0916 \\
Performing Arts & 3 & 0.0319 & Guidance & 10 & 0.0746 \\
Admin & 2 & 0.0213 & Office & 6 & 0.0444 \\
Business & 2 & 0.0211 & ESOL & 5 & 0.0391 \\
World Lang & 1 & 0.0108 & PE & 3 & 0.0229 \\
Special Needs & 1 & 0.0104 & Special. Needs & 3 & 0.0219 \\
Home Econ & 1 & 0.0103 & Art & 3 & 0.0217 \\
Art & 0 & 0.0000 & World Lang & 1 & 0.0074 \\
Office & 0 & 0.0000 & Home Econ & 0 & 0.0000 \\
& & & Performing Arts & 0 & 0.0000 \\
\hline Note. Ranked & & & &
\end{tabular}

Note. Ranked by normalized score.

The most central departments at both schools were the ITRTs (classified as a department of their own). There were changes in the positions of a number of departments from their positions on the curricular group centrality list (see Table 4-2). ITRT June Lyons moved from $10^{\text {th }}$ place on the curricular list to first place on the technology list, with a normalized score of .31 . ITRT Christine Branch moved from $12^{\text {th }}$ place to first place on the technology list, with a normalized score centrality of .34. At Reinhart Middle School, the Social Studies Department maintained its second place position from the curricular list, with a normalized centrality score of .22. The Special Education Department, which was in first place on the curricular list, moved into third place on this list, with a normalized score of .16. In fourth place was the Science 
Department, which moved up from eighth place on the curricular list, with a normalized centrality score of .15.

At Filz Middle School, the Special Education Department, which had been in first place on the curricular list, has moved to second place on this list, with a normalized score of .31. In third place was the Business Department with a normalized score of .20. This department moved up from $14^{\text {th }}$ place on the curricular. Moving from ninth place to fourth place was the Library, with a normalized score of .20. All of the top departments, including the ITRT, had higher normalized scores than the corresponding departments on the Reinhart list. The movement of the Business Department at Filz is interesting, since the Business Department at Reinhart has one more member, yet had only two incoming ties, versus 28 incoming ties for the same department at Filz Middle School. The possible reasons for these differences will be discussed in Chapter 5.

\section{Technology Support Network Micro-Structures}

An interesting phenomenon occurred at both schools regarding the patterns of reciprocal ties. In the curricular support networks at both schools, there were tightly interconnected reciprocal tie substructures, which resulted in numerous cliques. In the technology network at both schools, the reciprocal ties took the form of linear chains, with the exception of one triad clique at Filz Middle School. As with the curricular reciprocal tie substructures, departmental and team homophily played a role in the formation of the reciprocal ties in the technology support networks.

In the Reinhart technology network, reciprocal ties formed due to departmental membership in Component 2 and Component 3 (see Figure 4-11). This was also the case in Component 1 and Component 4 of the Filz sociogram (see Figure 4-12). The linear chains that made up Component 1 in the Reinhart sociogram and Components 2, 3 and 5 
in the Filz sociogram form, in part, due to a combination of shared departmental or shared team membership. It is unknown why the reciprocal tie substructures took these forms, considering both schools had highly interconnected reciprocal tie structures in their respective curricular support networks. The only possible explanation for this is that many teachers are still in the learning phases of technology integration, thus there is not enough shared expertise for collaboration to be occurring to the degree that it does occur in the curricular support networks. The phenomenon will be discussed further in the section on suggested future research.
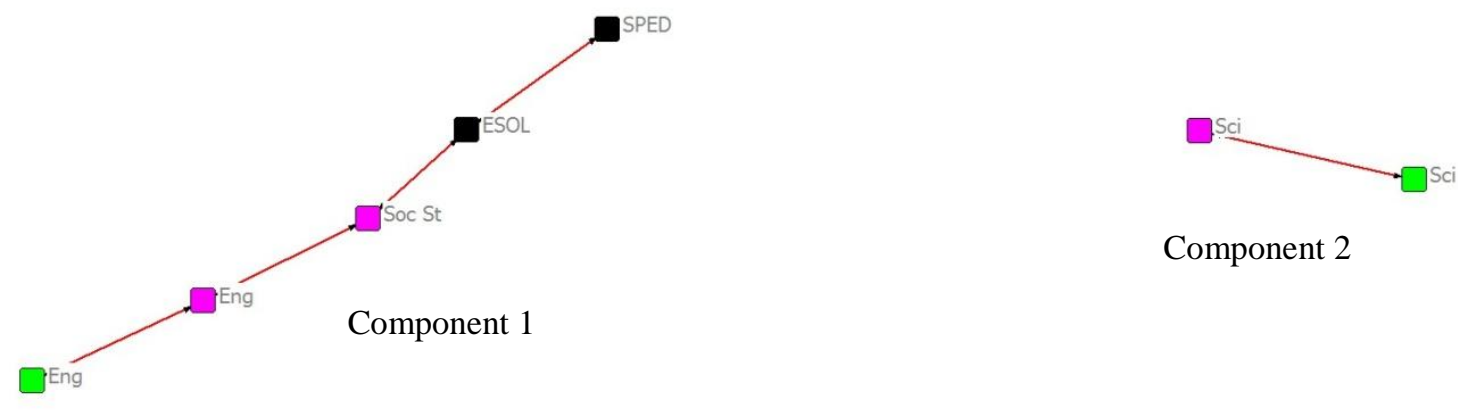

Component 2
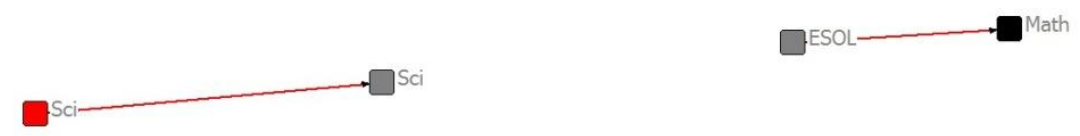

Component 3

Component 4

Figure 4-11: Reinhart Technology Reciprocal Ties

All ties are reciprocal ties. Node colors indicate the team membership of each teacher 


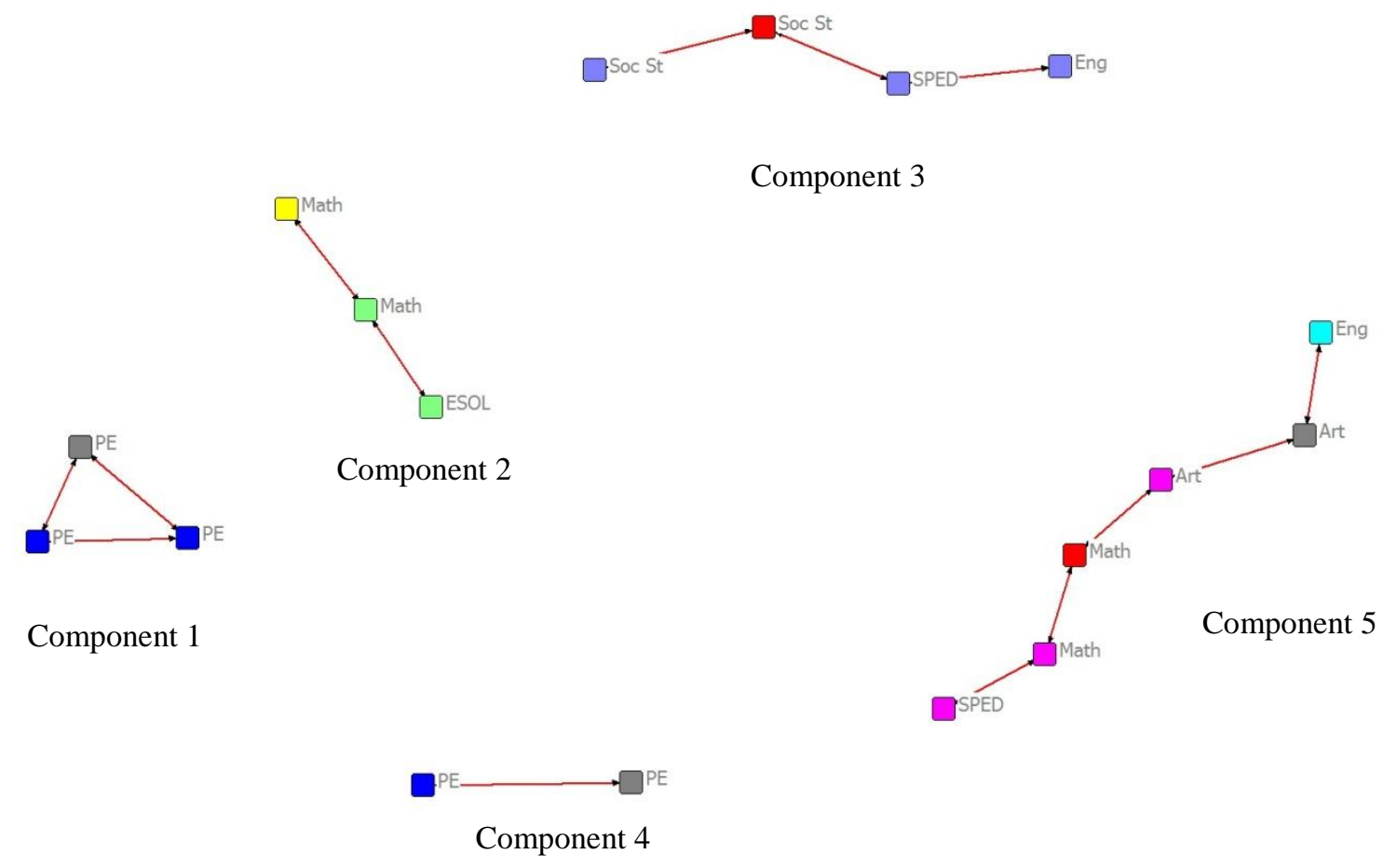

Figure 4-12: Filz Technology Reciprocal Ties

All ties are reciprocal. Node colors indicate the team membership of each teacher.

\section{Summary of Technology Support Networks}

After examining technology support networks at Reinhart Middle School and Filz Middle School, a number of conclusions can be drawn. There were some similarities in the technology support networks for the two schools. The ITRTs had the highest indegree centrality in both schools. Reciprocal ties took the form of linear chains in both schools as well. However, there were distinct differences between the overall structures of networks. At Reinhart Middle School, June Lyons was the dominant actor both with in-degree centrality and with two-step reach. At Filz Middle School, there were other actors who had high in-degree centrality. These other actors also were able to reach large areas of the network by way of their two-step reach. Thus, while Christine Branch was an important source of technology information, she was not the only source. Taking into consideration that the structures of the curricular support networks of the two schools 
were largely similar, some possible reasons for these differences in the structures of the technology networks will be discussed further in Chapter 5.

\section{Question 4: The Position of the ITRT in the Technology Support Network}

At both schools, the ITRT was the most central actor in the technology support network. At Reinhart Middle School, June Lyons had the highest in-degree centrality, with the next highest actor only having $24.4 \%$ the number of incoming ties that she had. At Filz Middle School, Christine Branch had the highest number of incoming ties, but the second actor had more than $50 \%$ the number of incoming ties she had.

There have been suggestions in the literature that teachers will not accept an ITRT who does not share their instructional background (Chen \& Chang, 2006; Davidson, 2003). This was not the case in this study. June Lyons had previously been a Special Education teacher. Christine Branch had been a Home Economics teacher before becoming an ITRT. However, both Christine and June followed similar paths to this role in a manner that has been identified in the literature (Angers \& Machtmes, 2005), in that they were self-taught early adopters of technology who helped colleagues. Over time, their role as a technology resource became more formalized.

In this case, both ITRTs were recognized in their respective schools as possessing important technological expertise by way of their incoming ties from close to $90 \%$ of the teachers sending out ties. Since the teachers sending these ties represented virtually every department in the school, it appears that the ITRTs' previous instructional background was immaterial for the type of support they did provide. Furthermore, the competence the ITRTs possessed apparently was sufficient to result in a high degree of centrality in the respective technology support networks. 


\section{Question 5: What Is the Relationship between In- and Out-Degree Centrality and Teacher Demographics?}

The review of the literature discussed the role of the "early adopters" in the adoption and diffusion of technology in a school. These early adopters are presumed to have developed higher level of the expertise that Mishra and Koehler (2006) have described as TPACK. Mishra and Koehler developed the concept of technological pedagogical and content knowledge (TPACK) as a grounded framework for understanding the knowledge teachers need to successfully integrate technology into instruction. Early adopters play an important role in the diffusion process by helping others learn to integrate technology (Glazer \& Hannafin, 2008; Zhao \& Frank, 2003), but tend not to seek help because of their already high level of expertise (Frank, et al., 2004).

The social network data was examined to see if there were correlations between in-degree centrality, out- degree centrality and the TPACK level. The age-range of the teachers, their years in the school and years teaching were also examined against in- and out-degree centrality. This was done to test the presumption that older, more experienced teachers would be in greater need of technology advice, since they might lack a prior conceptualization of its use in instruction due to their own lack of experience with it in their own schooling (Ertmer, 2005). Surprisingly, not much information was derived from this analysis since many of the correlation between these antecedents was weak to non-existent. Table 4-5 summarizes the results of analyses for the two schools. 
Table 4-5: Summary of Antecedent Correlations

\begin{tabular}{|c|c|c|c|c|c|c|}
\hline & $\begin{array}{c}\text { In- } \\
\text { degree }\end{array}$ & $\begin{array}{c}\text { Out- } \\
\text { degree }\end{array}$ & $\begin{array}{c}\text { Age } \\
\text { Range }\end{array}$ & TPACK & $\begin{array}{c}\text { Years } \\
\text { School }\end{array}$ & $\begin{array}{c}\text { Years } \\
\text { Teaching }\end{array}$ \\
\hline \multicolumn{7}{|c|}{ Reinhart } \\
\hline In-Degree & - & 0.017 & -0.124 & 0.232 & -0.045 & $-0.327 *$ \\
\hline Out-Degree & 0.017 & - & 0.198 & 0.077 & 0.007 & 0.036 \\
\hline \multicolumn{7}{|c|}{ Filz } \\
\hline In-Degree & - & -0.168 & 0.073 & $0.301^{* *}$ & 0.093 & 0.037 \\
\hline Out-Degree & -0.168 & - & $0.426 * *$ & -0.044 & $0.394 * *$ & $0.375^{* *}$ \\
\hline
\end{tabular}

$* p<.05 . * *_{p}<.01$.

At Reinhart Middle School, the only correlation found to be statistically

significant was a moderate negative correlation between in-degree centrality and the number of years teaching. This correlation with the number of years teaching was skewed by a group of teachers with over 20 years teaching, who only had two incoming ties between them. At Filz Middle School, four of the correlations were found to be statistically significant. The correlations that were significant also seemed to fit with what was expected from the literature. There was a mild direct relationship between in-degree centrality and the TPACK level, which seemed to indicate that teachers with higher levels of technology competence were being sought out by their colleagues, This has been found to be important factor in the adoption/diffusion process (Glazer \& Hannafin, 2006). Also statistically significant was a more moderate positive relationship between outdegree centrality, the age range, the number of years in the school and the number of years teaching. This also fits with the literature, since older teachers would be expected to be seeking more technology help (Ertmer, 2005).

Although not statistically significant, there was also very slight positive correlation at Filz between the number of years teaching and in-degree centrality. This was different from what was found at Reinhart Middle School, in part because the 
teachers with more than 20 years experience had 35 incoming ties, as opposed to only two for the same group at Reinhart Middle School. Despite this correlation being statistically significant at only one of the schools, there are other implications concerning these differences which will be discussed further in Chapter 5.

\section{Question 6: How much of the Technology Support Network Was Composed of Ties Created Specifically for Technology Support?}

Up to this point, the curricular support networks and the technology support networks at each school have been examined as separate entities. However, at each school, these networks are composed of the same set of actors, who are actually embedded in multiple complex social structures. In reality, ties and subsequent interactions between actors occur simultaneously across network structures. Combining networks is one way that these complex interactions can be analyzed (Hanneman \& Riddle, 2005). The analyses functions in both UCINET (Borgatti, et al., 2002) and NetDraw (Borgatti, 2002) were used to learn how much of the technology support network at each school was built upon the corresponding curricular support network. From these analyses, it could be determined how many of the ties in each technology network were new connections specifically created for technological support.

The curricular support network and technology support networks for each school were combined using UCINET. Sociograms were then created, which allowed NetDraw to remove the ties between actors that existed in both the curricular and the technology support networks. This left only the ties that were unique to the technology support network for each school. There were 178 ties in the Reinhart technology support network. Of these ties, 54 ties, or $30.3 \%$ of the network, were new ties created specifically for technology support. There were 359 ties in the Filz Technology Support Network. Of 
these ties, 145 , or $40.4 \%$ of the total network were composed of ties that were specifically created for technology support. In addition to there being one-third more ties, as a percentage of the total network in the Filz network, there were substantial differences in the structures and patterns of interactions between these two networks in the two schools.

The sociogram of the Reinhart technology-only network (see Figure 4-13) substructure takes on a hub and spoke appearance, showing June Lyons as the most central actor in the network. Her 20 direct ties equal a connection with $47.6 \%$ of this network, and a two-step reach with $88.1 \%$ of the network. Her ties also account for twothirds of the total ties in this network. The next two most central actors, with 3 ties each, are directly connected to $7.1 \%$ of the sub-network, and a two-step reaches of $26.1 \%$ and $23.8 \%$ respectively. This analysis shows the degree to which June Lyons is the dominant source of technology information at Reinhart Middle School. 


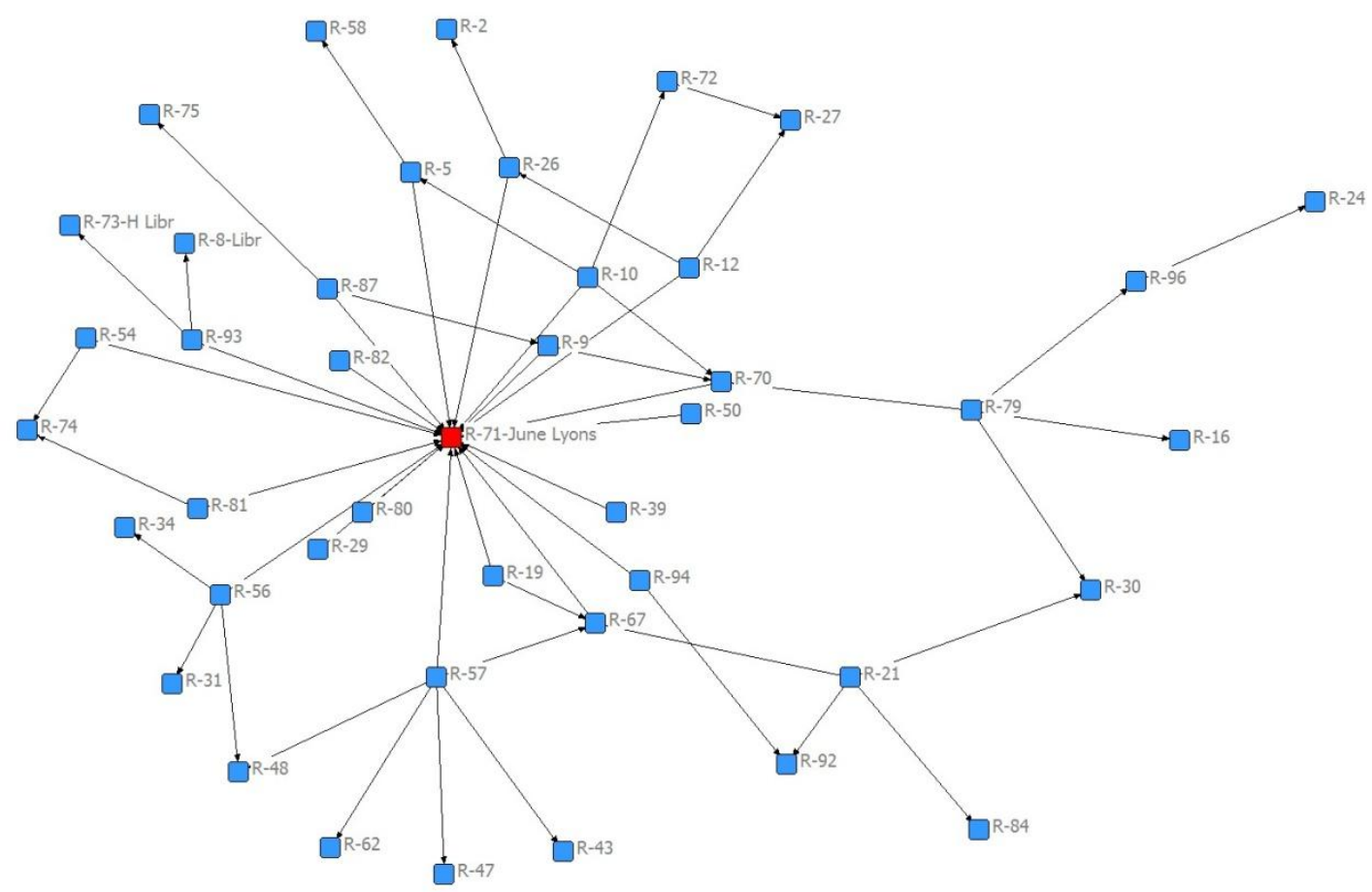

Figure 4-13: Reinhart Technology-only Network

This sociogram is the technology support network after the ties that also exist in the curricular support network have been removed. The ties that remain are ties designated by the teachers that were created specifically for technology support. ITRT June Lyons is shown in red.

The Filz technology-only substructure (see Figure 4-14), reveals a much more complex pattern of ties. Christine Branch was the most central actor, having 30 ties giving her a direct connection with $38 \%$ of the network. She also has a two-step reach with $77.2 \%$ of this sub-network. However, an examination of the sociogram shows that she was not the sole source of technology information in this network. Teacher F-34 has 12 incoming ties which equals direct connections with $15.1 \%$ of the network, and a twostep reach with $49.3 \%$ of the network. Head Librarian F-137 has 11 incoming ties for direct connections with $13.9 \%$ of the network, and a two-step reach with $57.0 \%$ of the network. Furthermore, the ties to these top three actors only accounted for $36 \%$ of the total ties in the network, which is a stark contrast to June Lyons, whose ties accounted for $67 \%$ of the ties in her network. 


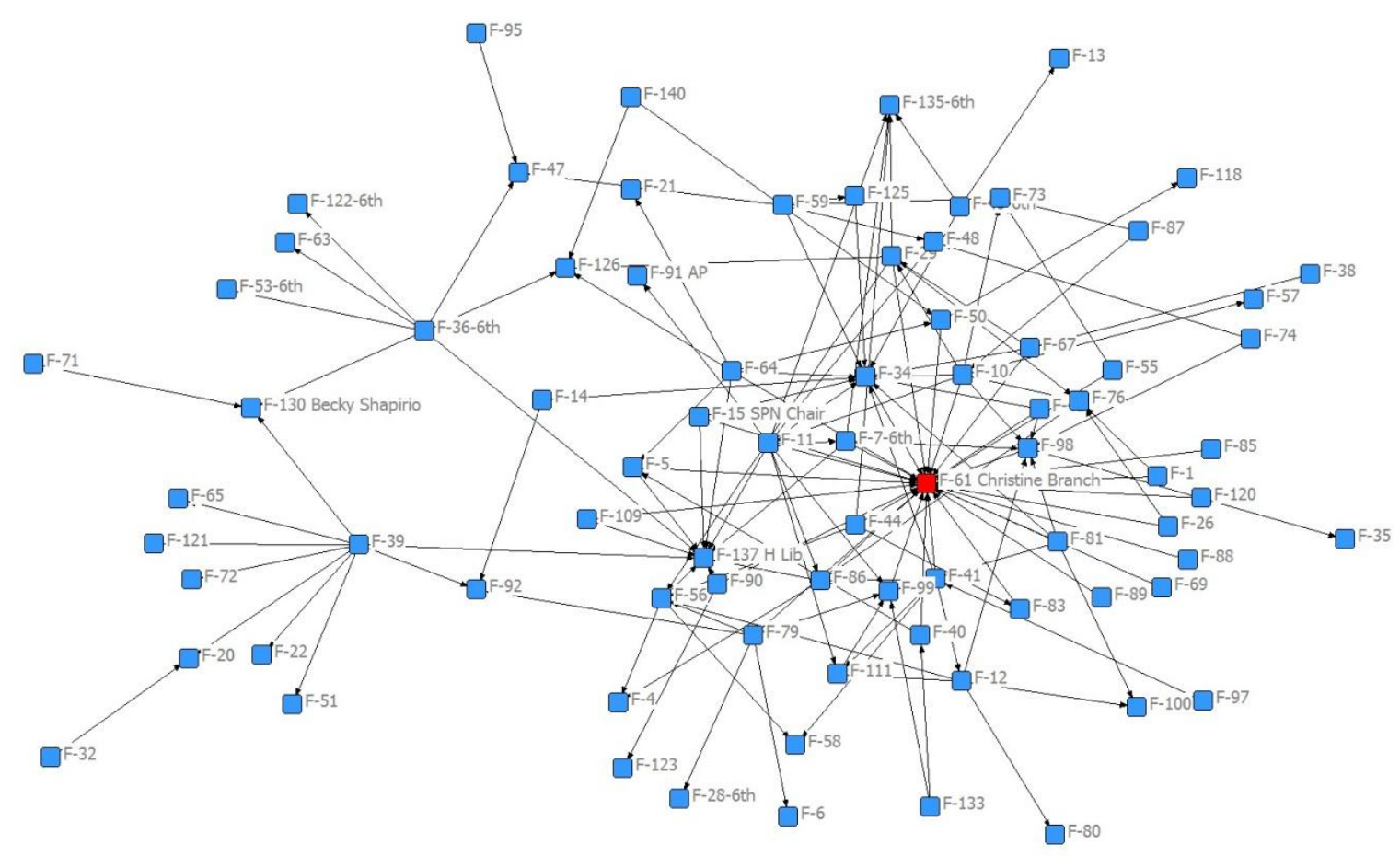

Figure 4-14: Filz Technology-only Network

This figure shows the ties that remain in the Filz technology support network after the ties that also exist in the curricular support network have been removed. These ties that remain are presumed to have been created by the teachers specifically for technology support. ITRT Christine Branch is shown in red.

\section{Reinhart Technology-only Core and Periphery Structure and Node Removal}

One measure of studying network centralization is the extent to which a core and periphery structure has developed. The core and periphery analysis examines the extent to which a highly centralized core of interconnected actors is surrounded by a periphery of less-connected actors (Daly \& Finnigan, 2009). Actors in the periphery tend to become marginalized since they have fewer interactions with their more knowledgeable colleagues (Daly \& Finnigan, 2011). A centralized core and periphery structure can also inhibit the free-flow of information throughout the networks, since the actors in the core have the ability to control and limit the information that does flow though the network (Daly \& Finnigan, 2009; Daly \& Finnigan, 2011). A highly centralized core and periphery structure has been found to be effective when the information being diffused is 
routine. However, this structure has been found to be highly ineffectual for the more complex exchanges of information surrounding innovation (Daly \& Finnigan, 2011). A core and periphery analysis was conducted on the technology-only portions of the Reinhart Technology Support and the Filz Technology Support Networks using UCINET (Borgatti, et al., 2002). The analysis of a core and periphery structure is expressed in the form of the correlation between the observed network, and a “theoretically perfect" core and periphery structure (Daly \& Finnigan, 2009). The overall core/periphery correlation for this network at Reinhart Middle School is .386, which is a moderate correlation to the theoretical perfect model. However, the analysis also suggested a core comprised of one actor, June Lyons, with all other actors on the periphery.

In certain cases, a network is totally dependent on its key players, without whom the network would collapse into disconnected components, halting any effective flow of information (Borgatti, 2006). This is the situation in the Reinhart technology-only network. When June was removed from the network, it began to come apart, with a disconnected component of five isolates and two other multi-node disconnected components. Removing the two actors with the second highest in-degree centrality (Figure 4-15), each of whom had three incoming ties, caused the network to completely unravel into six disconnected chains, along with the group of six isolates. This illustrates the lack of social capital distribution much beyond June Lyons. 


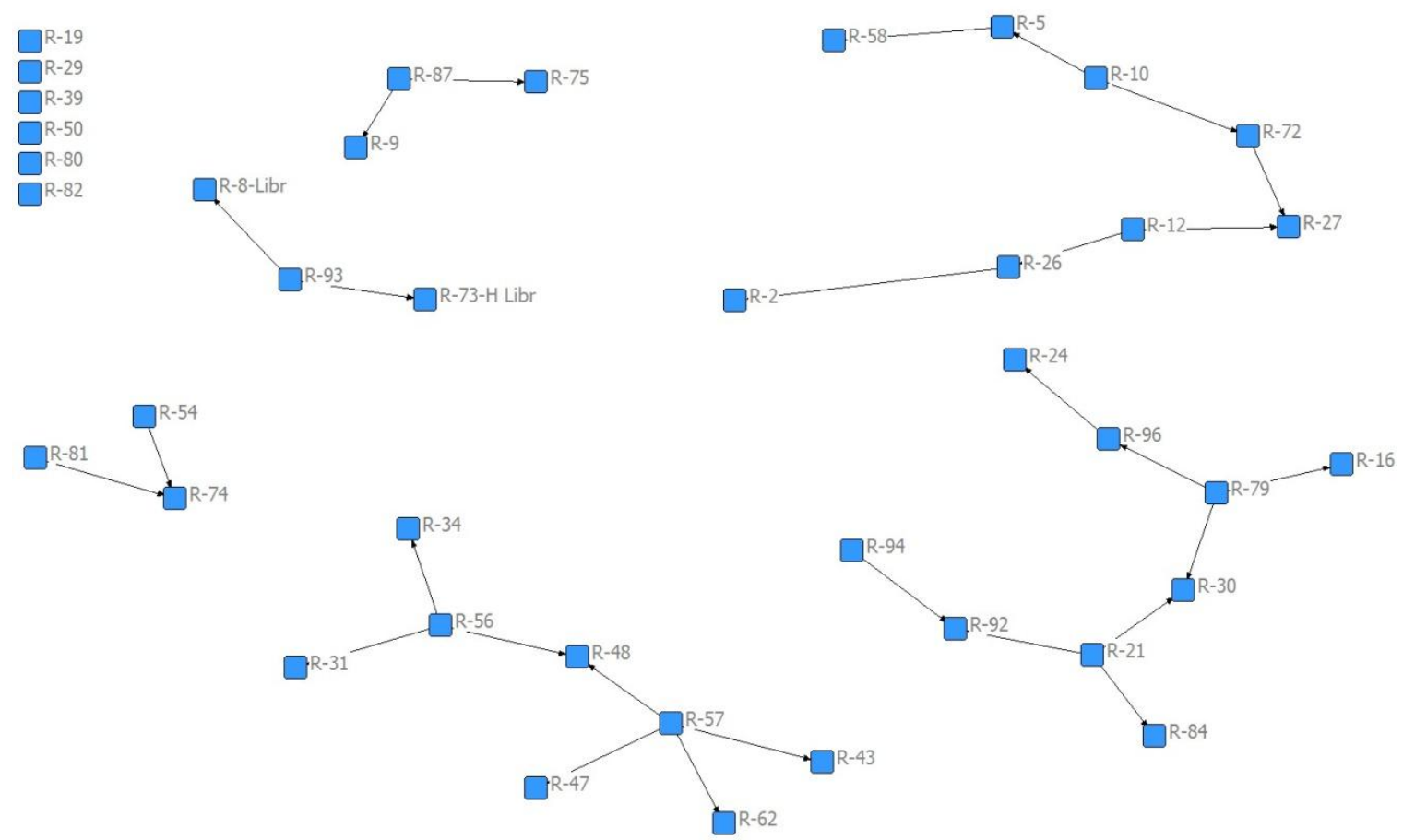

Figure 4-15 Reinhart Technology-only Top Three Actors Removed

This sociogram shows how removing June Lyons and the next two most central actors cause the network to fragment into disconnected components.

\section{Filz Technology-only Core and Periphery Structure and Node Removal}

For the Filz technology-only network, the core/periphery correlation was .212, much lower than the .389 correlation found at Reinhart Middle School. Although Christine Branch was identified in the analysis as the "top" node, the idealized core consisted of the 12 nodes with the highest "coreness" scores. This was quite different than the single-node core in the corresponding Reinhart network. This suggests a more cohesive network structure with a potentially more stable information flow than what is occurring at Reinhart.

When Christine Branch was removed from the Filz technology-only support network, five actors became isolates, but the rest of the network remained intact. When Teacher F-34 (12 ties) and Head Librarian F-137 (11 ties), the next two most central actors, were removed from the network (Figure 4-16), two more actors became isolates, 
but the network otherwise remained intact, preserving the potential for continued information flow.

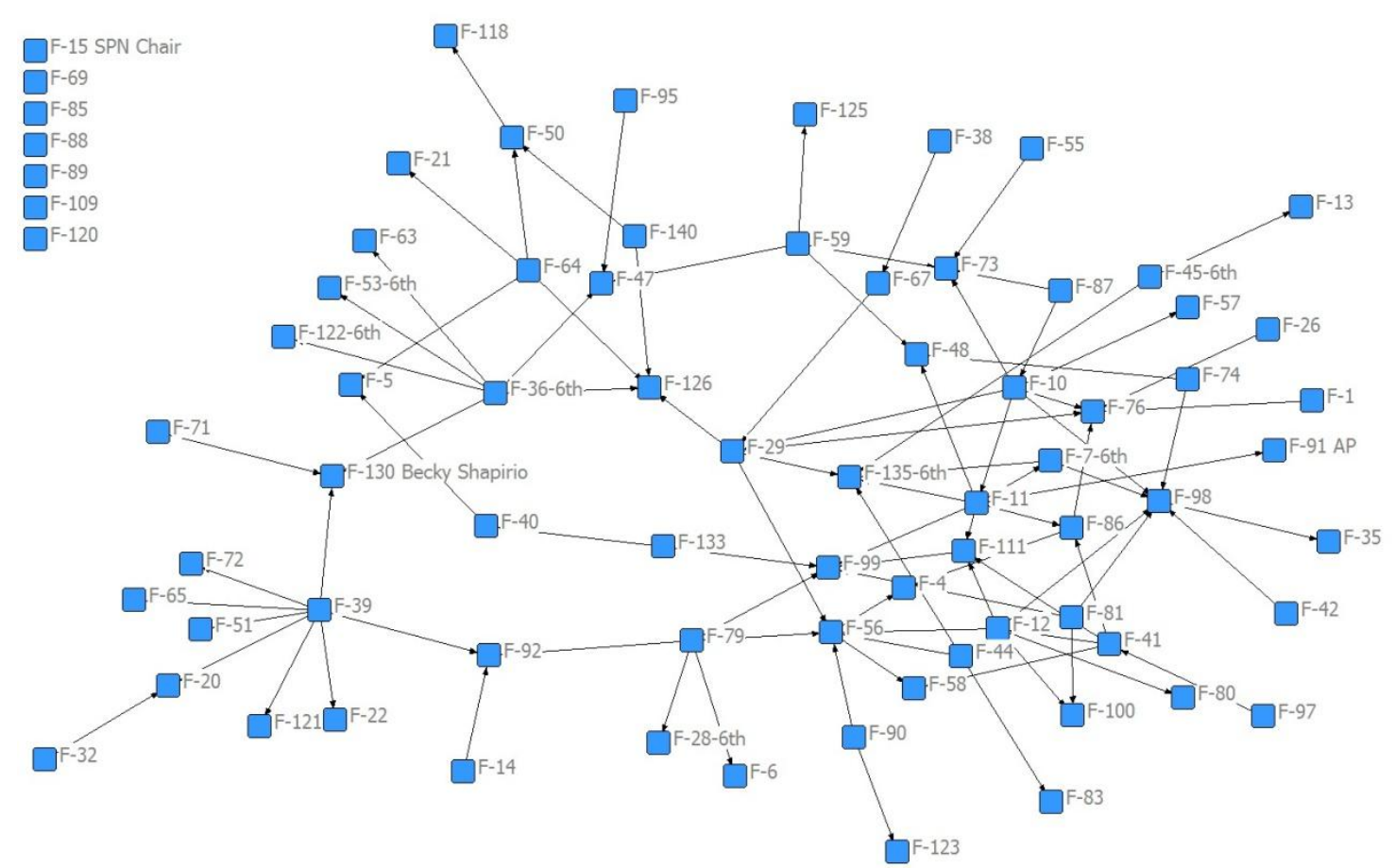

Figure 4-16: Filz Technology-only Top Three Actors Removed In this sociogram, a large connected component remains after the Christine Branch and the next two most central actors are removed from the network. This preserves the potential for technology information to flow throughout the entire network.

While Christine Branch, Teacher F-34 and Head Librarian F-137 are important sources of technology information in this school, this sociogram further illustrates the degree to which technology social capital has been distributed throughout the network, as the connected component of the sociogram maintains a complex structure. The teachers have multiple sources of technology social capital, either by way of their direct ties with others, or by way of two-step reach. The reasons behind this, as well as how principal leadership is believed to have contributed to the different structures of the technology support networks at the two schools is the topic of the next chapter. 


\section{CHAPTER FIVE: SUMMARY AND CONCLUSIONS}

This study examined the technology support networks at two middle schools where the principals exhibited the behaviors previously associated with successful instructional technology integration. The principals of both schools strongly believed in the importance of instructional technology in their individual schools. They personally identified with the technology initiatives they were trying to implement and were visible users of technology. They also recognized the expertise of their instructional technology resource teachers (ITRTs) and put these individuals to use helping teachers in their schools (R. E. Anderson \& Dexter, 2005; Dexter, et al., 2003; Jacobson \& Lock, 2004). However, the two principals took different approaches in the way that they set the direction of their technology vision and subsequently developed their ITRTs as technology leaders. These differences in leadership style and substance appeared to have had an effect on the structure of the technology support networks as evidenced by the patterns of interaction revealed by the social network analyses of these networks.

Using social network analysis as a methodology is in its early stages of being applied to phenomena in schools. Earlier works have focused on the importance of understanding social networks when implementing reform initiatives or organizational changes in schools (Coburn \& Russell, 2008; Daly, et al., 2010; Penuel, et al., 2009). At each school in this study, a knowledge network was examined to see how well connected the staffs were. Both schools had high knowledge network densities which suggested that at least initially, there was a high potential for information to flow unencumbered throughout the organization. 
A curricular support network was also examined at each school. This was done to provide a baseline for instructional collaboration and was needed to understand what new social structures emerged around instructional technology integration. This analysis showed that the curricular support networks were structurally similar at both schools. Both curricular support networks had similar network densities. There were the same number of highly central actors and these actors were primarily special education teachers, specialists such as the ITRT or the librarian, or an administrator such as the principal or an assistant principal.

Despite the similarities of the curricular support networks at both schools, the overall structures of the two technology support networks were much different. The Reinhart Middle School technology support network was highly centralized around the ITRT, while the Filz Middle School technology support network had a much broader distribution of social capital. This chapter will discuss how the contrasting methods the principals used to set the technology vision and develop the technology leadership in their schools may have influenced the different organizational structures of the technology support networks.

\section{Setting the Technology Direction}

Leadership on the part of the school principal has been found to be a more important factor in the implementation of technology integration efforts than either technology expenditures or technology infrastructure (R. E. Anderson \& Dexter, 2005; Dexter, et al., 2003). Studies have found that the type of emphasis that is placed on technology use will influence the degree to which it is adopted by teachers in the classroom (Hew \& Brush, 2007). This can have an effect on the outcome of any 
technology initiative. When the emphasis is more technical in nature, widespread instructional integration does not occur, with its application to classroom instruction restricted to the teachers most interested in its use. Conversely, when there is a greater emphasis on pedagogical applications, there is a greater focus by teachers to apply technology to support learning (Dexter, 2011).

Philosophically, Reinhart Middle School Principal Roberta Barnes indicated that the technology vision for the school needed to come from the top, an idea that seemed to frame her leadership outlook. Consistent with this outlook, Mrs. Barnes believed that her excitement about instructional technology was shared by the entire school. She also stated the expectation that its use would be observed during classroom visits by her and her assistant principals. While she did mention teachers learning about technology from each other, it was more as a passing comment rather than a description of the process occurring in the school. This linear approach to technology has not been shown to promote the type of belief change necessary for technology integration. Instead, it is the social interaction of teachers around technology that is more aligned with substantive belief change (Frank, et al., 2004).

As an enthusiastic supporter of instructional technology, Mrs. Barnes wanted to "beef up" the use of technology. However, her focus in doing so was a more technological approach, meaning a focus on acquiring more equipment, such as interactive white boards or "clickers," for use in her school. While she wanted all of her teachers to become comfortable with some type of classroom technology, she made no pedagogical connection to its use in instruction. For the most part, she described teachers using computers for creating PowerPoint presentations to show to students and using the 
technology to make "data-driven decisions" concerning instruction. This type of technology use centered on teachers is not considered to be the most beneficial application for student learning (Zhao \& Frank, 2003).

The direction set by Principal Becky Shapirio was much different at Filz Middle School, as her focus was more of a pedagogical approach, meaning her emphasis was on how technology applications could support student learning (Dexter, 2011). In her interview she described specific pedagogical applications across the disciplines. Some examples she provided included using robotics and gaming for mathematics instruction, streaming video clips in science classes and using Skype in social studies classes so that students could communicate with peers in other countries. Her equipment purchases were also tied to supporting these instructional goals, such as providing netbook computers for the science classes. She also supported the physical education teachers when they wrote a grant to purchase an interactive fitness program for their students. While it was clear that it was she who was setting an unambiguous vision for technology integration, it was through this support of teachers and instruction that she was able further these organizational goals (Leithwood, 2005).

Her approach to setting the expectations for the teachers was also much different than the approach used by Roberta Barnes. When the teachers were given laptop computers to replace the desktop units they were accustomed to, Mrs. Shapirio encouraged the teachers to take them home for use over the summer. She saw this as a way for the teachers to adjust to the change, as well as develop a sense of ownership with the new equipment. When new opportunities for using technology arose, Mrs. Shapirio would send an email to the entire faculty asking who wanted to try it out. Teachers who 
then wanted to try the new technology were given her full support. The support included an implied understanding that mistakes would be made during the implementation, which was not a problem. In these ways, the principal worked to encourage a supportive risktaking environment associated with successful organizational change (Moolenaar, et al., 2011).

\section{Developing the Technology Leadership}

These leadership differences between the two principals extended to their key leadership function of developing the technology leadership (Leithwood, 2005). In these two schools, this leadership function had two components. The first concerned the principals' cultural capital. Cultural capital refers to the relationships each principal developed with their ITRTs (Spillane, et al., 2003). The second had to do with the way that they defined the role of the ITRT to the school, which appeared to affect how each ITRT provided services to the teachers (Davidson, 2003). Although both principals understood their own needs as well as the needs of the school to have access to the expertise of the ITRT, they applied these two components of this key leadership function in distinctly different ways.

While Mrs. Barnes defined June's role as the primary technology resource in the school, her empowerment of June in this role was limited and superficial. This was due in part to Roberta Barnes not appearing to consider other building staff members as leaders. Instead of taking a "person-plus," or distributed leadership perspective (Spillane, et al., 2004), her leadership style appeared to be hierarchical. For example, she described having June give a technology report at the administrative team meetings. This meeting also gave June the opportunity to ask questions of the assistant principals. Giving a report 
suggested a more passive involvement between June and the administrative team. Asking the assistant principals questions implied a transfer of information from the assistant principals to June, rather than the other way around. The technology leadership that Mrs. Barnes described beyond June continued this hierarchical theme, with the department and team leaders scheduling June for her "trainings," rather collaborating with June to identify instructional needs for technology and then developing training around those needs.

Roberta Barnes also did not realize that she had a serious cultural capital problem with her ITRT. She did state that she greatly respected June's knowledge of technology and reported that she would meet with June and discuss the technology needs of the school. In this way, Mrs. Barnes believed that she in June had bonded and become of one mind over the technology needs of the school. However, this feeling was not shared by June, who made very clear in her interview that decisions on the technology needs of the school were "made at a higher level" and she had no input on these needs. June's belief that she was "not allowed" to provide input over the technology needs of the school further limited Mrs. Barnes ability to take full advantage of June's technology expertise, since June would be reluctant to share new ideas under these circumstances.

The manner in which the principal performed these key leadership functions also appeared to influence the ways that the ITRT delivered technology support to the school. In keeping with the direction set by her principal, June did not take a pedagogical approach to her staff development activities. Rather, the interactions she described with teachers were more technical in nature. She would help teachers remember passwords and showed the teachers how to track their students' progress over time for data-driven 
instruction. When she met with the instructional teams, she described making suggestions on how to make the teachers' lessons "a little bit better" and described helping a teacher arrange digital photographs for a presentation to students.

June also described making a presentation on what the integrated classroom should look like so teachers would know if they were doing it correctly. However, at no time during her interview did she indicate an understanding that her role gave her the potential to change teachers' perceptions of instructional technology integration. While she described working with the $25 \%$ of the teachers who were interested in more extensive uses of instructional technology, she did not speak of working on broader integration beyond this group. Instead, she made disdainful comments about the teachers' overall ability and interest in using technology. June's lack of interest in engaging teachers beyond this group of active users, which was based upon her belief that these teachers were simply not interested in instructional technology, was consistent with recent findings on the type of technology leadership focus found at this school (Dexter, 2011).

The knowledge and expertise held by Filz ITRT Christine Branch was also greatly respected by her principal, Becky Shapirio. However, Mrs. Shapirio’s relationship with Christine and the ways that she developed technology leadership beyond the ITRT were much different than what was seen at Reinhart. Mrs. Shapirio considered her ITRT to be "awesome" and described how they would meet each week to discuss ways that technology could be integrated into instruction to support student learning. This close relationship was confirmed by Christine as she described how the two of them had 
collaborated on an interactive staff-development exercise for creating podcasts that they presented to the faculty.

Mrs. Shapirio wanted Christine to be involved in "the whole instructional component" of the school and took concrete steps to define that role in the faculty. To that end, Christine was made co-chair of the Instructional Council. She was also given key leadership responsibilities with the Testing Team. The collaborative activity the two presented to the faculty not only reinforced this role to the faculty, but showed Mrs. Shapirio as a technology user, which further signaled to the faculty the direction being set for technology use in the school.

Mrs. Shapirio also described working at developing technology leadership beyond Christine. She spoke of a process that began with solicitations to the entire staff asking, "Who wants to try this new technology?" Anyone who responded to the missive was supported as they tried the new modalities. As time went on, some of the teachers developed greater technology expertise. As Mrs. Shapirio worked to expand the integration of technology in the school, the process became more of, "These are the people who know how to do this." In these ways, it appears that Mrs. Shapirio took a "person-plus" distributed perspective to her own leadership practice (Spillane, et al., 2004).

By understanding the situational complexities of technology integration, Becky Shapirio was able to "stretch" the technology leadership activity across the school by involving multiple actors to provide support to teachers. The broad leadership responsibilities given to Christine then provided a mechanism to coordinate the activities of these multiple leaders (Penuel, Frank, \& Krause, 2006; Spillane, et al., 2001). Taken as 
a whole, Becky Shapirio's leadership style made the connection between the constructs of vision, pedagogy, and embedding technology expertise throughout the organization. This is consistent with the types of contextually and pedagogically-focused technology integration efforts advocated by educational technology theorists (Jacobson \& Lock, 2004; Koehler \& Mishra, 2005; Niederhauser \& Stoddart, 2001).

ITRT Christine Branch's work with teachers "set the tone" along the direction and style of her principal. She described working with individual teachers, departments and teams to integrate technology pedagogically into lessons in a way that engaged the students and promoted higher-order thinking. The increased student achievement that resulted from these redesigned lessons provided teachers with the kinds of evidence previous research has shown is needed for changes in instructional beliefs and conceptions to occur regarding the use of technology in the classroom (King, 2002). When netbook computers were given to the science teachers, Christine arranged for the teachers to observe and interact with teachers in another school who were already using netbooks in the classroom. In this way Christine was able to provide her teachers with a source of human and social capital not yet available at Filz. As a whole, the type of technology support Christine described providing is the type that has been found to help teachers develop TPACK (Koehler, et al., 2007).

This cross-case analysis showed that two principals, who believed in the importance of increasing the use of instructional technology in their schools, can take vastly different approaches to setting the technology direction and developing the technology leadership. While June Lyons and Christine Branch reported providing many of the same technology support services in their respective schools, there was a stark 
contrast in the degree to which these ITRTs actively involved the teachers and students with technology integration. These differences in technology support appeared connected to the relationships the two ITRTs had with their respective principals.

At Reinhart Middle School, June held onto what little power she had, and did not appear to share her leadership function with others in the school. In contrast, Christine Branch at Filz Middle School spoke of empowering and developing others in the school as technology leaders. Previous research on reform initiatives has shown a relationship between teacher social networks and how school leaders set the direction of the reform as well as deploy personnel to support the reform (Coburn \& Russell, 2008; Penuel, et al., 2009). Congruent with that research, the data in this study suggest that the differences in the direction set by the principals, along with the relationships with their ITRTs and types of technology support provided by the ITRTs, were the antecedents to the technology support networks that developed in Reinhart and Filz Middle School.

\section{Technology Support Networks}

There has been an increasing understanding that collaboration between teachers is an important part of any reform movement (Stoll, et al., 2006). This is the theory behind the movement for professional learning communities (DuFour, 2004) and communities of practice (Glazer \& Hannafin, 2006). This leveraging of collective knowledge has also been recognized as a component of successful technology integration initiatives (Glazer \& Hannafin, 2008). When teachers have multiple role models to observe the innovation, in this case using technology in instruction, it can create an interest that helps diffuse the innovation throughout the organization (Liu, Madhaven, \& Sudharshan, 2005; Straub, 2009). Increased social interconnectivity also provides a sense that teachers are part of an 
innovative organization, due in part having support through their connections with others (Moolenaar, et al., 2011). Conversely, interest in the innovation can be lost when there is little institutional support among peers (Hatala \& Fleming, 2007).

The technology support network that developed at Reinhart Middle School was highly centralized and dependent upon the ITRT, June Lyons. This lack of interconnectedness displayed in this network has been shown to slow the diffusion process, as there are fewer exchanges of information between teachers (Liu, et al., 2005). Thus it is the type of network associated with transferring information around routine tasks rather than a network structure associated with innovation and positive organizational change (Daly \& Finnigan, 2011). This triangulated with the types of technology use reported by the principal and the ITRT at the school, which largely consisted of teacher created PowerPoint presentations, the use of "clickers" for gauging student understanding, and use of the computer labs for The Digital Cupboard assessment activities.

This centralized structure was even more apparent when the ties that also existed in the curriculum support network were removed. Removing these redundant ties displayed the network of new ties created specifically for technology support. The analysis for the core and periphery structure found that June Lyons comprised a core of one, with all other actors in the periphery. In this network, a teacher looking for technology support beyond June would have a problem, since $66 \%$ of the ties went directly to June. When June and the next two actors were removed as part of a node removal process used to assess key players, the network fragmented into isolates and disconnected components, totally disrupting the flow of technology information. 
This not only demonstrated the high level of reliance on June Lyons, but illustrated the lack of interaction between teachers concerning technology integration. June was the gatekeeper for all technology information in the school and held all of the power concerning the direction of technology integration. This dependence on a few key players and lack of interaction between teachers has been shown to stifle reform efforts, since what little social capital exists within the organization is inaccessible to the network members as a group (Daly, et al., 2010).

There was a different network structure at Filz Middle School. While Christine Branch was the primary person in the school for technology support, there were others with comparatively high levels of centrality. There were more teacher-to-teacher connections as well, which suggested a higher level of communication about technology taking place in the school. This is important, since teacher-to-teacher exchanges of ideas have been shown to result in a cascading effect, as teachers hear new ideas and then experiment in their own classrooms (Daly, et al., 2010). A teacher interested in increasing classroom use of technology in this network would find multiple sources of technology advice. There would also be the potential to observe a number of role models using instructional technology, another part of the process shown to fuel the diffusion of an innovation (Liu, et al., 2005).

This distribution of technology expertise at this school became more apparent when the ties that also existed in the curricular support network were removed, leaving the network of ties created specifically for technology support. In this network, the ties coming into Christine Branch and the next two highest actors comprised slightly more than one-third the total ties. This was in contrast to Reinhart, where connections with 
June alone accounted for two-thirds of the ties. The core and periphery analysis revealed a core of 12 actors, substantially larger than the core of one at Reinhart. With more teachers in the core, a teacher seeking technology support beyond the ITRT would have an easier time finding this support than a teacher at Reinhart would.

The removal of the top three actors' nodes created seven isolates (one more than when the top three nodes were removed from the much smaller Reinhart network), but the remainder of the network maintained a complex inter-connected structure, with many teacher-to-teacher connections remaining. This is further evidence that multiple pathways exist for technology support to flow through the school. Even with the loss of June and the next two most central actors, there were still others with multiple incoming ties. Although a single incoming tie does not necessarily denote leadership, multiple incoming ties do suggest some level of leadership function, since these highly central actors have the potential to influence a larger portion of the network (Pitts \& Spillane, 2009). This further suggests that the school does in fact have multiple technology leaders, which triangulated with the information supplied by the principal and the ITRT.

\section{Develop the Organization}

One important area of leadership function is developing organizational structures that support the direction being set around a reform initiative. To that end, it has been suggested that organizational structures need to be "malleable" in order to support change associated with the reform initiative (Leithwood, 2005). There were two examples of the reordering of the organizational structures that stood out when comparing Reinhart and Filz Middle Schools. The first had to do with the position of the Business Department in the group centrality rankings at the two schools. The other had to do with differences in 
the leveraging of the human capital held by the teachers with 20 or more years teaching experience. The difference in the position of these groups in their respective social networks seems related to the differences in the style of technology leadership at the two schools.

The complexities of the technologies available to teachers are in many ways outside the realm of traditional teacher understanding. Providing translation support was one of the reasons behind creating the ITRT position (Davidson, 2003). However, it is now also understood that teachers' ability to socially access the human capital within their school is an important part of successful reform efforts (Penuel, et al., 2006). The Business Department is a department where the members would be expected to have well-developed technological expertise by nature of their teaching assignment. The teachers in this department therefore would be expected to be sought out by their colleagues for technology support.

At Reinhart Middle School, this department had three members. In the curricular support network, the department had three incoming ties and was in $16^{\text {th }}$ place on the curricular departmental centrality list, with a normalized score of 0.03 . In the technology support network, the department had two incoming ties, and was in $13^{\text {th }}$ place on the technology departmental centrality list, with a normalized centrality score of 0.02 . Based on this information, it appears that the teachers at this school did not see this department as having valuable human capital for either curricular or technology support.

Roberta Barnes at Reinhart took a hierarchal approach to her leadership, with the transfer of knowledge flowing through the organizational chart. June Lyons followed this approach, with her Forefront Team, whose role was to pass information on to the teachers 
in their departments about meetings they attended and the expectations associated with introducing the NETS-S. When examining the technology support network, it appears that teachers do not deviate far from the established lines of communication. Since the Business Department does not seem to be part of the hierarchical chain of command, technology human capital held by the Business Department is not being leveraged by the school - potentially valuable technology knowledge that is being lost to the entire network.

At Filz Middle School, the Business Department had two members, one fewer than at Reinhart. In the curricular support network, the department had 10 incoming ties, more than three times the number of ties of the Business Department at Reinhart. However, the Filz department's normalized score was 0.07 , placing it in $14^{\text {th }}$ place on the departmental group centrality list. In this context, it was not an influential department in the curricular support network. However, it had a much different position in the technology support network where it was tied with the library for $3^{\text {rd }}$ place on the departmental centrality list. The department had 28 incoming ties distributed between the two teachers, giving a centrality score of 0.20. Unlike at Reinhart Middle School, the teachers at this school recognized that the members of this department possessed valuable knowledge about technology, thus actively sought their advice.

Both the principal and the ITRT at Filz described a "person-plus" distributed perspective to their leadership practice (Spillane, et al., 2004). Becky Shapirio was very active in letting the teachers in the school know who had developed technology expertise. Christine Branch assembled a Forefront Team of technology experts who were charged 
with actively assisting teachers about integrating technology into their instructional programs.

One of business teachers had been a longtime member of the Forefront team and had been cited by Christine as a technology leader in the school. The other business teacher was in her first year at the school, but had already become one of the most central teachers in the network. In addition, she was not part of the Forefront Team and Christine had not cited this teacher as being a technology leader known to her. However, without hierarchical constraints, teachers appear to have had the freedom to seek out those best suited to provide the technology advice they needed. Thus it appears this business teacher's central position in the social network developed organically, by way of the other teachers learning on their own of her expertise and her willingness to share that expertise with others.

Another area where there was a difference in the apparent reordering of the organizational structure in the two schools had to do with the teachers who had 20 or more years teaching experience. One reason there has been resistance to integrating technology into instruction is that many teachers do not have prior conceptions of how technology can be used in the classroom since they did not experience its use in their own schooling (Ertmer, 2005). Research has also shown that the longer conceptions are held, the harder they are to change (Pajares, 1992). Therefore, it has not been unreasonable to assume that the actors who had been teaching the longest would be less likely to be users of technology in the classroom. It was also assumed they would also be less likely to have their colleagues turn to them for technology advice. Learning if this was actually 
true was the reasoning behind measuring the correlation between the attribute variable of "the number of years teaching" with the in-degree centrality of each actor.

At Reinhart Middle School, there was a mild inverse relationship (-0.32) between these variables, which was also found to be significant at the .05 level. The seven actors that had 20 or more years experience teaching only had two incoming ties among them, for a mean of 0.28 incoming ties. By comparison, the actors who had between one and nine years of teaching experience had a mean of 2.08 incoming ties and the actors with $10-19$ years experience had a mean of 2.25 incoming ties. To put this into perspective, in the curricular support network, the teachers with 20 or more years teaching experience had 28 incoming ties among them, for a mean of 4 incoming ties. Therefore, these teachers with 20 or more years experience were seen as having valuable expertise that was worth accessing, as long as technology was not involved.

This suggests that a number of things could be occurring at Reinhart Middle School. First, and perhaps most important, these teachers' human capital - their knowledge and experience about instruction - is not being leveraged as part of the technology initiative. In addition, this seems to also imply that adopting technology into instruction is optional, as this group of teachers has become isolated from rest of the network. There is also a potential loss for students, since they are most likely not being instructed using the most up-to-date modalities, that can leverages their interactive, technologically infused lives.

Once again, the situation at Filz Middle School was much different. First, there was an imperceptibly small (0.037) and not statistically significant direct correlation between in-degree centrality and the number of years teaching in the technology support 
network. The 14 teachers with 20 or more years teaching experience had 35 incoming ties among them, for a mean of 2.5 , almost ten times the mean of the corresponding group at Reinhart. More notable was the discovery that this mean was slightly higher than the mean for the teachers who had between one and nine years teaching experience $(2.33$ incoming ties), a group that would be thought to be more open about using technology in instruction. Both of these groups had slightly lower means than the teachers who had between 10 and 19 years experience, with a mean of 3.22 incoming ties.

Unlike at Reinhart, the human capital held by the most experienced teachers is being leveraged in the technology support network. In reality, at this school, there was a near-even distribution of the human capital across the years of teaching, which was the true meaning of the 0.03 correlation. With this technology knowledge distributed throughout the experience level of the teachers, there is a greater possibility that the students will experience technologically infused instruction more consistently throughout the school. This implies that the technology integration vision of the school principal has been adopted throughout the school as well, regardless of teachers' previous long-held conceptions about its use in instruction.

\section{Implications for Policy}

Reinhart principal Roberta Barnes’approach to technology leadership was hierarchical in nature, in that she wanted her ITRT to be the primary resource for technology support. She expressed technology goals that for the most part were routine in nature and centered on teacher use of equipment. In many ways the technology network structure that emerged was aligned with her stated goals, in that teachers tended to direct their ties to the ITRT. However, this network structure was also riddled with pockets of 
isolation, reducing the teachers' access to the technology knowledge embedded in the network. It was also a structure that has not been associated with innovation and organizational change (Borgatti \& Everett, 2000).

Filz principal Becky Shapirio’s technology leadership was more distributed in nature. She wanted her ITRT to be involved in the whole instructional component but worked to develop additional technology leadership throughout the school. Her technology goals were pedagogically focused and centered on specific disciplines. The social network that emerged at this school was aligned with the principal's stated goals. Unlike at Reinhart Middle School, this network showed the potential for engaging interactions between different groups in the school, giving teachers access to diverse sources of expertise.

The structure of this network also resembled network structures associated with innovation and organizational change. There have been long-standing policy goals for more far-reaching integration of technology into instruction (Cuban, et al., 2001; Dexter, 2011; Frank, et al., 2004; King, 2002). Although this study was limited to two schools, the findings suggests that for meeting these policy goals, a principal's technology leadership focus should be more like Becky Shapirio's focus, rather than the focus of Roberta Barnes.

\section{Prescriptions for Practice}

When this study was first designed, it was decided to have teachers self-assess their computer competence using a instrument based on the TPACK model (Schmidt, Baran, Thompson, Koehler, Mishra, et al., 2009). The decision to incorporate TPACK into this study was made in part due to the frequency this framework was appearing in the 
literature, some of which has been included in this study (J. B. Harris, et al., 2007; Hofer \& Swan, 2008; Koehler \& Mishra, 2005; Koehler, et al., 2007; Neiss, 2008). The thinking at the beginning of the study was that TPACK would be playing a major role in the formation of ties teachers would be making in their social networks, with teachers having lower TPACK scores seeking help from teachers with higher TPACK scores. In fact, a mild positive correlation was found between the TPACK level and the number of incoming ties, but this correlation was only found to be statistically significant at Filz Middle School.

The more noteworthy manifestation of TPACK turned out not to occur at the dyadic or teacher level, rather, it occurred at the leadership level. In many ways Becky Shapirio's vision of technology integration resembled the TPACK framework Mishra and Koehler (2006) use to illustrate the knowledge teachers need to develop for high-quality technology use in the classroom. One example was the staff development activity she created with her ITRT, which included the teachers having to create their own podcasts. This type of activity was aligned with the Learning by Design process believed to be central to the development of TPACK in teachers (Koehler, et al., 2007).

Therefore, it appears that Mrs. Shapirio’s technology leadership knowledge, which guided how she enacted her vision for technology in the school, reflected the intersection of Mishra and Koehler's (2006) three domains of technological knowledge, content knowledge and pedagogical knowledge. Although further research is needed, this could be thought of as a leadership form of TPACK. Based on this idea and the other findings from this study, a series of prescriptions for practice have been generated, for 
principals, for school system central offices and for university principal preparation programs.

\section{Prescriptions for Principals}

Principals looking to lead a technology integration initiative need to understand that this is a process with many components. As instructional leaders, principals need to set pedagogical goals around specific disciplines. Since a large part of this involves changing teachers' long-held conceptions about instruction, principals should envision this as growing the use of technology rather than commanding its use. This is accomplished in part by developing a culture of trust, where teachers are able to make mistakes while discovering the value of this change in instructional modalities.

A strong relationship with the ITRT is another component of a successful integration effort. This relationship should be thought of as a partnership, so that the ITRT's expertise is fully leveraged. The ITRT's staff development activities should have a pedagogical focus, with the overall goals of helping teachers develop TPACK. In this

way, the results of the integration effort become largely centered on student learning. The principal should also work with the ITRT to develop technology leadership throughout the organization, understanding that the early-adopters fuel the adoption/diffusion process both by acting as role models as well providing their expertise to colleagues.

\section{Prescriptions for School Systems Central Offices}

At the school system level, staff development activities for current principals can be created where principals would become familiar with different technologies by being placed into "authentic" situations where they become designers of activities that could be used in their teachers' instructional programs, such as podcasts, wiki's and blogs. This 
could be similar to the Understanding by Design model used with teachers (Koehler \& Mishra, 2005).

Opportunities can also be created to allow current administrators to observe schools and work directly with principals who have successful technology initiatives in place. In this way, a social network for principals can be created. School systems can also use results from this study as part of the recruitment process for new principals.

Individuals could be sought for these positions that have an understanding of how the goals for technology integration need to be discipline-specific. This will increase the potential for these new principals to nurture successful integration initiatives in their schools.

\section{Prescriptions for Principal Preparation Programs}

At the university level, principal preparation programs can create courses in technology leadership that encourage the development of sound leadership for technology integration. This can be done by way of placing the students into authentic situations for using technology as teams along the lines of the staff development activity Becky Shapirio and Christine Branch created for the staff at Filz Middle School. The programs can also work with their students to examine their own leadership ideas from the "personplus" perspective described in the literature about distributed leadership (Spillane, et al., 2004). In addition, principal preparation programs can introduce their students to social network analysis, so the future administrators can more fully understand the power of leveraging the human capital in their schools.

\section{Suggestions for Further Research}

This was a small-scale descriptive study that involved two schools in a single school system. The results may or may not be generalized to other schools. Therefore, 
replicating this study in other similar schools to see if similar results are obtained would be worthwhile. In addition, the study was conducted in two middle schools. It would be informative to learn if similar phenomena occur at the elementary or at the high school levels. Further understanding of teacher support networks could be developed by examining the frequency of contact (daily, weekly, monthly) as well as asking respondents the types of technology assistance they seek from each person they nominate.

A second area of further research involves the technology leadership knowledge that Becky Shapirio developed. This was closely aligned with the TPACK framework of Mishra and Koehler (2006) in the ways that she set her technology direction for the school. An interesting area of further inquiry would be to study other principals who are successfully leading technology initiatives to see if their technology vision also had a TPACK alignment. If this turns out to be common characteristic of these principals, then it would be possible to establish a TPACK-like framework for understanding technology leadership that encompasses the constructs of technological knowledge, pedagogical knowledge, content knowledge and leadership knowledge.

Another area of further inquiry involves the formation of reciprocal ties in the technology network which is evidence of a collaborative process shown to increase technology integration (Glazer \& Hannafin, 2006). Densely interconnected reciprocal tie and clique sub-structures existed in the curricular support networks at both schools. Yet in the technology support networks at both schools, there were far fewer reciprocal ties, and these ties took the form of linear chains or dyads. The reason that reciprocal ties took these structures at both schools was beyond the scope of this study and remains unknown. 
The final area for recommended further study has to do with the collective efficacy of the school staff. Collective efficacy refers to the belief by school staff members that as a collective group, they are able to have a positive impact on student achievement (Goddard, Hoy, \& Hoy, 2004). One area of research would be to examine if there is a relationship between the collective efficacy of a faculty and the structure of their social network. An example of this would to study the Filz and Reinhart technology support networks and see if there is a different sense of collective efficacy at each school. There could also be a study conducted within a school that compared the collective efficacy of the teachers who were part of the tightly interconnected reciprocal tie substructures and the collective efficacy of those who were outside these structures. If this were found to exist, the results could lead to interventions using social ties to increase collective efficacy.

\section{Conclusion}

This study illustrates principals' leadership skills of setting direction and developing others and how the method of applying these skills may have direct bearing on the type of organizational reordering that occurs around the integration of technology into instruction. The leadership traits include developing a vision that is subject-specific and pedagogically-focused and empowering the instructional technology resource teacher as a technology leader who, in turn, empowers others, which appeared to influence the creation of a technology support network that is less centralized, and with a broader distribution of social capital. The resulting network structure displays a higher level of teacher-to-teacher interactions, with expertise embedded throughout the network, characteristics which previous network structure research has shown to be associated with innovation and successful organizational change. 


\section{References}

Adler, P. S., \& Kwon, S.-W. (2002). Social capital: Prospects for a new concept. The Academy of Management Review, 27(1), 17-40.

Anderson, R. E., \& Dexter, S. (2005). School technology leadership: An empirical investigation of prevalence and effect. Educational Administration Quarterly, 41(49), 49-82.

Anderson, S. E. (1997). Understanding teacher change: Revisting the concerns based adoption model. Curriculum Inquiry, 27(3), 331-367.

Angers, J., \& Machtmes, K. (2005). An ethnographic-case study of beliefs, context factors and practices of teachers integrating technology. The Qualitative Report, 10(4), 771-794. Retrieved from http://www.nova.edu/ssss/QR/QR10-4/angers.pdf

BCPS Web (2010). Baldon County Public Schools Webpage Retrieved August 28, 2010

Bellotti, E. (2009). Brokerage roles between cliques: A secondary clique analysis. Methodological Innovations Online, 4, 53-73. Retrieved from http://www.pbs.plym.ac.uk/mi/pdf/17-04-09/6.\%20Bellotti\%20paper\%2053$\underline{\text { 73.pdf }}$

Blackboard Inc. (2010). Blackboard Inc Website Retrieved September 8, 2010, from http://www.blackboard.com/default.aspx

Bolton, F. E. (1907). Requirements and standards. In R. P. Halleck (Ed.), Report of committee of seventeen on the preparation of high-school teachers (pp. 600-617). Los Angeles: National Education Association.

Borgatti, S. P. (2002). Netdraw network visualization (Version 2.085). Harvard, MA: Analytic Technologies.

Borgatti, S. P. (2006). Identifying sets of key players in a social network. Computational \&amp; Mathematical Organization Theory, 12(1), 21-34.

Borgatti, S. P., Carley, K. M., \& Krackhardt, D. (2006). On the robustness of centrality measures under conditions of imperfect data. Social Networks, 28(2), 124-136.

Borgatti, S. P., \& Everett, M. G. (2000). Models of core/periphery structures. Social Networks, 21(4), 375-395.

Borgatti, S. P., Everett, M. G., \& Freeman, L. C. (2002). Ucinet for Windows: Software for social network analysis (Version 6.220). Harvard, MA: Analytic Technologies.

Borgatti, S. P., Mehra, A., Brass, D. J., \& Labianca, G. (2009). Network analysis in the social sciences. Science, 323(5916), 892-895. 
Bransford, J., Brown, A. L., \& Cocking, R. (2003). How people learn: Brain, mind experience, and school (2 ed.). Washington, DC: National Academy Press.

Brass, D. J. (1995). A social network perspective on human resource management. Research in personneland Human Resources Management, 13(39 -79).

Brass, D. J., Galaskiewicz, J., Greve, H. R., \& Tsai, W. (2004). Taking stock of networks and organizations: A multilevel perspective. Academy of Management Journal, 47(6), 795-817.

Brooks, S. D. (1907). Individual paper on the preparation of high school teachers. In R. P. Halleck (Ed.), Report of committee of seventeen on the preparation of high-school teachers (pp. 600-617). Los Angeles: National Education Association.

Bullough Jr., R. V. (2001). Pedagogical content knowledge circa 1907 and 1987: A study in the history of an idea. Teaching and Teacher Education, 17, 655-666.

Burkhardt, M. E., \& Brass, D. J. (1990). Changing patterns or patterns of change: The effects of a change in technology on social network structure and power. Administrative Science Quarterly, 35(1), 104-127.

Burt, R. S. (1987). Social contagion and innovation: cohesion versus structural equivalence. The American Journal of Sociology, 92(6), 1287-1335.

Chen, J.-Q., \& Chang, C. (2006). A Comprehensive Approach to Technology Training for Early Childhood Teachers. Early Education \& Development, 17(3), 443 - 465.

Christakis, N. A., \& Fowler, J. H. (2007). The Spread of Obesity in a Large Social Network over 32 Years. N Engl J Med, 357(4), 370-379.

Christakis, N. A., \& Fowler, J. H. (2008). The Collective Dynamics of Smoking in a Large Social Network. N Engl J Med, 358(21), 2249-2258.

Coburn, C. E., \& Russell, J. L. (2008). District policy and teachers' social networks. Educational Evaluation and Policy Analysis, 30(3), 203-235.

Conley, S., Fauske, J., \& Pounder, D. G. (2004). Teacher work group effectiveness. Educational Administration Quarterly, 40(5), 663-703.

Costenbader, E., \& Valente, T. W. (2003). The stability of centrality measures when networks are sampled. Social Networks, 25(4), 283-307.

Cuban, L., Kirkpatrick, H., \& Peck, C. (2001). High access and low use of technologies in high school classrooms: Explaining an apparent paradox. American Educational Research Journal, 38(4), 813-834. 
Daly, A. J., \& Finnigan, K. (2009). A bridge between worlds: understanding network structure to understand change strategy. Journal of Educational Change, 11(2), 111-138.

Daly, A. J., \& Finnigan, K. S. (2011). The ebb and flow of social network ties between district leaders under high-stakes accountability. American Educational Research Journal.

Daly, A. J., Moolenaar, M. N., Bolivar, J., M. , \& Burke, P. (2010). Relationships in reform: the role of teachers' social networks. Journal of Educational Administration, 48(3), 359-391.

Davidson, J. (2003). A new role in facilitating school reform: The case of the educational technologist. Teachers College Record, 105(5), 729-752.

Davidson, J., \& Olson, M. (2003). School leadership in networked schools: deciphering the impact of large technical systems on education. International Journal of Leadership in Education, 6(3), 261-281.

Deal, T. E., Purinton, T., \& Waetjen, D. C. (2009). Making sense of social networks in schools (1st ed.). Thousand Oaks Califonia: A joint publication of the Corwin Press and the American Association of School Administrators.

Dexter, S. L. (2011). School technology leadership: Artifacts in systems of practice. Journal of School Leadership, 21, 166 - 189.

Dexter, S. L., Anderson, R. E., \& Ronnkvist, A. M. (2002). Quality technology support: What is it? Who has it? And what difference does it make? Journal of Educational Computing Research, 26(3), 265-285.

Dexter, S. L., Seashore, K. R., \& Anderson, R. E. (2003). Leading and learning: Expertise and technology integration support staff. Paper presented at the Annual Meeting of the American Educational Research Association.

DuFour, R. (2004). What is a "Professional learning Community"? Educational Leadership, 16(8).

Entwistle, N., Skinner, D., Entwistle, D., \& Orr, S. (2000). Conceptions and beliefs about "good teaching": an integration of contrasting research areas. Higher Education Research \& Development, 19(1), 5-25.

Ertmer, P. A. (2005). Teacher pedagogical beliefs: The final frontier in our quest for technology integration? Educational Technology Research and Development, 52(4), 25-39.

Everett, M. G., \& Borgatti, S. P. (2005). Extending Centrality. In P. J. Carrington, J. Scott \& S. Wasserman (Eds.), Models and methods in social network analysis. Available from http://www.steveborgatti.com/papers/extendending_centrality.pdf 
Foss, D. H., \& Kleinsasser, R. C. (2001). Contrasting research perspectives: What the evidence yields. Teachers and Teaching: Theory and Practice, 7(3), 271-295.

Frank, K. A., Zhao, Y., \& Borman, K. (2004). Social Capital and the Diffusion of Innovations within Organizations: The Case of Computer Technology in Schools. Sociology of Education, 77(2), 148-171.

Fullan, M. (2002). The role of leadership in the promotion of knowledge management in schools. Teachers and Teaching: Theory and Practice, 8, 409-419.

Giles, C., \& Hargreaves, A. (2006). The sustainability of innovative schools as learning organizations and professional learning communities during standardized reform. Educational Administration Quarterly, 42(1), 124-156.

Glazer, E., \& Hannafin, M. (2008). Factors that influence mentor and teacher interactions during technology integration collaborative apprenticeships. Journal of Technology and Teacher Education, 16(1), 35-61.

Glazer, E., Hannafin, M., \& Song, L. (2005). Promoting technology integration through collaborative apprenticeship. Educational Technology Research and Development, 53(4), 57-67.

Glazer, E., \& Hannafin, M. J. (2006). The collaborative apprenticeship model: Situated professional development within school settings. Teaching and Teacher Education, 22(2), 179-193.

Goddard, R. D., Hoy, W. K., \& Hoy, A. W. (2004). Collective efficacy beliefs: Theoretical developments, empirical evidence, and future directions. Educational Researcher, 33(3), 3-13.

Goetzel, W. (2008). Certification and Staffing of Instructional Technology Specialists. Paper presented at the Society for Information Technology and Teacher Education International Conference 2008, Las Vegas, Nevada, USA.

Halleck, R. P. (1907a). The professional preparation of high-school teachers. The School Review, 15(7), 489-507.

Halleck, R. P. (1907b). Report of committee of seventeen on the preparation of highschool teachers. Paper presented at the National Education Association Metting in Los Angeles. Retrieved December 31, 2007, from http://ia350640.us.archive.org/1/items/committeeseventeen00natirich/committees eventeen00natirich.pdf

Hanneman, R. A., \& Riddle, M. (2005). Introduction ot social network methods Available from http://faculty.ucr.edu/ hanneman/ 
Hanus, P. H. (1907). Individual paper on the preparation of high school teachers. In R. P. Halleck (Ed.), Report of committee of seventeen on the preparation of high-school teachers (pp. 563-577). Los Angeles: National Education Association.

Harris, A., \& Spillane, J. (2008). Distributed leadership through the looking glass. Management in Education, 22(1), 31-34.

Harris, J. B., Mishra, P., \& Koehler, M. J. (2007). Teachers "Technological pedagogical content knowledge: Curriculum-based technology integration reframed. Paper presented at the American Educational Reserach Association Conference. Retrieved March 13, 2008, from http://mkoehler.educ.msu.edu/OtherPages/Koehler_Pubs/TECH_BY_DESIGN/A ERA_2007/AERA2007_HarrisMishraKoehler.pdf

Hatala, J.-P. (2006). Social network analysis in human resource development: A new methodology. Human Resource Development Review, 5(1), 45-71.

Hatala, J.-P., \& Fleming, P. (2007). Making transfer climate visible: Utilizing social network analysis to facilitate the transfer of training. Human Resource Development Review, 6(33), 33-63.

Hawe, P., \& Ghali, L. (2007). Use of social network analysis to map the social relationships of staff and teachers at school. Health Education Research Advance Access cyl162.

Hawe, P., Webster, C., \& Shiell, A. (2004). A glossary of terms for navigating the field of social network analysis. Journal of Epidemiology and Community Health, 58, 971-975.

Haythornthwaite, C. (1996). Social network analysis: An approach and technique for the study of information exchange. Library \& Information Science Research, 18(4), 323-342.

Hew, K. F., \& Brush, t. (2007). Integrating technology into K-12 teaching and learning: current knowledge, gaps and recommendations for future research. Educational Technology Research and Development, 55(3), 223-253.

Hofer, M., Chamberlin, B., \& Scot, T. (2004). Fulfilling the need for a technology integration specialist. T.H.E. Journal, 32(3).

Hofer, M., \& Swan, K. O. (2008). Technological pedagogical content knowledge in action: A case study of a middle school digital documentary project. Journal of Research on Technology in Education, 41(2), 179-200.

Huang, K., \& Provan, K. G. (2007). Resource tangibility and patterns of interaction in a publicly funded health and human services network. Journal of Public Administration Research and Theory, 17(3), 435-454. 
Hughes, J. (2005). The role of teacher knowledge and learning experiences in forming technology-integrated pedagogy. Journal of Technology and Teacher Education, 13(2), 277-302.

International Society for Technology in Education (2007). The ISTE national educational technology stardards (NETS-S) and performance indicators for students. Retrieved from http://www.iste.org/Content/NavigationMenu/NETS/ForStudents/2007Standards/ NETS_for_Students_2007_Standards.pdf

Jacobs, W. B. (1897). The training of teachers for secondary schools. The School Review, $5(6), 375-386$.

Jacobsen, D. M. (2000). Excellent Teaching and Early Adopters of Instructional Technology. Paper presented at the World Conference on Educational Multimedia, Hypermedia and Telecommunications 2000.

Jacobsen, D. M., \& Lock, J. V. (2004). Technology and teacher education for a knowledge era: Mentoring for student futures,not our past. Journal of Technology and Teacher Education, 12(1), 75-100.

Jacobson, D. M., \& Lock, J. V. (2004). Technology and teacher education for a knowledge era: Mentoring for student futures,not our past. Journal of Technology and Teacher Education, 12(1), 75-100.

Jamali, M., \& Abolhassani, H. (2006, 18-22 Dec. 2006). Different aspects of social network analysis. Paper presented at the Web Intelligence, 2006. WI 2006. IEEE/WIC/ACM International Conference on.

Johnson, R. B., \& Onwuegbuzie, A. J. (2004). Mixed methods research: A research paradigm whose time has come. Educational Researcher, 33(7), 14-26.

Joram, E., \& Gabriele, A. J. (1998). Preservice teachers' prior beliefs: Transforming obstacles into opportunities. Teaching and Teacher Education, 14(2), 175-191.

Kahn, W. A., Cross, R., \& Parker, A. (2003). Layers of diagnosis for planned relational change in organizations. The Journal of Applied Behavioral Science, 39(3), 259280 .

King, K. P. (2002). Educational technology professional development as transformative learning opportunities. Computers \& Education, 39(3), 283-297.

Koballa, T. R., Glynn, S. M., Upson, L., \& Coleman, D. C. (2005). Conceptions of teaching science held by novice teachers in an alternative certification program. Journal of Science Teacher Education, 16(4), 287-308. 
Koehler, M. J., \& Mishra, P. (2005). What happens when teachers design educataional technology? The development of technological pedagogical content knowledge. Journal of Computing Research, 32(2), 131-152.

Koehler, M. J., Mishra, P., \& Yahya, K. (2007). Tracing the development of teacher knowledge in a design seminar: Integrating content, pedagogy and technology. Computers and Education, 49(3), 740-762.

Koliba, C., \& Gajda, R. (2009). Communities of practice as an analytical construct: Implications for theory and practice. International Journal of Public Administration, 32, 97-135.

Lee, K., Suharwoto, G., Niess, M., \& Sadri, P. (2006). Guiding inservice mathematics teachers in developing TPCK (Technology pedagogical content knowledge). Paper presented at the Society for Information Technology and Teacher Education International Conference 2006, Orlando, Florida, USA.

Leithwood, K. (2005). Educational leadership: A Review of the Research Available from http://www.temple.edu/lss/pdf/ReviewOfTheResearchLeithwood.pdf

Leithwood, K., Mascall, B., Strauss, T., Sacks, R., Memon, N., \& Yashkina, A. (2007). Distributing leadership to make schools smarter: Taking the ego out of the system. Leadership and Policy in Schools, 6(1), 37 - 67.

Leithwood, K., \& Riehl, C. (2003). What do we already know about successful school leadership? Washington, DC: American Educational Research Association.

Lindahl, R. A. (2007). Why is leading school improvement such a diffecult process? School Leadership and Management, 27(4), 319-332.

Liu, B. S.-C., Madhaven, R., \& Sudharshan, D. (2005). DiffuNET: The impact of network structure on diffusion of innovation. European Journal of Innovation Management, 8, 240-262.

Markauskaite, L., Reimann, P., Reid, D., \& Goodwin, N. (2006). Exploring the Fit of an Information Technology Course to the ICT Literacy of Trainee Teachers. Paper presented at the Society for Information Technology and Teacher Education International Conference 2006, Orlando, Florida, USA.

McVee, M. B., Bailey, N. M., \& Shanahan, L. E. (2008). Teachers and teacher educators learning from new literacies and new technologies. Teaching Education, 19(3), $197-210$.

Mellado, V. (1998). The classroom practice of preservice teachers and their conceptions of teaching and learning science. Science Education, 82(2), 197-214.

Mishra, P., \& Koehler, M. J. (2006). Technological pedagogical content knowledge: A framework for teacher knowledge. Teachers College Record, 108(6), 30. 
Moolenaar, N. M., Daly, A. J., \& Sleegers, P. J. C. (2011). Ties with potential: Social network structure and innovative climate in dutch schools. Teachers College Record, 113(9).

Neiss, M. (2008). Mathematics teachers developing technology, pedagogy and content knowledge (TPACK). In C. Crawford, D. A. Willis, R. Carlsen, I. Gibson, K. McFerrin, J. Price \& R. Weber (Eds.), Proceedings of society for informational technology and teacher education international conference 2008 (pp. 5297-5394). Chesapeake, VA: AACE.

Niederhauser, D. S., \& Stoddart, T. (2001). Teachers' instructional perspectives and the use of educational software. Teaching and Teacher Education, 17(1), 15-31.

Otte, E., \& Rousseau, R. (2002). Social network analysis: a powerful strategy, also for the information sciences. Journal of Information Science, 28(6), 441-453.

Owston, R. (2007). Contextual factors that sustain innovative pedagogical practice using technology: an international study. Journal of Educational Change, 8(1), 61-77.

Pajares, M. F. (1992). Teachers' beliefs and educational research: Cleaning up a messy construct. Review of Educational Research, 3(3), 307-332.

Parise, S. (2007). Knowledge management and human resource development: An application in social network analysis methods. Advances in Developing Human Resources, 9(3), 359-383.

Patton, M. Q. (2002). Qualitative research \& evaluation methods (Third ed.). Thousand Oaks, California: Sage Publications.

Penuel, W. R., Frank, K. A., \& Krause, A. (2006). The distribution of resources and expertise and the implementation of schoolwide reform initiatives. Paper presented at the Proceedings of the 7th international conference on Learning sciences.

Penuel, W. R., Riel, M., Krause, A. E., \& Frank, K. A. (2009). Analyzing teachers' professional interactions in a school as social capital: A social network approach. Teachers College Record, 111(1), 124-169.

Pitts, V. M., \& Spillane, J. P. (2009). Using social network methods to study school leadership. International Journal of Research \& Method in Education, 32(2), 185 $-207$.

Pusey, P., Sadera, W., \& Kenton, J. (2007). The technology coordinator: An analysis of the interactions and perceptions that influence effectiveness. Paper presented at the Society for Information Technology and Teacher Education International Conference 2007, San Antonio, Texas, USA. 
Sandholtz, J. H., \& Reilly, B. (2004). Teachers, not technicians: Rethinking technical expectations for teachers. Teachers College Record, 106(3), 487-512.

Schmidt, D., Baran, E., Thompson, A., Koehler, M., Mishra, P., \& Shin, T. (2009). Survey of preservice teachers' knowledge of teaching and technology.

Schmidt, D., Baran, E., Thompson, A., Koehler, M., Punya, M., \& Shin, T. (2009). Examining preservice teachers' development of technological pedagogical content knowledge in an introductory instructional technology course. Paper presented at the Society for Information Technology and Teacher Education International Conference 2009, Charleston, SC, USA.

Segall, A. (2004). Revisiting pedagogical content knowledge: the pedagogy of content/the content of pedagogy. Teaching and Teacher Education, 20(5), 489504.

Shin, T., Koehler, M., Mishra, P., Schmidt, D., Baran, E., \& Thompson, A. (2009). Changing technological pedagogical content knowledge (TPACK) through course experiences. Paper presented at the Society for Information Technology and Teacher Education International Conference 2009, Charleston, SC, USA.

Shoffner, M. B. (2001). Models of Instructional Technology Leadership in U.S. Schools. Paper presented at the Society for Information Technology and Teacher Education International Conference 2001, Norfolk, VA.

Shulman, L. S. (1986). Those who understand: Knowledge growth in teaching. Educational Researcher, 15, 4 - 14.

Smart Technologies (2010). Smart Technologies Website Retrieved September 5, 2010, from http://smarttech.com/

Spillane, J. P., Hallett, T., \& Diamond, J. B. (2003). Forms of Capital and the Construction of Leadership: Instructional Leadership in Urban Elementary Schools. Sociology of Education, 76(1), 1-17.

Spillane, J. P., Halverson, R., \& Diamond, J. (2004). Towards a theory of leadership practice: a distributed perspective. Journal of Curriculum Studies, 36, 3-34.

Spillane, J. P., Halverson, R., \& Diamond, J. B. (2001). Investingating school leadership practice: A distributed perspective. Educational Researcher, 30(3), 23-28.

Stoll, L., Bolam, R., McMahon, A., Wallace, M., \& Thomas, S. (2006). Professional Learning Communities: A Review of the Literature. Journal of Educational Change, 7(4), 221-258.

Straub, E. T. (2009). Understanding technology adoption: Theory and future directions for informal learning. Review of Educational Research, 79(2), 625-649. 
Thompson, A. D., \& Mishra, P. (2007). Breaking news: TPCK becomes TPACK! Journal of Computing in Teacher Education, 24(2).

Virginia Department of Education (2003). Educational technology plan for Virginia 2003 -09. Richmond, VA: Virginia Department of Education.

Virginia Department of Education (2008). Instructional technology resource teacher: Guidelines for teachers and administrators. Retrieved August 20, 2009. from http://www.doe.virginia.gov/VDOE/Technology/OET/itrt_guidelines.pdf.

Webster-Wright, A. (2009). Reframing professional development through understanding authentic professional learning. Review of Educational Research, 79(2), 702-739.

Yin, R. K. (2009). Case study reserach: Design and methods (4th ed.). Thousand Oaks, California: SAGE, Inc.

Zhao, Y., \& Frank, K. A. (2003). Factors affecting technology uses in schools: An ecological perspective. American Educational Research Journal, 40(4), 807-840.

Zhao, Y., Pugh, D., Sheldon, S., \& Byers, J. L. (2002). Conditions for classroom technology innovations. Teachers College Record, 104(3), 482-515. 


\section{Appendix 1: Sample Survey Form}

\section{Study on Instructional Support Networks -- Instructional Staff Survey}

You have been selected to participate in a study of teacher support networks. The results of this stud y will be used to improve staff development programs regarding instruction technology. Please answer all questions to the best of your ability. The information from this form will be kept in a secure location, be seen only by the researcher and will be destroyed once the report is complete, no longer than one year from now. Your name as well as the name and location of your school will be replaced by aliases in the final report. Thank you very much for completing this survey. Your help in this project is greatly appreciated!

\section{Demographic Information}

\begin{tabular}{|l|l|}
\hline Name: & Position: \\
\hline Number of Years at this school: & Total Number of Years Teaching: \\
\hline Department: & Subject taught: \\
\hline Team Membership: & Classroom Assignment (Room \#): \\
\hline Gender: M F & \\
\hline
\end{tabular}

Age Range (Place an $\mathrm{X}$ in the correct Box):

\begin{tabular}{|l|l|l|l|l|l|}
\hline $20-25$ & $26-35$ & $36-45$ & $46-55$ & $56-65$ & $66+$ \\
\hline
\end{tabular}

\section{Survey of Educators' Knowledge of Computers and Technology (Adopted from Schmidt et. al. 2009)}

Directions: Technology is a wide-ranging concept that encompasses many different things. For the purpose of this questionnaire, technology refers to digital technologies. This includes any digital tools such as computers, laptops, iPods, Whiteboards/Promethium Boards, Blogs, Wiki's, FCPS 24/7 (Blackboard) Twitter, Discovery Educational Streaming, e-Cart or any other software programs. It is important that you answer all four questions. If you are uncertain or neutral regarding your response to a question, please select "Neither Agree nor Disagree"

\begin{tabular}{|c|c|c|c|c|c|}
\hline & $\begin{array}{l}\text { Strongly } \\
\text { Disagree }\end{array}$ & Disagree & $\begin{array}{l}\text { Neither } \\
\text { Agree nor } \\
\text { Disagree }\end{array}$ & Agree & $\begin{array}{l}\text { Strongly } \\
\text { Agree }\end{array}$ \\
\hline $\begin{array}{l}\text { 1. I can teach lessons that appropriately } \\
\text { combine my content, technologies } \\
\text { and teaching approaches }\end{array}$ & & & & & \\
\hline $\begin{array}{l}\text { 2. I can select technologies to use in my } \\
\text { classroom that enhance what I teach, } \\
\text { how I teach and what students learn. }\end{array}$ & & & & & \\
\hline $\begin{array}{l}\text { 3. I can provide leadership in helping } \\
\text { others to coordinate the use of } \\
\text { content, technologies and teaching } \\
\text { approaches in my school. }\end{array}$ & & & & & \\
\hline $\begin{array}{l}\text { 4. I can choose technologies that } \\
\text { enhance the content for a lesson }\end{array}$ & & & & & \\
\hline
\end{tabular}

Please give examples of the digital technologies you use in your classroom: 


\section{$\underline{\text { Instructional Support Networks }}$}

Directions: This next section will help to identify several teacher networks in your school. Emerging research is showing that identifying teacher networks is important to understanding how information flows through a school. This information can then be used to improve staff development programs. We are interested in three networks common in a school: the Staff Knowledge Network, the Curricular Support Network and the Instructional Technology Support Network. In the chart below, you will find a staff list from your school.

In Column A: Staff Knowledge - place an X in the box next to the names of people who you are aware work in your school.

In Column B: Curricular Support - place an X in the box next to the names of the people to whom you have gone to, or collaborated with, regarding advice or ideas about instruction in your classroom.

In Column C: Instructional Technology Support - place an X in the box of the people you have gone to for advice or ideas about using instructional technology in your classroom. This includes any digital tool such as computers, laptops, iPods, Whiteboards/Promethium Boards, blogs, Wiki's, FCPS 24/7 (Blackboard), Twitter, Discovery Educational Streaming e-Cart or any other software programs.

\begin{tabular}{|l|l|l|l|}
\hline Name & $\begin{array}{l}\text { Column A } \\
\text { Staff } \\
\text { Knowledge }\end{array}$ & $\begin{array}{l}\text { Column B } \\
\text { Curricular } \\
\text { Support }\end{array}$ & $\begin{array}{l}\text { Column C } \\
\text { Instructional } \\
\text { Technology } \\
\text { Support }\end{array}$ \\
\hline R-1 & & & \\
\hline R-2 & & & \\
\hline R-3 & & & \\
\hline R-4 & & & \\
\hline R-5 & & & \\
\hline R-6 & & & \\
\hline R-7 & & & \\
\hline R-8-Libr & & & \\
\hline R-9 & & & \\
\hline R-10 & & & \\
\hline R-11 & & & \\
\hline R-12 & & & \\
\hline R-13-Gui Dir & & & \\
\hline R-14 & & & \\
\hline R-15 & & & \\
\hline R-16 & & & \\
\hline R-17 & & & \\
\hline R-18 & & & \\
\hline R-19 & & & \\
\hline R-20 & & \\
\hline
\end{tabular}




\begin{tabular}{|c|c|c|c|}
\hline Name & $\begin{array}{l}\text { Column A } \\
\text { Staff } \\
\text { Knowledge }\end{array}$ & $\begin{array}{l}\text { Column B } \\
\text { Curricular } \\
\text { Support } \\
\end{array}$ & $\begin{array}{l}\text { Column C } \\
\text { Instructional } \\
\text { Technology } \\
\text { Support } \\
\end{array}$ \\
\hline \multicolumn{4}{|l|}{$\mathrm{R}-21$} \\
\hline \multicolumn{4}{|l|}{$\mathrm{R}-22$} \\
\hline \multicolumn{4}{|l|}{$R-23$} \\
\hline \multicolumn{4}{|l|}{$\mathrm{R}-24$} \\
\hline \multicolumn{4}{|l|}{$\mathrm{R}-25$} \\
\hline \multicolumn{4}{|l|}{$\mathrm{R}-26$} \\
\hline \multicolumn{4}{|c|}{$\mathrm{R}-27$} \\
\hline \multicolumn{4}{|c|}{ R-28-AP } \\
\hline \multicolumn{4}{|c|}{$\mathrm{R}-29$} \\
\hline \multicolumn{4}{|l|}{$R-30$} \\
\hline \multicolumn{4}{|l|}{ R-31 } \\
\hline \multicolumn{4}{|l|}{$R-32$} \\
\hline \multicolumn{4}{|l|}{$R-33$} \\
\hline \multicolumn{4}{|l|}{$R-34$} \\
\hline \multicolumn{4}{|l|}{$R-35$} \\
\hline \multicolumn{4}{|l|}{$R-36$} \\
\hline \multicolumn{4}{|l|}{$R-37$} \\
\hline \multicolumn{4}{|l|}{$R-38$} \\
\hline \multicolumn{4}{|l|}{$R-39$} \\
\hline \multicolumn{4}{|l|}{$R-40$} \\
\hline \multicolumn{4}{|l|}{ R-41 } \\
\hline \multicolumn{4}{|l|}{ R-42 } \\
\hline \multicolumn{4}{|l|}{$R-43$} \\
\hline \multicolumn{4}{|l|}{$R-44$} \\
\hline \multicolumn{4}{|l|}{$R-45$} \\
\hline \multicolumn{4}{|l|}{$R-46$} \\
\hline \multicolumn{4}{|l|}{$R-47$} \\
\hline $\mathrm{R}-48$ & & & \\
\hline$R-49-R$ & & & \\
\hline $\mathrm{R}-50$ & & & \\
\hline$R-51$ & & & \\
\hline R-52 & & & \\
\hline$R-53$ & & & \\
\hline$R-54$ & & & \\
\hline$R-55$ & & & \\
\hline R-56 & & & \\
\hline$R-57$ & & & \\
\hline R-58 & & & \\
\hline$R-59$ & & & \\
\hline$R-60$ & & & \\
\hline
\end{tabular}




\begin{tabular}{|l|l|l|l|}
\hline Name & $\begin{array}{l}\text { Column A } \\
\text { Staff } \\
\text { Knowledge }\end{array}$ & $\begin{array}{l}\text { Column B } \\
\text { Curricular } \\
\text { Support }\end{array}$ & $\begin{array}{l}\text { Column C } \\
\text { Instructional } \\
\text { Technology } \\
\text { Support }\end{array}$ \\
\hline R-61 & & & \\
\hline R-62 & & & \\
\hline R-63-AP & & & \\
\hline R-64 & & & \\
\hline R-65 & & & \\
\hline R-66 & & & \\
\hline R-67 & & & \\
\hline R-68 & & & \\
\hline R-69 & & & \\
\hline R-70 & & & \\
\hline R-71-June Lyons & & & \\
\hline R-72 & & & \\
\hline R-73-H Libr & & & \\
\hline R-74 & & & \\
\hline R-75 & & & \\
\hline R-76 & & & \\
\hline R-77 & & & \\
\hline R-78 & & & \\
\hline R-79 & & & \\
\hline R-80 & & & \\
\hline R-81 & & & \\
\hline R-82 & & & \\
\hline R-83 & & & \\
\hline R-84 & & & \\
\hline R-85 & & & \\
\hline R-86 & & \\
\hline R-87 & & \\
\hline R-88 & & \\
\hline R-89 & & \\
\hline R-90 & & \\
\hline R-91 & & \\
\hline R-92 & & \\
\hline R-93 & & \\
\hline R-94 & & \\
\hline R-95 & & \\
\hline R-96 & & \\
\hline R-97 & & \\
\hline R-98 & & \\
\hline
\end{tabular}

Thank you so very much! 